Cochrane Database of Systematic Reviews

\title{
Homeopathic medicinal products for preventing and treating acute respiratory tract infections in children (Review)
}

Hawke K, van Driel ML, Buffington BJ, McGuire TM, King D

Hawke K, van Driel ML, Buffington BJ, McGuire TM, King D.

Homeopathic medicinal products for preventing and treating acute respiratory tract infections in children.

Cochrane Database of Systematic Reviews 2018, Issue 9. Art. No.: CD005974.

DOI: 10.1002/14651858.CD005974.pub5.

www.cochranelibrary.com 
TABLE OF CONTENTS

HEADER

ABSTRACT

PLAIN LANGUAGE SUMMARY

SUMMARY OF FINDINGS

BACKGROUND

OBJECTIVES

METHODS

RESULTS

Figure 1.

Figure 2.

Figure 3.

DISCUSSION

AUTHORS' CONCLUSIONS

ACKNOWLEDGEMENTS

REFERENCES

CHARACTERISTICS OF STUDIES

DATA AND ANALYSES

Analysis 1.1. Comparison 1 Prevention studies, Outcome 1 Recurrence of ARTI - individualised homeopathy.

Analysis 1.2. Comparison 1 Prevention studies, Outcome 2 Mean number of ARTI episodes - non-individualised homeopathy. .

Analysis 1.3. Comparison 1 Prevention studies, Outcome 3 Recurrence of ARTI - non-individualised homeopathy.

Analysis 1.4. Comparison 1 Prevention studies, Outcome 4 Days off work for parents - individualised homeopathy.

Analysis 1.5. Comparison 1 Prevention studies, Outcome 5 Adverse events - individualised homeopathy.

Analysis 1.6. Comparison 1 Prevention studies, Outcome 6 Adverse events - non-individualised homeopathy.

Analysis 1.7. Comparison 1 Prevention studies, Outcome 7 Need for antibiotics - individualised homeopathy.

Analysis 1.8. Comparison 1 Prevention studies, Outcome 8 Number of courses of antibiotics - individualised homeopathy. ....

Analysis 2.1. Comparison 2 Treatment studies, Outcome 1 Short-term cure - individualised homeopathy.

Analysis 2.2. Comparison 2 Treatment studies, Outcome 2 Long-term cure - individualised homeopathy.

Analysis 2.3. Comparison 2 Treatment studies, Outcome 3 Adverse events - individualised homeopathy.

Analysis 2.4. Comparison 2 Treatment studies, Outcome 4 Adverse events - non-individualised homeopathy.

APPENDICES

WHAT'S NEW

HISTORY

CONTRIBUTIONS OF AUTHORS

DECLARATIONS OF INTEREST

SOURCES OF SUPPORT

DIFFERENCES BETWEEN PROTOCOL AND REVIEW

NOTES

INDEX TERMS 
[Intervention Review]

\section{Homeopathic medicinal products for preventing and treating acute respiratory tract infections in children}

Kate Hawke1, Mieke L van Driel1,2,3, Benjamin J Buffington4, Treasure M McGuire5,6,7, David King1

1Primary Care Clinical Unit, Faculty of Medicine, The University of Queensland, Brisbane, Australia. ${ }^{2}$ Centre for Research in EvidenceBased Practice (CREBP), Bond University, Gold Coast, Australia. ${ }^{3}$ Department of Family Medicine and Primary Health Care, Ghent University, Ghent, Belgium. ${ }^{4}$ Department of Paediatrics, Wide Bay Hospital and Health Service, Bundaberg, Australia. ${ }^{5} \mathrm{School}$ of Pharmacy, The University of Queensland, Brisbane, Australia. 6 Mater Pharmacy Services (Practice \& Development), Mater Health Services, South Brisbane, Australia. ${ }^{7}$ Faculty of Health Sciences and Medicine, Bond University, Gold Coast, Australia

Contact address: David King, Primary Care Clinical Unit, Faculty of Medicine, The University of Queensland, 288 Herston Road, Herston, Brisbane, Queensland, 4006, Australia.d.king@uq.edu.au, d.king@som.uq.edu.au.

Editorial group: Cochrane Acute Respiratory Infections Group.

Publication status and date: Edited (no change to conclusions), published in Issue 9, 2018.

Citation: Hawke K, van Driel ML, Buffington BJ, McGuire TM, King D. Homeopathic medicinal products for preventing and treating acute respiratory tract infections in children. Cochrane Database of Systematic Reviews 2018, Issue 9. Art. No.: CD005974. DOI: 10.1002/14651858.CD005974.pub5.

Copyright @ 2018 The Cochrane Collaboration. Published by John Wiley \& Sons, Ltd.

\section{A B S T R A C T}

\section{Background}

Acute respiratory tract infections (ARTIs) are common and may lead to complications. Most children experience between three and six ARTIs annually. Although these infections are self-limiting, symptoms can be distressing. Many treatments are used to control symptoms and shorten illness duration. Most have minimal benefit and may lead to adverse effects. Oral homeopathic medicinal products could play a role in childhood ARTI management if evidence for effectiveness is established.

\section{Objectives}

To assess the effectiveness and safety of oral homeopathic medicinal products compared with placebo or conventional therapy to prevent and treat acute respiratory tract infections in children.

\section{Search methods}

We searched CENTRAL (2017, Issue 11) including the Cochrane Acute Respiratory Infections Specialised Register, MEDLINE (1946 to 27 November 2017), Embase (2010 to 27 November 2017), CINAHL (1981 to 27 November 2017), AMED (1985 to December 2014), CAMbase (searched 29 March 2018), British Homeopathic Library (searched 26 June 2013 - no longer operating). We also searched the WHO ICTRP and ClinicalTrials.gov trials registers (29 March 2018), checked references, and contacted study authors to identify additional studies.

\section{Selection criteria}

Double-blind, randomised controlled trials (RCTs) or double-blind cluster-RCTs comparing oral homeopathy medicinal products with identical placebo or self-selected conventional treatments to prevent or treat ARTIs in children aged 0 to 16 years.

\section{Data collection and analysis}

We used standard methodological procedures expected by Cochrane.

\section{Main results}

We included eight RCTs of 1562 children receiving oral homeopathic medicinal products or a control treatment (placebo or conventional treatment) for upper respiratory tract infections (URTIs). Four treatment studies examined the effect on URTI recovery, and four studies 
investigated the effect on preventing URTIs after one to three months of treatment, followed up for the remainder of the year. Two treatment and two prevention studies involved homeopaths individualising treatment. The other studies used predetermined, nonindividualised treatments. All studies involved highly diluted homeopathic medicinal products.

We found several limitations to the included studies, in particular methodological inconsistencies and high attrition rates, failure to conduct intention-to-treat analysis, selective reporting, and apparent protocol deviations. We assessed three studies as at high risk of bias in at least one domain, and many had additional domains with unclear risk of bias. Three studies received funding from homeopathy manufacturers; one support from a non-government organisation; two government support; one was cosponsored by a university; and one did not report funding support.

Methodological inconsistencies and significant clinical and statistical heterogeneity precluded robust quantitative meta-analysis. Only four outcomes were common to more than one study and could be combined for analysis. Odds ratios (OR) were generally small with wide confidence intervals $(\mathrm{Cl})$, and the contributing studies found conflicting effects, so there was little certainty that the efficacy of the intervention could be ascertained. All studies assessed as at low risk of bias showed no benefit from oral homeopathic medicinal products; trials at uncertain and high risk of bias reported beneficial effects.

We found low-quality evidence that non-individualised homeopathic medicinal products confer little preventive effect on ARTIs (OR 1.14, $95 \% \mathrm{Cl} 0.83$ to 1.57). We found low-quality evidence from two individualised prevention studies that homeopathy has little impact on the need for antibiotic usage $(\mathrm{N}=369)(\mathrm{OR} 0.79,95 \% \mathrm{Cl} 0.35$ to 1.76$)$. We also assessed adverse events, hospitalisation rates and length of stay, days off school (or work for parents), and quality of life, but were not able to pool data from any of these secondary outcomes.

There is insufficient evidence from two pooled individualised treatment studies $(\mathrm{N}=155)$ to determine the effect of homeopathy on shortterm cure (OR 1.31 favouring placebo, $95 \% \mathrm{Cl} 0.09$ to 19.54 ; very low-quality evidence) and long-term cure rates $(\mathrm{OR} 0.99,95 \% \mathrm{Cl} 0.10$ to 9.67; very low-quality evidence). Adverse events were reported inconsistently; however, serious events were not reported. One study found an increase in the occurrence of non-severe adverse events in the treatment group.

\section{Authors' conclusions}

Pooling of two prevention and two treatment studies did not show any benefit of homeopathic medicinal products compared to placebo on ARTI recurrence or cure rates in children. We found no evidence to support the efficacy of homeopathic medicinal products for ARTIs in children. Adverse events were poorly reported, so conclusions about safety could not be drawn.

\section{PLAIN LANGUAGE SUMMARY}

\section{Are oral homeopathic medicinal products effective and safe to prevent and treat acute respiratory tract infections in children?}

\section{Review question}

We investigated whether oral homeopathic medicinal products are effective and safe to prevent or treat acute respiratory tract infections (ARTIs) in children compared with an inactive (placebo) treatment or other medicines.

\section{Background}

Most respiratory infections resolve without treatment, but sometimes symptoms persist after the initial infection has gone. Treatment is therefore aimed at relieving symptoms. Respiratory infections are commonly caused by viruses, especially colds and flu, though some lung and ear infections are caused by bacteria. It may be difficult to distinguish between viral and bacterial infections, and they may coexist. Antibiotics are often prescribed for respiratory infections even though they are ineffective against viruses.

Children have on average three to six respiratory tract infections annually. Although most are mild and treatable, they sometimes require hospital treatment, and very rarely result in death.

Homeopathy may treat respiratory infections with few side effects, but its effectiveness and safety has not been well researched.

We assessed evidence from randomised controlled trials (studies that allocate people by chance to receive treatment), which is the best way to assess the safety and efficacy of medical treatments.

\section{Search date}

Our evidence is current to 27 November 2017

\section{Study characteristics}

We included eight studies involving 1562 children that compared oral homeopathic treatment to either placebo or standard treatment to prevent or treat respiratory infections in children. All studies investigated upper respiratory tract (from the nose to the windpipe (trachea)) infections, but one combined reporting of upper and lower respiratory tract (from the windpipe to the lungs and pleura (membranes covering the lungs)) infections, so the numbers of children with upper or lower infections is unknown. 


\section{Study funding sources}

Three studies received funding from homeopathy manufacturers; one reported support from a non-government organisation; two received government support; one was cosponsored by a university; and one did not report funding support.

\section{Key results}

Studies investigated a range of interventions for various illnesses and populations using different outcome measures, so only a small number could be combined for analysis. All moderate-quality studies (low risk of bias) showed little or no beneficial effects for homeopathic medicinal products, whether individualised by a trained homeopath or a standard, non-individualised commercially available therapy. Where results could be combined, there was probably little or no difference in benefit on short- or long-term cure, or in prevention of ARTI.

Two low-quality studies (unclear or high risk of bias) showed some benefit of homeopathic medicinal products for a limited number of outcomes. One study showed a reduction in disease severity for the homeopathy group at some time points. The other study showed a reduction in number of respiratory infections over the following year in the treatment groups, although more than a quarter of participants were not accounted for in the results. There was no difference between homeopathy and placebo groups for parents' time off work, antibiotic use, or adverse effects. Consequently, there is no convincing evidence homeopathic medicinal products are effective in treating ARTIs in children. We are unsure about safety because data on adverse events were poorly reported.

\section{Quality of the evidence}

We rated evidence as moderate or low quality for most outcomes. Three outcomes provided very low-quality evidence because study populations and results differed significantly among studies; there were significant limitations in study design and reporting; and sample sizes were small. 


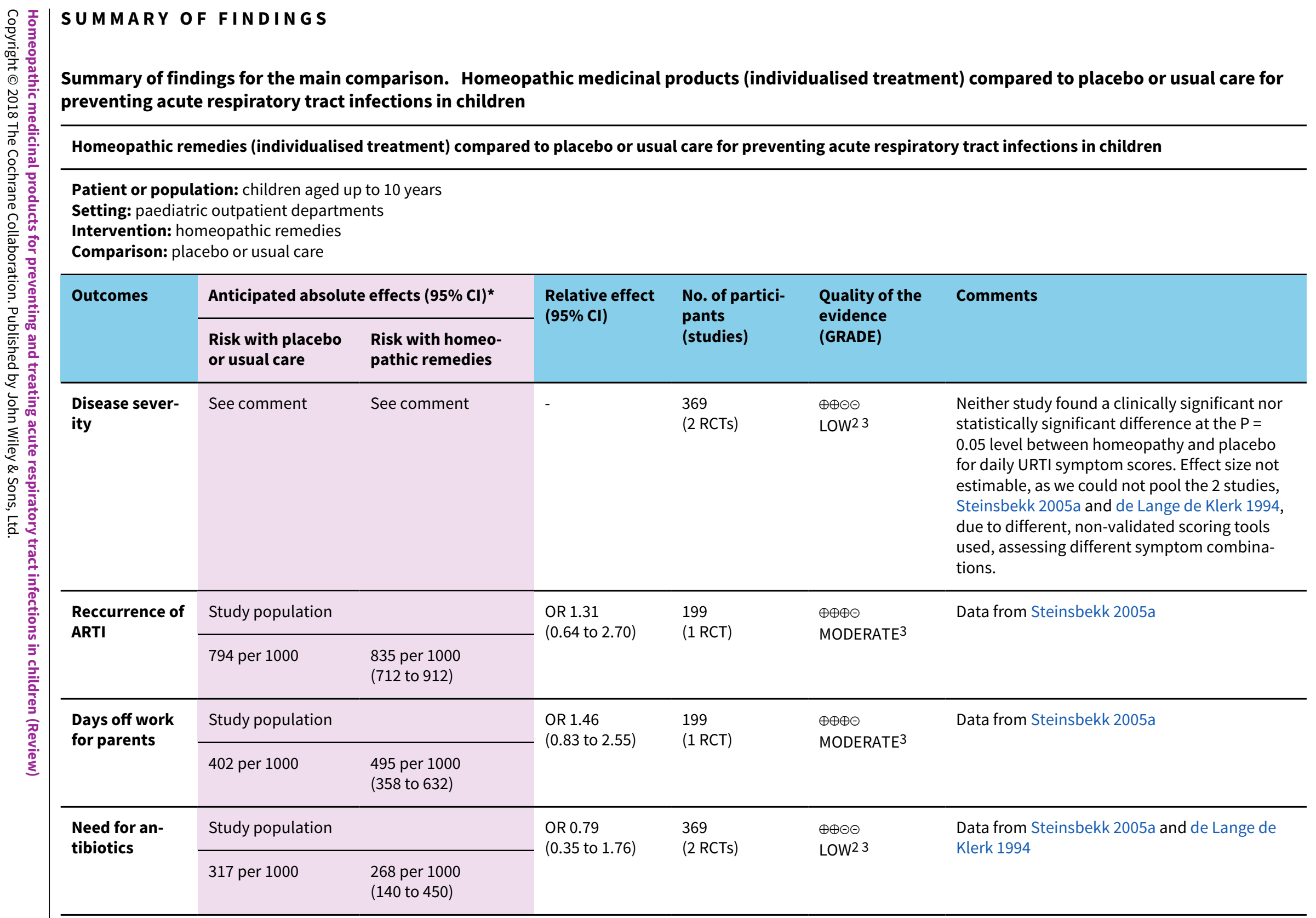




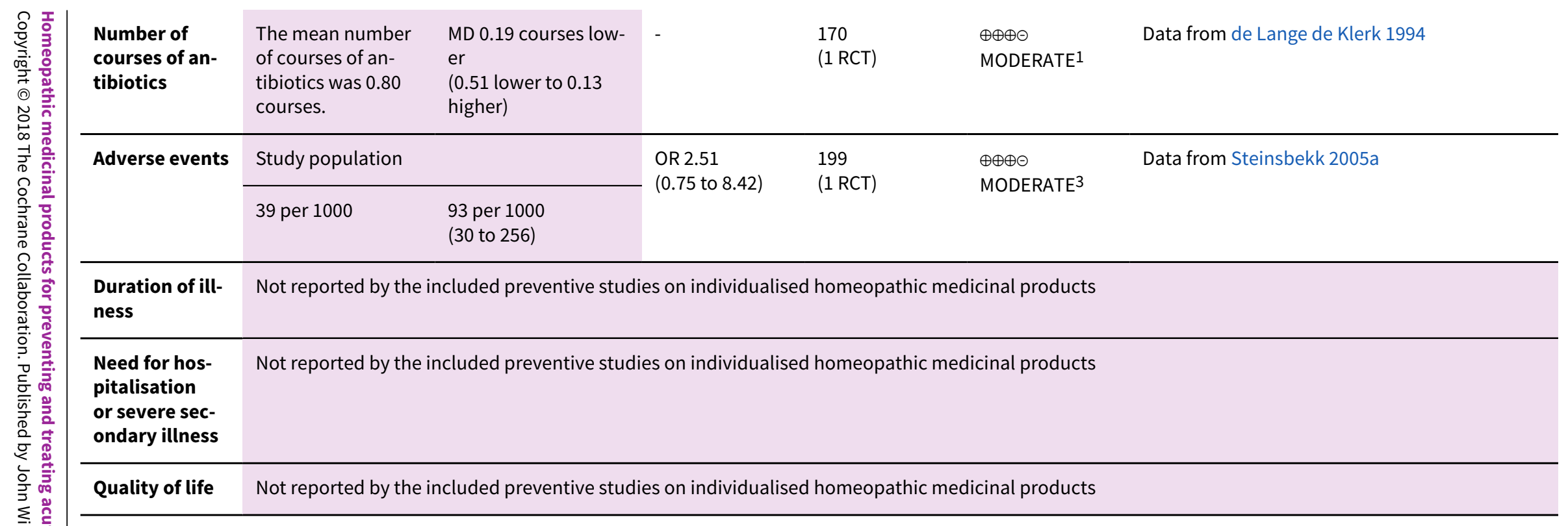

${ }^{*}$ The risk in the intervention group (and its $95 \%$ confidence interval) is based on the assumed risk in the comparison group and the relative effect of the intervention (and its $95 \% \mathrm{Cl})$.

ARTI: acute respiratory infection; Cl: confidence interval; MD: mean difference; OR: odds ratio; $\mathbf{R C T}$ : randomised controlled trial; URTI: upper respiratory tract infection

\section{GRADE Working Group grades of evidence}

High quality: We are very confident that the true effect lies close to that of the estimate of the effect.

Moderate quality: We are moderately confident in the effect estimate: the true effect is likely to be close to the estimate of the effect, but there is a possibility that it is substantially different.

Low quality: Our confidence in the effect estimate is limited: the true effect may be substantially different from the estimate of the effect.

Very low quality: We have very little confidence in the effect estimate: the true effect is likely to be substantially different from the estimate of effect.

1Downgraded one level due to limitations in the design and implementation of available studies suggesting high likelihood of bias.

2Downgraded one level due to unexplained heterogeneity or inconsistency of results.

3Downgraded one level due to imprecision of results (wide confidence intervals).

Summary of findings 2. Homeopathic medicinal products (non-individualised treatment) compared to placebo or usual care for preventing acute respiratory tract infections in children

Homeopathic medicinal products (non-individualised treatment) compared to placebo or usual care for preventing acute respiratory tract infections in children

Patient or population: children aged up to 12 years 


\begin{tabular}{|c|c|c|c|c|c|c|}
\hline \multirow{3}{*}{ 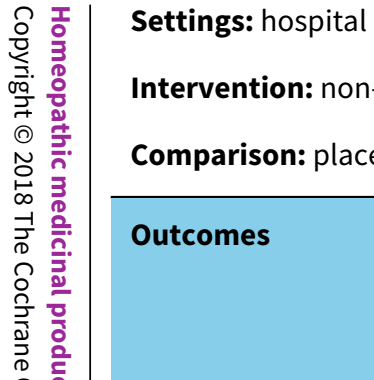 } & $\begin{array}{l}\text { individualised homeo } \\
\text { bo or usual care }\end{array}$ & athic remedies & & & & \\
\hline & \multicolumn{2}{|c|}{ Anticipated absolute effects $(95 \% \mathrm{Cl})^{\star}$} & \multirow{2}{*}{$\begin{array}{l}\text { Relative effect } \\
(95 \% \mathrm{Cl})\end{array}$} & \multirow{2}{*}{$\begin{array}{l}\text { No. of partici- } \\
\text { pants } \\
\text { (studies) }\end{array}$} & \multirow{2}{*}{$\begin{array}{l}\text { Quality of the } \\
\text { evidence } \\
\text { (GRADE) }\end{array}$} & \multirow[t]{2}{*}{ Comments } \\
\hline & $\begin{array}{l}\text { Risk with placebo } \\
\text { or usual care }\end{array}$ & $\begin{array}{l}\text { Risk with homeo- } \\
\text { pathic remedies }\end{array}$ & & & & \\
\hline \multirow{2}{*}{$\begin{array}{l}\text { Reccurrence of } \\
\text { ARTI }\end{array}$} & \multicolumn{2}{|l|}{ Study population } & \multirow{2}{*}{$\begin{array}{l}\text { OR } 1.14 \\
(0.83 \text { to } 1.57)\end{array}$} & \multirow{2}{*}{$\begin{array}{l}695 \\
\text { (2 RCTs) }\end{array}$} & \multirow{2}{*}{$\begin{array}{l}\oplus \oplus \ominus \ominus \\
\text { LOW1 } 2\end{array}$} & \multirow{2}{*}{$\begin{array}{l}\text { Large loss to follow-up (major limitations } \\
\text { that are likely to result in a biased assess- } \\
\text { ment of the intervention effect) (Siqueira } \\
\text { 2016) }\end{array}$} \\
\hline & 448 per 1000 & $\begin{array}{l}481 \text { per } 1000 \\
(402 \text { to } 560)\end{array}$ & & & & \\
\hline \multirow[t]{2}{*}{ Number of ARTIs } & \multicolumn{2}{|l|}{ Study population } & \multirow[t]{2}{*}{-} & \multirow{2}{*}{$\begin{array}{l}600 \\
(1 \mathrm{RCT})\end{array}$} & \multirow{2}{*}{$\begin{array}{l}\oplus \oplus \oplus \odot \\
\text { MODERATE } 1\end{array}$} & \multirow{2}{*}{$\begin{array}{l}\text { Large loss to follow-up (major limitations } \\
\text { that are likely to result in a biased assess- } \\
\text { ment of the intervention effect) (Siqueira } \\
\text { 2016) }\end{array}$} \\
\hline & $\begin{array}{l}\text { The mean number } \\
\text { of ARTIs was } 1.3 \\
\text { episodes. }\end{array}$ & $\begin{array}{l}\text { MD } 0.47 \text { episodes low- } \\
\text { er } \\
\text { ( } 0.25 \text { to } 0.69 \text { lower) }\end{array}$ & & & & \\
\hline \multirow[t]{2}{*}{ Adverse events } & \multicolumn{2}{|l|}{ Study population } & \multirow{2}{*}{$\begin{array}{l}\text { OR } 0.26 \\
\text { (0.03 to } 2.43)\end{array}$} & \multirow{2}{*}{$\begin{array}{l}95 \\
(1 \mathrm{RCT})\end{array}$} & \multirow{2}{*}{$\begin{array}{l}\oplus \Theta \Theta \Theta \\
\text { VERY LOW1 } 2\end{array}$} & \multirow{2}{*}{$\begin{array}{l}\text { Homeopathy was used for a different indi- } \\
\text { cation (OME) in this trial (Pedrero-Escalas } \\
\text { 2016). }\end{array}$} \\
\hline & 80 per 1000 & $\begin{array}{l}22 \text { per } 1000 \\
\text { ( } 3 \text { to } 174)\end{array}$ & & & & \\
\hline Disease severity & \multicolumn{6}{|c|}{ Not reported by the included preventive studies on non-individualised homeopathic medicinal products } \\
\hline $\begin{array}{l}\text { Days off work } \\
\text { for parents }\end{array}$ & \multicolumn{6}{|c|}{ Not reported by the included preventive studies on non-individualised homeopathic medicinal products } \\
\hline $\begin{array}{l}\text { Duration of ill- } \\
\text { ness }\end{array}$ & \multicolumn{6}{|c|}{ Not reported by the included preventive studies on non-individualised homeopathic medicinal products } \\
\hline $\begin{array}{l}\text { Need for antibi- } \\
\text { otics }\end{array}$ & \multicolumn{6}{|c|}{ Not reported by the included preventive studies on non-individualised homeopathic medicinal products } \\
\hline $\begin{array}{l}\text { Number of } \\
\text { courses of an- } \\
\text { tibiotics }\end{array}$ & \multicolumn{6}{|c|}{ Not reported by the included preventive studies on non-individualised homeopathic medicinal products } \\
\hline $\begin{array}{l}\text { Need for hospi- } \\
\text { talisation or se- }\end{array}$ & \multicolumn{6}{|c|}{ Not reported by the included preventive studies on non-individualised homeopathic medicinal products } \\
\hline
\end{tabular}




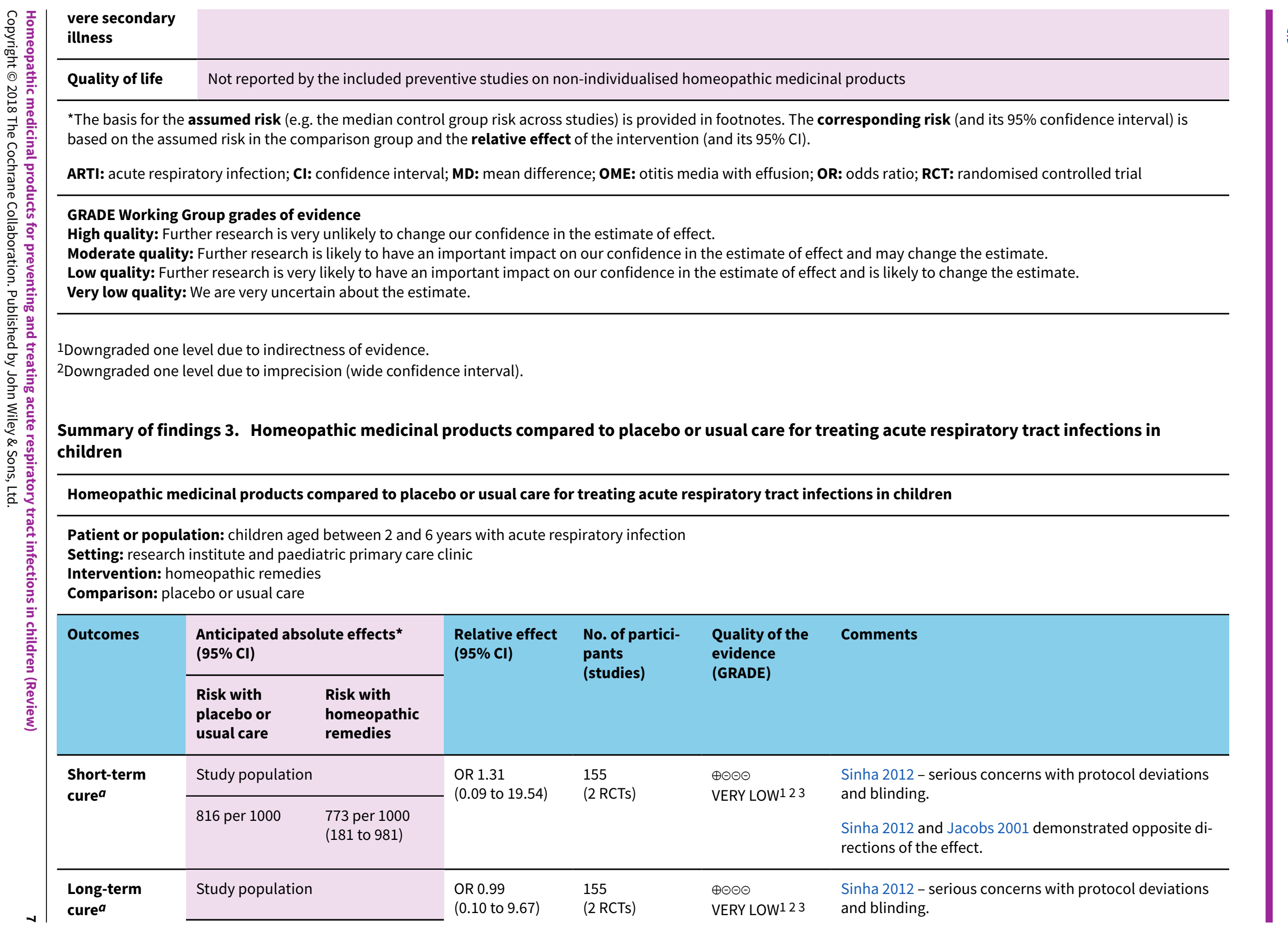




\begin{tabular}{|c|c|c|c|c|c|c|}
\hline & 696 per 1000 & $\begin{array}{l}698 \text { per } 1000 \\
\text { (186 to } 958)\end{array}$ & & & & $\begin{array}{l}\text { Sinha } 2012 \text { and Jacobs } 2001 \text { demonstrated opposite di- } \\
\text { rections of the effect. }\end{array}$ \\
\hline \multirow[t]{2}{*}{$\begin{array}{l}\text { Disease sever- } \\
\text { ity } \\
\text { assessed with } \\
\text { symptom } \\
\text { scoresa b }\end{array}$} & \multirow[t]{2}{*}{ See comment } & \multirow[t]{2}{*}{ See comment } & \multirow[t]{2}{*}{-} & \multirow[t]{2}{*}{$\begin{array}{l}339 \\
(4 \mathrm{RCTs})\end{array}$} & \multirow[t]{2}{*}{$\begin{array}{l}\oplus \oplus \ominus \ominus \\
\text { LOW1 } 2\end{array}$} & $\begin{array}{l}\text { Effect size not estimable as none of the studies assessed } \\
\text { symptoms using the same symptom scoring scales; also } \\
\text { significant clinical heterogeneity and different methods } \\
\text { of reporting symptom scores between the studies, so we } \\
\text { were unable to pool the results. }\end{array}$ \\
\hline & & & & & & $\begin{array}{l}\text { The individualised homeopathy treatment studies did } \\
\text { not find a consistent effect: higher symptom scores } \\
\text { were observed in the placebo or conventional treatment } \\
\text { groups at some time points and lower scores were ob- } \\
\text { served at other time points (Jacobs 2001; Sinha 2012). } \\
\text { The non-individualised homeopathy studies did not find } \\
\text { a consistent effect: Jacobs } 2016 \text { found a difference in } \\
\text { symptom scores in favour of the homeopathy group at } \\
\text { day } 1 \text { (among participants who returned symptom di- } \\
\text { aries), but otherwise no significant effect of symptom } \\
\text { scores was seen. Malapane } 2014 \text { only found a signifi- } \\
\text { cant difference at day } 6 \text { in children with viral sore throat } \\
\text { treated with homeopathy. }\end{array}$ \\
\hline Antibiotic use & See commen & See comment & - & $\begin{array}{l}40 \\
(1 \mathrm{RCT})\end{array}$ & $\begin{array}{l}\oplus \ominus \ominus \ominus \\
\text { VERY LOW } 1\end{array}$ & $\begin{array}{l}\text { Antibiotic use outcome in Sinha } 2012 \text { cannot be inter- } \\
\text { preted as a valid study outcome due to apparent proto- } \\
\text { col deviations. We have therefore not included this out- } \\
\text { come as a quantitative outcome in the data and analy- } \\
\text { ses. } \\
\text { Sinha } 2012 \text { - serious concerns with protocol deviations } \\
\text { and blinding for this outcome specifically (downgraded } \\
3 \text { levels) }\end{array}$ \\
\hline \multirow{2}{*}{$\begin{array}{l}\text { Adverse } \\
\text { events } a\end{array}$} & \multicolumn{2}{|c|}{ Study population } & \multirow[t]{2}{*}{ Not estimable } & \multirow{2}{*}{$\begin{array}{l}75 \\
(1 \mathrm{RCT})\end{array}$} & \multirow{2}{*}{$\begin{array}{l}\oplus \oplus \ominus \ominus \\
\text { LOW1 } 3\end{array}$} & Individualised homeopathy \\
\hline & 0 per 1000 & $\begin{array}{l}0 \text { per } 1000 \\
(0 \text { to } 0)\end{array}$ & & & & $\begin{array}{l}\text { Note: zero adverse events were reported for both groups } \\
\text { (Jacobs 2001). }\end{array}$ \\
\hline \multirow{2}{*}{$\begin{array}{l}\text { Adverse } \\
\text { events }^{b}\end{array}$} & \multicolumn{2}{|c|}{ Study population } & \multirow{2}{*}{$\begin{array}{l}\text { OR } 3.55 \\
(1.27 \text { to } 9.96)\end{array}$} & \multirow{2}{*}{$\begin{array}{l}249 \\
(1 \mathrm{RCT})\end{array}$} & \multirow{2}{*}{$\begin{array}{l}\oplus \oplus \ominus \ominus \\
\text { LOW1 } 3\end{array}$} & Non-individualised homeopathy \\
\hline & 41 per 1000 & $\begin{array}{l}133 \text { per } 1000 \\
(52 \text { to } 300)\end{array}$ & & & & Jacobs 2016 - concerns with attrition bias \\
\hline
\end{tabular}




\section{B A C K G R O U N D}

\section{Description of the condition}

Acute respiratory tract infection (ARTI) is a major cause of morbidity and mortality worldwide. On average, children have between three and six ARTIs annually, and they are the most common cause of both illness and mortality in children aged under five years outside the neonatal period (Simoes 2006). A systematic analysis estimated that in 2010 almost 12 million episodes of severe and 3 million episodes of very severe acute lower respiratory tract infection (ALRTI) resulted in hospital admission worldwide in young children (Nair 2013). Acute respiratory tract infections are responsible for $25 \%$ of all deaths in children aged under five years (excluding neonates); $90 \%$ of these deaths are due to pneumonia (GBD 2015).

Acute respiratory tract infections can be classified as upper respiratory tract infections (URTIs) or lower respiratory tract infections (LRTIS). The upper respiratory tract consists of the airways from the nostrils to the vocal cords in the larynx, including the paranasal sinuses and middle ear. The lower respiratory tract comprises the airways from the trachea and bronchi to the alveoli. Upper respiratory tract infections may include nasopharyngitis, laryngitis, pharyngo-tonsillitis, and otitis media. Lower respiratory tract infections comprise bronchiolitis, bronchitis, and pneumonia. For the purposes of this review, we used 'ARTI' to represent both URTIS and LRTIs.

Current conventional interventions to control ARTIs are based on basic health care and environmental health, such as the widespread use of vaccinations, simple case-by-case management to diagnose and treat children promptly using conventional pharmaceutical therapies, and improvements in nutrition (Chen 2011). Conventional medical therapy for URTIs includes analgesics, decongestants, antihistamines, expectorants, various types of antibiotics, and nutritional supplements (eTG 2016).

\section{Description of the intervention}

Complementary and alternative medicines (CAM) are becoming increasingly popular (Clarke 2015). Homeopathy, one of the many forms of CAM, is based on treatments using the principles of 'similars' and 'dilutions' (Lee-Treweek 2006). Homeopathic medicinal products are produced by serial dilutions with vigorous shaking between dilutions (potentisation) of a substance (such as an herb or trace element). This process is thought to imprint information from the diluted substance to the solvent (Schulte 1999). Homeopathic practitioners claim benefit, especially for children, and in particular when dealing with respiratory infections that account for the most common cause of morbidity in children. In addition, the overuse of antibiotics and their lack of benefit against viral respiratory illnesses calls for new approaches to treat common respiratory infections (Fahey 1998).

Homeopathic care is the holistic primary care role provided by a homeopath involving interventions that may range from reassurance to behavioural strategies to provision of a homeopathic medicinal product (Linde 1997; Lüdtke 2008; Rutten 2008; Shang 2005). One of the basic tenets of homeopathic treatment is individualisation, whereby two or more patients with the same medical diagnosis might receive different medicines, based on the specific symptoms of illness in each patient, the patient's mood, type of pain, and amount of thirst, and the time of aggravation of symptoms (Jacobs 2001). When a homeopathic medicinal product is prescribed by a homeopath, individual substances for treatment are selected based on a thorough assessment, including a comprehensive history of presenting symptoms. However, commercially available over-the-counter homeopathic medicinal products sold without an individualised assessment or prescription are increasingly popular.

When assessing the evidence, it is important to consider the effect of holistic homeopathic care including an individualised medicinal product prescribed by a homeopath (Linde 1997; Lüdtke 2008; Rutten 2008; Shang 2005), versus homeopathic medicinal product alone (e.g. non-individualised remedies available for a specific indication, or an over-the counter, one-size-fits-all basis). In this review we therefore distinguish between and separately analyse studies of individualised homeopathy (participants were assessed and prescribed an individualised remedy) and nonindividualised homeopathy (all treatment arm participants were given the same pre-formulated, often commercially available homeopathic medicinal product). The role of self or parentselected homeopathic medicinal products based on simplified constitutional indications, for example personality descriptions, has been studied (Steinsbekk 2007). We considered such therapeutic options as falling within individualised homeopathy.

\section{How the intervention might work}

The interventions considered in this review included homeopathic medicinal products with single or multiple components initiated by homeopaths after a consultation (individualised homeopathy), or the use of homeopathic medicinal products not individually prescribed, usually obtained over the counter (non-individualised homeopathy).

The basic concept behind homeopathic remedies is 'similia similibus curentur' (like cures like) (Grimes 2012; Walach 2005). Practically, this means that a substance that causes symptoms in a healthy person is the same substance that can cure symptoms in an ill patient.

Whether or not homeopathy can be effective is a subject of debate, as actual doses of homeopathic drugs are far below what is considered to have any medically quantifiable effect. The compounds involved in the medicinal products are highly diluted in either alcohol or water. The original substance is diluted 1:99 parts of water or alcohol, followed by a second dilution of 1:99 parts and so on. The process may occur more than 30 times before the final mixture is produced. Furthermore, the mixture must be shaken a set number of times in a particular manner between every dilution because this is believed to lead to memory in the molecules and release the healing energy of the compounds, that is succussion (Rao 2007). The compounds involved may be diluted based on a number of established potency scales such as originally described by Hahnemann as the centesimal or ' $\mathrm{C}$ scale' and more recent scales such as the D, Q, or LM scales (Jonas 2003). However, there are no established explanatory models for how highly diluted homeopathic medicinal products might work. For this reason, homeopathy remains highly controversial because the key concepts governing this form of medicine are not consistent with the established laws of conventional therapeutics (Grimes 2012). 


\section{Why it is important to do this review}

Homeopathy is a popular method of treatment for respiratory-type illnesses, but its effectiveness and potential side effects are not well researched.

Most analyses of the research on homeopathy have concluded there is little or no evidence to support homeopathy as an effective treatment for any specific condition, based on flawed or inadequate studies conducted. However, some individual observational studies, randomised, placebo-controlled trials, and laboratory research have reported positive effects (Ullman 2010). Most also failed to differentiate between the efficacy of nanopharmacological and behavioural components of homeopathic care. Two recent systematic reviews examined separately individualised and non-individualised placebocontrolled trials (Mathie 2014; Mathie 2017). Both reviews found a small potential benefit for homeopathy, but cautioned that low or unclear overall quality of the evidence prompts caution in interpreting the findings. Variation and uncertainty in the efficacy of homeopathic remedies outlines the need for future research on homeopathy to be conducted with rigorous attention to design elements that would reduce risk of bias. We focused only on studies that were double-blind, as this potentially removes some of the possible biases that may account for positive results seen in some single-blind and observational studies.

There are a limited number of homeopathy studies and analyses available in comparison to conventional therapy and, hence, there is no structured, unbiased outline of homeopathic medicinal products that would serve as a guideline for practitioners interested in CAM. A systematic review of double-blind randomised controlled trials on the effects of homeopathic products and care in respiratory infections in children would inform consumers and practitioners on the highest level of evidence base for homeopathy and contribute to the development of comprehensive guidelines for the management of respiratory tract infections in children.

\section{OB JECTIVES}

To assess the effectiveness and safety of oral homeopathic medicinal products compared with placebo or conventional therapy to prevent and treat acute respiratory tract infections in children.

\section{METHOD S}

\section{Criteria for considering studies for this review}

\section{Types of studies}

Double-blind randomised controlled trials (RCTs) or double-blind cluster-RCTs comparing homeopathy with placebo or conventional treatments to prevent or treat acute respiratory tract infections (ARTIs) in children. We included ' $\mathrm{N}$ of 1 ' studies in which a single participant received both the homeopathy treatment and the control intervention (assigned in a randomly allocated sequence) if randomisation and blinding were performed.

\section{Types of participants}

Children of either gender, aged up to 16 years with ARTIs. We included children with other acute or chronic comorbidities and who were not immunodeficient.

\section{Types of interventions}

We included trials if one of the groups received any type of homeopathic treatment involving the delivery of an oral homeopathic medicinal product (either individualised homeopathy by a homeopath following a consultation or nonindividualised homeopathy where a homeopathic product was delivered without a consultation). Medicinal products included both simple preparations involving single substances, or complex preparations involving more than one substance. The control group participants received either standard treatments currently used clinically to treat various ARTIs (such as antihistamines, decongestants, analgesics, antibiotics, and combinations of these treatments), or identical oral placebo, usually the biotherapy vehicle consisting of ethanol, water, and other additives apart from the active ingredient to ensure a similar colour and taste.

We did not include herbal or other non-homeopathic medicinal products available over the counter such as echinacea, which has been reviewed previously (Karsch-Völk 2014).

\section{Types of outcome measures}

\section{Primary outcomes}

1. Cure: defined as the reduction or resolution of symptoms of ARTIs (fever/body temperature, cough, pain, malaise/feeling of illness, rhinorrhoea, etc.) in the short- (up to 14 days) and longterm (up to 3 months).

2. Disease severity as measured by mean symptom scores.

3. Recurrence of ARTIs (time to recurrence included).

\section{Secondary outcomes}

1. Duration of illness from time of randomisation until resolution of symptoms (measured longitudinally at intervals of weeks to months or years).

2. Need for hospitalisation or severe secondary illness.

3. Days off school and days off work for parents.

4. Any adverse events.

5. Quality of life.

6. Antibiotic use.

\section{Search methods for identification of studies}

\section{Electronic searches}

We searched CENTRAL (2017, Issue 11), which contains the Cochrane Acute Respiratory Infections Specialised Register, MEDLINE (1946 to 27 November 2017), Embase (2010 to 27 November 2017), CINAHL (1981 to 27 November 2017), AMED (1985 to December 2014), CAMbase (searched 29 March 2018), British Homeopathic Library (searched 26 June 2013 - no longer operating). We also searched the WHO ICTRP and ClinicalTrials.gov trials registers (29 March 2018), checked references, and contacted study authors to identify additional studies.

We searched the Cochrane Central Register of Controlled Trials (CENTRAL; 2017, Issue 11), part of the Cochrane Library (www.thecochranelibrary.com), (last searched 27 November 2017), MEDLINE (Ovid and EBSCOhost) (1946 to 27 November 2017), Embase (Elsevier) (2010 to 27 November 2017), CINAHL (Cumulative Index to Nursing and Allied Health Literature) (EBSCO) (1981 to 27 November 2017), AMED (Allied and Complementary Medicine 
database) (Ovid) (1985 to December 2014), CAMbase (searched 29 March 2018), and British Homeopathic Library (searched 26 June 2013 - no longer operating). We did not search AMED beyond December 2014 due to lack of institutional access to this database.

We used the search strategy described in Appendix 1 to search MEDLINE and CENTRAL. We combined the MEDLINE search with the Cochrane Highly Sensitive Search Strategy for identifying randomised trials in MEDLINE: sensitivity and precision maximising version (2008 revision); Ovid format (Lefebvre 2011). We adapted the search strategy to search Embase (Appendix 2), CINAHL (Appendix 3), AMED (Appendix 4), the British Homeopathic Library (Appendix 5), and CAMbase (Appendix 6).

We searched the World Health Organization International Clinical Trials Registry Platform (WHO ICTRP) (apps.who.int/trialsearch) and ClinicalTrials.gov (www.clinicaltrials.gov) trials registers for completed and ongoing trials (last searched 29 March 2018).

\section{Searching other resources}

We searched for reviews and scanned the reference lists of retrieved reviews for references to trials. This included searches of the NIHR Dissemination Centre (www.dc.nihr.ac.uk) for summaries of new research (last searched 29 March 2018), the Database of Abstracts of Reviews of Effects (DARE), and the NHS Economic Evaluation Database (NHSEED) (note: bibliographic records were published on DARE and NHS EED until 31 March 2015 and included in Issue 4, 2015, and have now all been searched via the Cochrane Library).

We scanned reference lists of identified publications for additional trials and contacted trial authors to retrieve other RCTs and systematic reviews relevant to this review. We also contacted trial authors for published and unpublished studies.

\section{Data collection and analysis}

\section{Selection of studies}

Two review authors (BB, or DK, $\mathrm{KH}$ ) independently reviewed titles and abstracts to select potentially eligible studies. Two review authors (BB, DK, KH or TM) independently conducted a full-text analysis to assess if these studies met the eligibility criteria. Disagreements about inclusion of one study were resolved first by discussion, and supported by independent review by a third review author (DK).

\section{Data extraction and management}

We designed a data extraction form which was reviewed by all review authors, then pilot tested with a sample of studies, reviewed and edited again to produce a final copy. Two review authors (BB, $\mathrm{DK}, \mathrm{KH}$ or TM) independently extracted data from the included studies using the standardised data collection form to minimise errors and reduce potential bias. A third review author (DK) independently verified a random selection of data extraction.

We included the following information on the data collection forms.

1. Authors.

2. Publication year.

3. Name of journal.

4. Participants (including total number, demographics, duration and characteristics of illness, etc.).
5. Study type and methods

6. Intervention (type, route and duration).

7. Results (outcome measures, time points, effect, statistical significance, and adverse effects).

\section{Assessment of risk of bias in included studies}

Two review authors (BB, or $\mathrm{DK}, \mathrm{KH}, \mathrm{TM})$ independently assessed the risk of bias of each study using Cochrane's tool for assessing risk of bias (Higgins 2011).

The features of the 'Risk of bias' tool include:

- random sequence generation;

- allocation concealment;

- blinding of participants and personnel;

- blinding of outcome assessment;

- incomplete outcome data;

- selective outcome reporting; and

- other sources of bias.

We expressed the judgements for each 'Risk of bias' domain as low, high, or unclear risk of bias. Disagreements about inclusion of a study were resolved by discussion and consensus first. A third review author (DK) arbitrated where disagreement was due to difference in interpretation.

\section{Measures of treatment effect}

We expressed dichotomous data recording the primary outcome of cure and secondary outcomes of adverse events or requirement for parental absence from work as odds ratios (OR) with 95\% confidence intervals (Cls). We expressed outcomes measured as continuous data (e.g. for number of antibiotic courses required) using the mean difference (MD) with standard deviations (SDs). We planned to calculate the absolute risk reduction (ARR) and numbers needed to treat for an additional beneficial outcome (NNTB) if the results were statistically significant.

\section{Unit of analysis issues}

The individual participant was the unit of analysis. Cluster analysis did not occur in any of the included studies.

\section{Dealing with missing data}

We contacted study authors to request information on missing data wherever possible and planned to perform an intention-to-treat (ITT) analysis (assuming missing data as treatment failure) if results were unattainable. We addressed the potential impact of missing data on the review in the Discussion.

\section{Assessment of heterogeneity}

We assessed study heterogeneity in two ways. First, we assessed face value heterogeneity by comparing study populations, settings, and methods. Second, we planned to assess the presence of statistical heterogeneity by calculating the $\mathrm{Chi}^{2}$ test and $\mathrm{I}^{2}$ statistic (Higgins 2011). We used a cut-off value of $P<0.10$ to determine statistical significance of the $\mathrm{Chi}^{2}$ test. We considered an $\mathrm{I}^{2}$ statistic $>50 \%$ as important heterogeneity. If heterogeneity was present, we examined the methodological and clinical characteristics of the included studies to explore the possible causes. We planned to conduct sensitivity analyses and summarise our findings. We 
planned to produce a table to report findings and subsequently assess to see if this impacted on the overall effect.

\section{Assessment of reporting biases}

If more than 25 trials were available, we planned to construct funnel plots to assess the risk of publication bias. We planned to follow the recommendations on testing for funnel plot asymmetry as described in Section 10.4 of the Cochrane Handbook for Systematic Reviews of Interventions (Higgins 2011). We planned to explore the results in the Discussion, if applicable.

\section{Data synthesis}

We used Review Manager 5 to synthesise data (Review Manager 2014).

We analysed prevention studies and treatment studies separately. We also analysed individualised homeopathy and nonindividualised homeopathy studies separately because these were considered to be different types of interventions.

We performed fixed-effect meta-analysis in the absence of heterogeneity. We did not pool data but reported study results where there was obvious face value heterogeneity. Where we detected important statistical heterogeneity, we applied a randomeffects model (Higgins 2011). Where possible, we planned to pool studies and perform sensitivity analysis to investigate which studies contributed to the heterogeneity.

\section{GRADE and 'Summary of findings' table}

We created 'Summary of findings' tables using the following outcomes:

- short- and long-term cure;

- disease severity;

- recurrence of ARTI;

- days off work for parents;

- antibiotic use; and

- adverse effects.

We used the five GRADE considerations (study limitations, consistency of effect, imprecision, indirectness, and publication bias) to assess the quality of a body of evidence as it relates to the studies that contribute data to the meta-analyses for the prespecified outcomes (Atkins 2004). We used methods and recommendations described in Section 8.5 and Chapter 12 of the Cochrane Handbook for Systematic Reviews of Interventions (Higgins 2011), employing GRADEpro GDT software (GRADEpro GDT 2014). We justified all decisions to downgrade the quality of studies using footnotes, and made comments to aid the reader's understanding of the review where necessary.

\section{Subgroup analysis and investigation of heterogeneity}

We intended to conduct subgroup analyses if we found multiple outcome measures with significant heterogeneity. Groupings that may have been relevant to this review included children aged under six years versus older children, URTI versus LRTI, and various combinations of homeopathic care or remedies versus placebo or other active treatments including antibiotics. This was not relevant because there were insufficient studies to analyse subgroups.

\section{Sensitivity analysis}

We intended to undertake sensitivity analysis to explore the impact of risk of bias on the overall treatment effect by pooling studies with low risk of bias first, and then adding studies with high risk of bias. However, these analyses were not required because of the small number of outcomes for few included studies.

\section{RES U LTS}

\section{Description of studies}

\section{Results of the search}

After de-duplication, we identified 1006 records from searches of databases using strategies outlined in the Electronic searches section. We found no further records by checking reference lists of included studies or by handsearching. Searches of trials registers identified five potential studies.

We assessed 1006 records by title and abstract for inclusion and excluded 977 records. Two studies (recommended by an expert in the field) await classification. The remaining 27 records were obtained as full-text papers and checked against our inclusion criteria. We excluded 19 papers that did not meet inclusion criteria (see Excluded studies). We included eight studies (see Included studies). A study selection flowchart is shown in Figure 1. 
Figure 1. Study flow diagram.

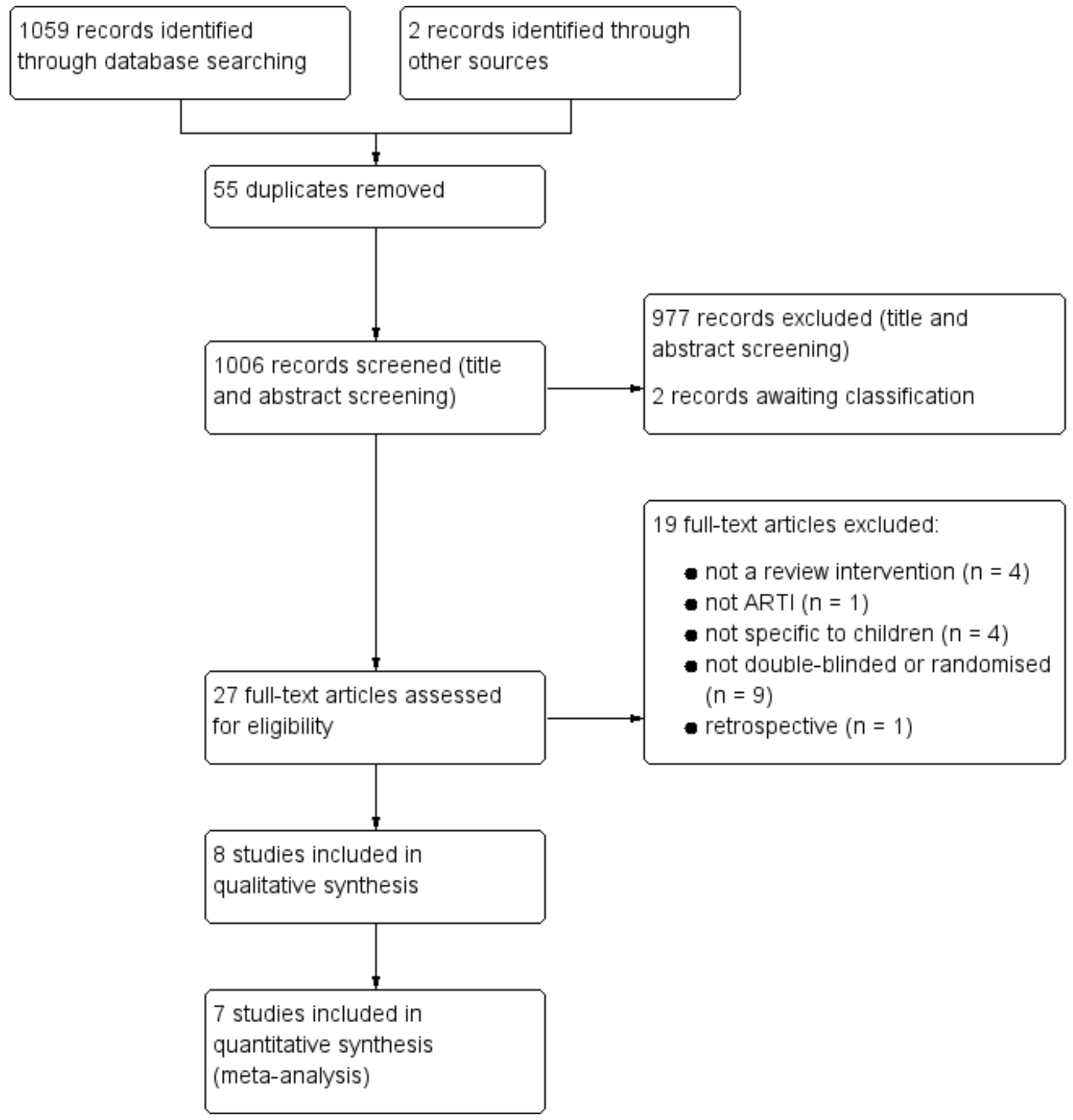

\section{Included studies}

We included eight studies that randomised a total of 1562 children (see Characteristics of included studies) (de Lange de Klerk 1994; Jacobs 2001; Jacobs 2016; Malapane 2014; Pedrero-Escalas 2016; Sinha 2012; Siqueira 2016; Steinsbekk 2005a). All included studies investigated upper respiratory tract infections (URTIS). Siqueira 2016 combined cold and flu diagnoses, so included an unknown number of children with lower respiratory tract infection (LRTI).

\section{Prevention studies}

de Lange de Klerk 1994 was a parallel-group randomised controlled trial (RCT) examining the efficacy of individualised homeopathy for daily burden of symptoms in children with recurrent URTI; we considered it a study of URTI prevention for this review. It was conducted at a paediatric outpatient department of a university hospital in Belgium. Participant inclusion required at least three URTI episodes in the previous year or the presence of otitis media with effusion (OME) at study entry. The study included 170 children aged from 18 months to 10 years; 86 children were randomised to the homeopathy and 84 to the placebo group. Homeopathic medicines were chosen individually by a homeopathic practitioner 
for each child in the homeopathy group. Mainly 6th, 30th, and 200th decimal potencies were used. Components of the preparations and the dose frequencies were not reported. Non-homeopathic drugs could be prescribed for either group by the child's usual doctor as needed throughout the study. Children were followed up for 12 months. The outcomes were mean daily symptom score (non-validated scoring tool designed for this study with a scale of 0 to 56 measuring four dimensions (symptoms of the nose, ear, throat, and general symptoms)), percentage of days symptom-free, requirement for antibiotics, number of antibiotic courses required, and number of surgeries (adenoidectomy, tonsillectomy). There was insufficient reporting of details of the intervention including medication frequency and which homeopathic medicines were used.

Pedrero-Escalas 2016 was a parallel-group RCT examining the efficacy of a non-individualised homeopathy regimen in children with OME for cure and preventing recurrences and complications such as acute otitis media (AOM). It was conducted at a tertiary healthcare hospital in Spain. The study included 95 children with OME, 45 randomised to three months of homeopathy treatment and 50 randomised to placebo. The homeopathy treatment involved a combination of two non-individualised homeopathic treatments: homeopathic treatment A (Agraphis nutans $5 \mathrm{CH}$ and Thuya occidentalis $5 \mathrm{CH}$ ) with a dosage of 5 granules of each, once daily (preferably in the evening) and homeopathic treatment B (Kalium muriaticum $9 \mathrm{CH}$ and Arsenicum iodatum $9 \mathrm{CH}$ ) with a dosage of 5 granules, twice daily. Homeopathy and placebo groups both also received co-intervention therapy of aerolised ambroxol, budesonide, and saline. Because this review focused on ARTI, the only effect outcome we drew from this study was occurrence of AOM; we therefore treated Pedrero-Escalas 2016 as a prevention study for this review. Occurrence of AOM was defined otologically during examination by an ear, nose, and throat specialist. Adverse events were reported; however, numbers of participants affected was provided only in relation to adverse events causing withdrawal from the study. Mild adverse events were reported as total episodes, not numbers of children who experienced events.

Siqueira 2016 was a parallel-group RCT examining the efficacy of two different non-individualised homeopathy regimens in children for prevention of influenza and URTIs in the following 12 months. It was conducted by the public health system in Petropolis, Rio de Janeiro. Participants were children from families of low economic and social background who did not have access to the private health system, additional health care, or both. The study included 600 children: 200 children were randomised to receive "InfluBio" (prepared from intact influenza A virus sample), 200 to receive "homeopathic complex" (prepared from Streptococcus and Staphylococcus bacterial strains and inactivated influenza virus), and 200 to receive placebo twice daily for 30 days. The placebo was the biotherapy vehicle, that is ethanol $30 \%$ (volume per volume), which is commonly employed as a vehicle for homeopathic medicines. Each test solution was administered by the child's tutor twice a day, for 30 days (in April); the dosage applied was 1 drop/ year of age, and the sample was previously diluted in a tablespoon of filtered water. Children were then monitored once a month for one year, with health agents using a standardised questionnaire to assess for episodes of ARTI. The outcomes were number and duration of episodes of flu and acute respiratory infection in one year (characterised by the presence of at least two of the following symptoms: fever (temperature greater than $37.8^{\circ} \mathrm{C}$ ), runny nose, prostration, myalgia, headache, and cough).

Steinsbekk 2005a was a parallel-group RCT examining the efficacy of individualised (parent-selected) homeopathy for URTI prevention in children with a previous URTI. Children were recruited via casualty department presentations at a university hospital in Norway. Although 251 children were randomised, 199 commenced the trial, with 97 children in the homeopathy group and 102 children in the placebo group. The homeopathy group received 12 weeks of treatment with one of three homeopathic therapies (C30 potency of either Calcarea carbonica, Pulsatilla, or sulphur) chosen by child's parents based on an information sheet, two pills two days per week. The placebo comparator was lactose pills, two pills two days per week. The outcomes were median daily symptom score over the 12 weeks (using a non-validated scoring tool that scored 9 symptoms), antibiotic use, adverse events, need for days off work for parents, and number of URTIs. The two independent investigators of this double-blinded trial, evaluating the effect of self treatment with homeopathic medicine, concurrently conducted an open and pragmatic RCT evaluating the effect of individualised treatments by homeopaths. Steinsbekk 2005b did not meet the inclusion criteria for this review.

\section{Treatment studies}

Jacobs 2001 was a parallel-group RCT of individualised homeopathy treatment for AOM. It was conducted at a private group paediatric practice in Seattle, WA, USA. The study included 75 children with AOM of less than 36 hours' duration, with 36 randomised to homeopathy and 39 randomised to placebo. The homeopathy group received individually prescribed homeopathic medicine given three times daily for five days or until symptom resolution. The individually prescribed medicines included eight different variants; the four most common were prescribed in $88 \%$ of cases: Pulsatilla nigricans (62.7\%), Chamomilla (10.7\%), sulphur (9.3\%), and Calcarea carbonica (5.3\%). The placebo comparator was placebo tablets (water/alcohol solution lacking active substance) three times daily for five days or until symptom resolution. The outcomes were adverse events, daily symptom score (using a non-validated scoring system from 0 to 9), and treatment failure. The study authors provided additional data on the converse outcome of treatment failure, that is cure, on request. Cure was defined as no severe persistent fever or pain after 24 hours and no moderate persistent fever or pain after 48 hours.

Jacobs 2016 was a parallel-group RCT of non-individualised homeopathy treatment for URTI conducted at a private paediatric practice at a university medical centre in Seattle, WA, USA. The study included 261 children diagnosed with URTI of less than seven days' duration, with 128 randomised to homeopathy and 121 randomised to placebo. The homeopathy group received 5 $\mathrm{mL}$ of commercial liquid formulation (Hyland's Cold 'n Cough 4 Kids; see Characteristics of included studies for ingredients), up to six times daily as needed for cold symptoms. The placebo group received $5 \mathrm{~mL}$ placebo liquid up to six times daily as needed; the placebo was similar in appearance, with some similarity of taste (liquid preparation included Glycyrrhiza extract as sweetener). The outcomes were all parent scored. Outcomes assessed based on symptom diaries included change in severity of cold symptoms one hour after a dose and change in non-specific symptoms one hour after a dose. Outcomes based on 5- to 10-day follow-up phone interviews included change in functional status of the child, change 
in health status, overall symptom severity at 5- to 10-day followup, and adverse events. The only outcome suitable for quantitative analysis was adverse events; the data for this outcome were based on 154 children due to low rates of diary return.

Malapane 2014 was a parallel-group RCT of non-individualised homeopathy treatment for acute viral tonsillitis. It was conducted at a primary school in Gauteng, South Africa. Thirty children with acute viral tonsillitis of less than two days' duration were included, with 15 randomised to homeopathy and 15 randomised to placebo. The homeopathy group received a commercially available preparation (Tonzolyt), two tablets four times daily dissolved under the tongue (see Characteristics of included studies for ingredients). The placebo group received two placebo tablets four times daily dissolved under the tongue, similar in appearance and taste and labelled in the same manner as the treatment medication. The outcomes were pain score, pain on swallowing, referred ear pain, examination findings, and vital signs. This study did not examine any of the primary or secondary outcomes of this review, except for a comment made regarding adverse events.

Sinha 2012 was a parallel-group RCT of individualised homeopathy treatment for AOM conducted at the General Paediatric Clinic of the Regional Research Institute of Homeopathy in Jaipur, India. The study included 80 children with AOM of less than 36 hours' duration, with 40 children randomised to homeopathy and 40 to the conventional treatment group. The homeopathy participants received selected homeopathic medicines repeated two to six hourly depending on severity; the potency and the identity of the medicine was changed according to the outcome of the first prescription, with a maximum of two changes in prescription permitted (see Characteristics of included studies for range of medicines prescribed). The conventional treatment participants received observation and treatment with antipyretics and antiinflammatories. The outcomes were symptom scores at days 3, 7, and 10 (using validated Acute Otitis Media Severity of Symptoms (AOM-SOS) scale from 0 to 14), scores on Tympanic Membrane Examination scale (novel to this study), cure, and requirement for antibiotics. Cure was defined as a symptom score of zero and a Tympanic Membrane Examination score of zero. There was a follow-up treatment phase with antibiotics if there was less than
$50 \%$ improvement in symptom score after three days. We noted an apparent protocol deviation in the study results (see Effects of interventions, Treatment studies, Secondary outcomes, Antibiotic use).

\section{Excluded studies}

We excluded 19 studies. Reasons for exclusion were: study intervention was not a homeopathic intervention (Lasfargues 1983; Salami 2008); not oral administration (Taylor 2011; Torbicka 1998); did not assess children with ARTI (Friese 2001); was not specific to children (Attena 1995; Ferley 1987; Rottey 1995; Zanasi 2014); was not randomised (Antonello 2012); was not double-blinded (D'Souza 2012; Harrison 1999; Jong 2016; NCT00858494; Steinsbekk 2005b; Steinsbekk 2007; Thinesse-Mallwitz 2015; Torbicka 1998; Van Haselen 2016); had no placebo or conventional treatment comparator arm (Jong 2016); or was a retrospective study (Beghi 2016).

\section{Studies awaiting classification}

We identified two studies by contact with experts in the field near the time of submission (Furuta 2017; Niederle 2001). Furuta 2017 appears to be a re-publication of a study first published in the Portuguese language in the same publication in 2007. Niederle 2001 is a non-English language study that was not peer-reviewed, nor indexed in the major databases, nor found online. Full-text articles for both studies have not yet been received or reviewed.

\section{Ongoing studies}

We identified two ongoing studies (CTRI/2014/06/004673; CTRI/2014/12/005294), which if complete and published will be assessed for inclusion when this review is updated.

\section{Risk of bias in included studies}

A 'Risk of bias' summary is shown in Figure 2 and Figure 3. Considering that inclusion criteria were limited to double-blind randomised trials, there was a moderate amount of bias in either the design or selective reporting of results. In the following section we have assessed risk of bias for the included studies based on specific domains.

Figure 2. Risk of bias graph: review authors' judgements about each risk of bias item presented as percentages across all included studies.

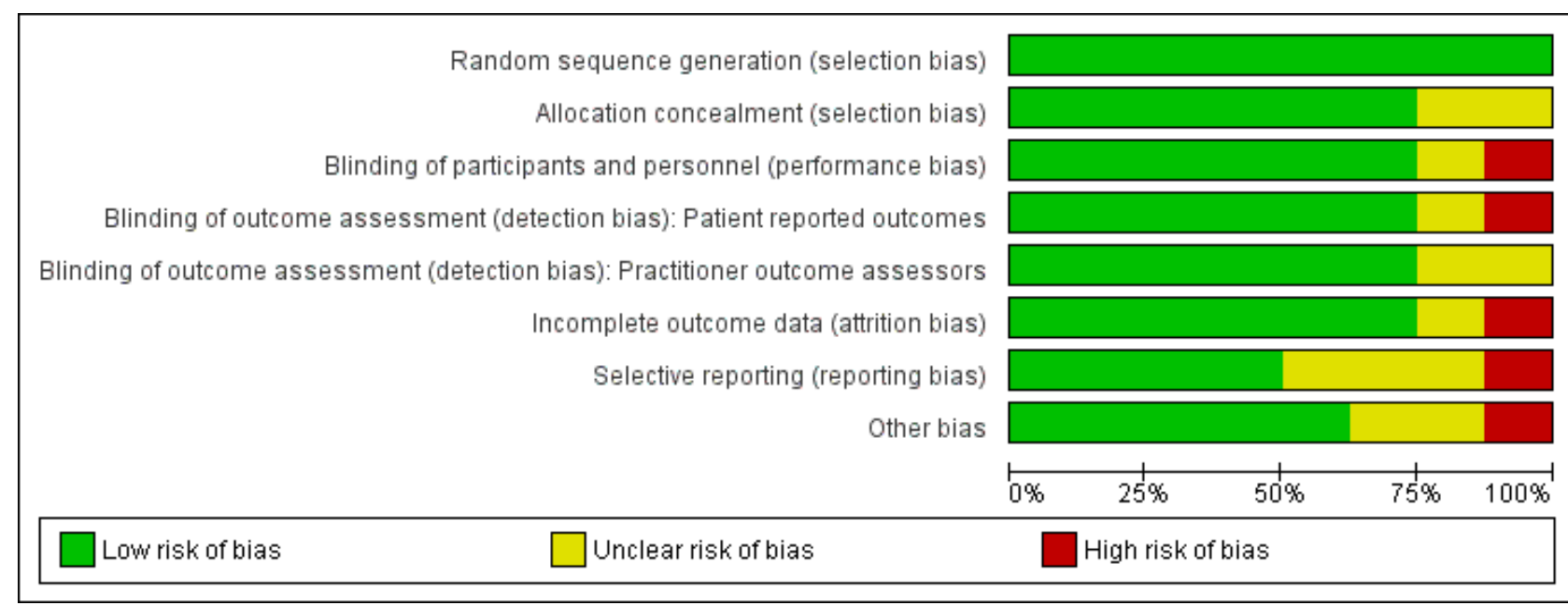


Figure 3. Risk of bias summary: review authors' judgements about each risk of bias item for each included study.

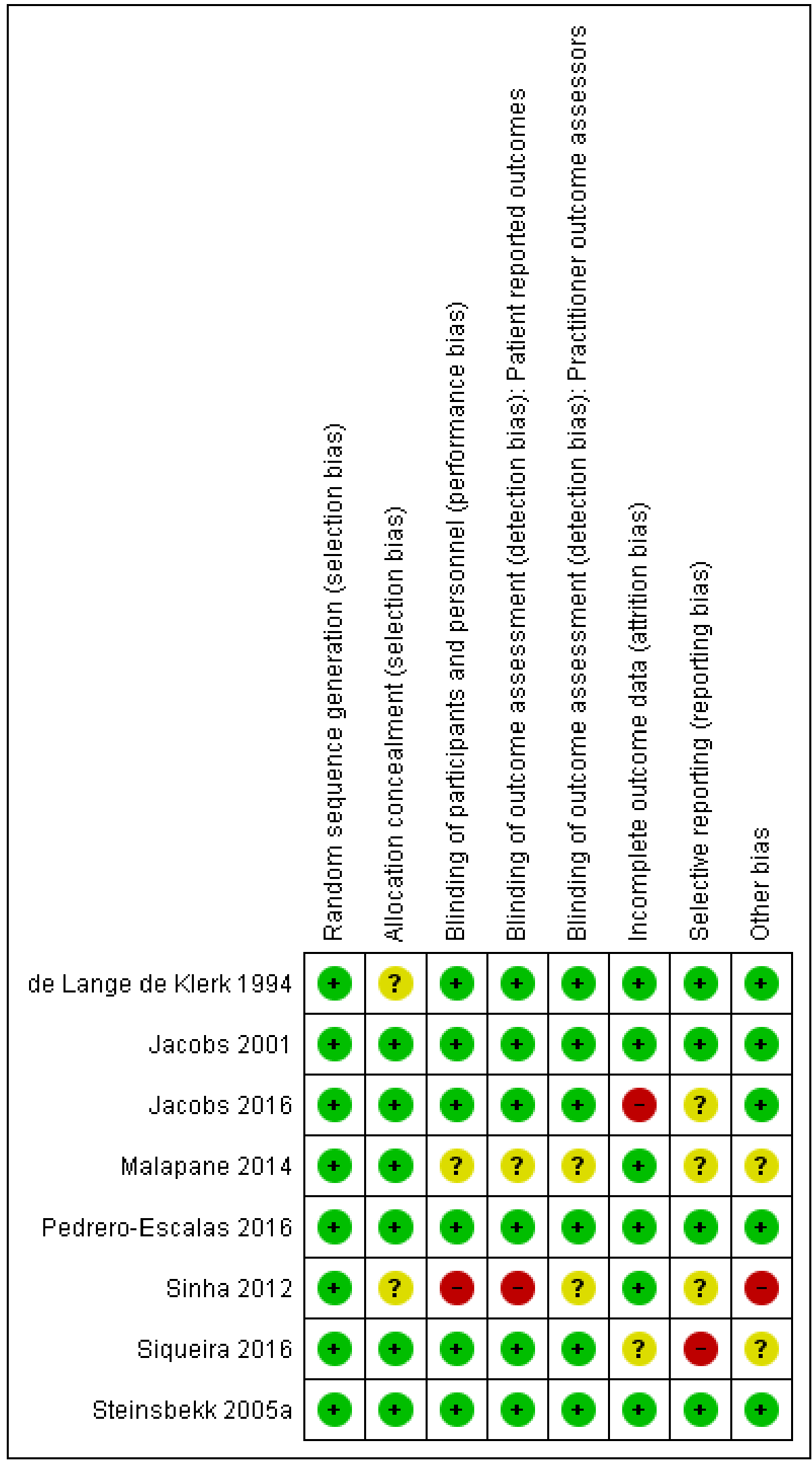

Homeopathic medicinal products for preventing and treating acute respiratory tract infections in children (Review) 


\section{Allocation}

Random sequence generation was adequate in all eight studies, which we assessed as at low risk of bias for this domain.

Concealment of allocation to homeopathy and control groups was adequate and appropriate in six studies (Jacobs 2001; Jacobs 2016; Malapane 2014; Pedrero-Escalas 2016; Siqueira 2016; Steinsbekk 2005a), which we assessed as at low risk of bias for this domain. Two studies did not describe the method by which children were allocated to groups and were assessed as at unclear risk of bias (de Lange de Klerk 1994; Sinha 2012).

\section{Blinding}

Blinding of participants (including parents), personnel, and outcome assessors was ensured in six studies (de Lange de Klerk 1994; Jacobs 2001; Jacobs 2016; Pedrero-Escalas 2016; Siqueira 2016; Steinsbekk 2005a), which we assessed as at low risk of bias for blinding of participants, blinding of outcome assessment for participant-reported outcomes, and blinding of outcome assessment by practitioners.

We assessed Malapane 2014 as at unclear risk of bias for all aspects of blinding due to inadequate description of blinding methods. No information was provided on how the investigator was kept blinded or who safeguarded the allocations.

Sinha 2012 did not provide details of blinding, for example did not describe a double-dummy technique or method of making treatments indistinguishable to participants. The Sinha 2012 homeopathy group was commenced on two to six hourly medication, while the placebo group took "analgesics, anti-pyretics and anti-inflammatories", so there was a high risk of the treatment group being revealed to participants and personnel in this study. Importantly, the homeopathy and conventional groups appear to have been treated differently with regard to commencement of antibiotics, raising further concerns about the validity of blinding. Therefore we assessed this study as at high risk of bias for blinding of participants and personnel (performance bias). Given the different administration regimens, we assessed this study as high risk of bias for blinding of blinding of outcome assessment for participant-reported outcomes. We assessed blinding of outcome assessment by practitioners as unclear risk for this study because blinding of the ear, nose, and throat surgeons was not described.

\section{Incomplete outcome data}

There was no loss to follow-up in Malapane 2014, and only small numbers of explained withdrawals in de Lange de Klerk 1994, Jacobs 2001, Pedrero-Escalas 2016, and Sinha 2012. Withdrawals were appropriately accounted for in Steinsbekk 2005a. We assessed these six studies as at low risk of attrition bias.

We assessed Siqueira 2016 as at unclear risk of bias for incomplete outcome data: the reasons for loss to follow-up were mentioned in a general sense, but no specific numbers were provided for each group. Furthermore, while intention-to-treat (ITT) analysis was planned in methods described by Siqueira 2016, it was unclear if this was performed. Children lost to follow-up were not included in the study flowchart (Figure 1), baseline characteristics (Table 1), or the analysis of the number of flu and acute respiratory infections symptomatic episodes in the first year postintervention (Table 2), and key outcome data in Figure 2 were presented in a way that rendered it difficult to determine if ITT analysis was actually used.

In Jacobs 2016, symptom diary-based outcomes were subject to high risk of attrition bias: only 162 of 261 participants returned symptom diaries. Although the baseline demographics reported for those who returned symptom diaries did not significantly differ from those who failed to return the diaries, there is a reasonable likelihood that failure to return a symptom diary may have been associated with some unmeasured differences in illness progression, or participant or family characteristics. The small number of participants who returned symptom diaries also resulted in inadequate power for the relevant outcomes. This is particularly noteworthy given that the only outcomes showing statistical significance in favour of the homeopathy group were symptom diary-based outcomes (analysis of twice-daily data on severity of cold symptoms), while other outcomes with lower risk of attrition bias (e.g. phone follow-up) found no significant results.

\section{Selective reporting}

Published prospective protocols were not available for most studies, with the exception of Jacobs 2016 (NCT01257503) and Steinsbekk 2005a (Steinsbekk 2004).

All primary outcomes in the methods were reported in five studies (de Lange de Klerk 1994; Jacobs 2001; Pedrero-Escalas 2016; Sinha 2012; Steinsbekk 2005a), which we assessed as at low risk of reporting bias.

We assessed Malapane 2014 as at unclear risk of selective reporting. Despite all outcomes described in the methods being reported in the results, inadequate raw data were provided. Intergroup analysis was performed for only three of five outcomes reported, while intragroup analysis was performed for all outcomes. The use of mean score on rating scales for the whole group, with small sample sizes, obscured the difference between groups from percentages with less and more severe disease at baseline. Due to the omission of reporting of subgroup frequencies at the end of the trial, use of mean rating scale scores only in the study meant that we could not interpret the distribution of severity of outcome between the groups with confidence.

We assessed Jacobs 2016 as at unclear risk of selective reporting because results of some planned outcomes were not reported (time off school and days off work for parents were not reported in the results). Results with positive findings (i.e. diary symptom scores at assessment points 1 and 2) were described in detail, but some results with negative outcomes (e.g. composite cold scores at 5to 10-day phone follow-up, functional outcomes at 5- to 10-day follow-up) had no actual data provided in the results. It should be noted that additional data not in the publication were publicly available from the trial registry (NCT01257503).

We assessed Sinha 2012 as at unclear risk of selective reporting, as the criterion for judging the need for additional antibiotic treatment was less than 50\% improvement on the AOM-SOS scale; however, no AOM-SOS scale data were reported anywhere in the paper, despite the importance to the study design and protocol.

We assessed Siqueira 2016 as at high risk of selective reporting bias for several reasons. Firstly, for the primary outcomes, the results did not provide mean numbers of ARTIs, but 
focused on an arbitrary cut-off of three or more flu and ARTI episodes for comparison between groups, a benchmark that was not established prospectively in the study methods. Secondly, outcomes were listed in the methods that were not reported on in the results (duration in days of flu and acute respiratory infection symptoms, and adverse events). Thirdly, points were made in the results without presentation of the relevant data (e.g. mention of increase in ARTI episodes in first two months in the placebo group).

\section{Other potential sources of bias}

We assessed five included studies as at low risk of bias for this domain (de Lange de Klerk 1994; Jacobs 2001; Jacobs 2016; Pedrero-Escalas 2016; Steinsbekk 2005a).

We assessed Malapane 2014 as at unclear risk of other bias. Rating scales for some examination items appeared to be subjective, for example red/inflamed pharynx was measured in ordinal categories: absent (code 0 ), slightly red (code 2 ), red (code 4), very red (code $6)$, severely red (code 8), and extremely red (code 10). Also, 10 of the 15 children in the placebo group were reported to still have pain on swallowing at about one week since onset of diagnosis, despite mention in the discussion section that viral tonsillitis typically lasts for seven days. The predominance of results reported as mean rating score for each group led to a statistically significant difference at trial end for most outcomes that was probably not clinically significant. For example, pain on swallowing at day 6 between groups was 0.67 for treatment and 1.87 for placebo group $(P=0.037)$. The paper states that this difference had a large effect size $(r=0.6)$, yet a score of 2 on the 10 -point rating scale was "slightly red throat", and a score of zero was absent redness.

Malapane 2014 drew several conclusions that were difficult to justify in the setting of a small sample size, and appeared potentially biased in its discussion, with overemphasis on positive outcomes, while negative findings were downplayed (e.g. analysis between groups showed that the homeopathic complex outperformed placebo, with a large effect size). The homeopathy treatment was stated to be well tolerated with no adverse events; however, with a very small sample size in a population from a single source and demographic group, this statement should be qualified. The authors stated that symptoms in the treatment group improved between days 5 and 6 , yet the daily rating scale means showed a linear, progressive downward trend rather than an obvious day of recovery. The interpretation of this benefit was compared to the known average duration of viral URTIs from the literature, rather than data from this trial, with a conclusion that the homeopathic treatment may reduce the duration of acute viral tonsillitis by up to two days. Furthermore, there were no measures in place to ensure adherence to correct administration of the study medication, which could be considered an oversight given that children as young as six years were self administering a sublingual preparation.

We assessed Siqueira 2016 as at unclear risk of other bias due to an unexplained decrease in ARTI/flu episodes for all participants. This suggests that perhaps not all ARTIs that occurred were captured by the study data. The mean number of flu/ARTI episodes in the year before the study (apparently based on consulting medical records) was 1.51 episodes per child (calculated by review author $\mathrm{KH}$ based on Table 1 data). Of note, this refers only to the 445 children who completed the study and that greater than or equal to four episodes were calculated as four episodes. This is a very low annual ARTI incidence for young children, and is unlikely to capture additional episodes for which the child did not present for medical care. It is therefore particularly surprising that the mean number of ARTI episodes during the 12-month study period was even lower for both placebo and homeopathy groups. The mean number of ARTI episodes was 1.07 in the placebo group and 0.40 in the intervention group (also calculated by $\mathrm{KH}$ based on Table 2 , which refers only to the 445 children who completed the study and that "greater than or equal to four" episodes were calculated as four episodes). The study authors did not address this low overall incidence of ARTI in the discussion or suggest reasons for a decrease in incidence among all study groups. This issue is considered a risk factor because it raised concern about the overall rigour of data collection.

There appears to have been a protocol deviation in Sinha 2012. The day 3 commencement of antibiotics (for those with less than 50\% improvement) in the conventional group, but not the homeopathy group, led to a biased reporting of the outcome requirement for rescue antibiotics. We therefore assessed this study as at high risk of other bias.

\section{Effects of interventions}

See: Summary of findings for the main comparison Homeopathic medicinal products (individualised treatment) compared to placebo or usual care for preventing acute respiratory tract infections in children; Summary of findings 2 Homeopathic medicinal products (non-individualised treatment) compared to placebo or usual care for preventing acute respiratory tract infections in children; Summary of findings 3 Homeopathic medicinal products compared to placebo or usual care for treating acute respiratory tract infections in children

There was a lack of standardisation of outcome assessment among the included studies. We considered prevention and treatment studies separately, and individualised homeopathy and non-individualised homeopathy separately. Where possible, we performed quantitative meta-analysis. Due to the clinical heterogeneity of studies (regarding nature of illnesses, the time points of outcome measures, and the measurement scales of outcome measures), quantitative meta-analyses must be interpreted with caution.

\section{Prevention studies}

We have summarised results in Summary of findings for the main comparison for individualised homeopathic remedies and Summary of findings 2 for non-individualised homeopathic remedies.

\section{Primary outcomes}

1. Cure

The primary outcome of cure was not applicable to prevention studies.

\section{Disease severity (symptom scores)}

de Lange de Klerk 1994 used a non-validated scoring tool designed for this study with a scale of 0 to 56 measuring four dimensions (symptoms of the nose, ear, throat, and general symptoms), and reported mean daily symptom score over one year. The mean score 
in the homeopathy group was 2.21 (86 children) and 2.61 in the placebo group (differences in mean $0.41,95 \%$ confidence interval (CI) -0.02 to $0.83 ; \mathrm{P}=0.06 ; 84$ children). This mean difference (MD) of 0.4 out of a total score of 56 is not clinically significant.

Steinsbekk 2005a assessed disease severity with a non-validated scoring tool that scored nine symptoms (fever, pain, mood, appetite, energy, sleep, discharge, obstruction of nose, cough) with a scale of 0 to 11 and reported median daily symptom scores for 12 weeks. The median scores across the entire study period (i.e. additive) for the homeopathy group was 26 ( 97 children) and 25 for the placebo group (102 children) $(P=0.73)$.

Because the scoring tools used in both studies assessed different symptom combinations, we did not pool data for this outcome (de Lange de Klerk 1994; Steinsbekk 2005a). Insufficient raw data were provided in these studies to enable calculation of mean or median symptom scores where they were not provided.

In summary, these two studies of individualised homeopathy for prevention of URTI over 12 weeks (Steinsbekk 2005a), and one year (de Lange de Klerk 1994), did not find a clinically significant nor statistically significant difference at the $\mathrm{P}=0.05$ level between homeopathy and placebo for daily URTI symptom scores.

We downgraded the quality of the evidence for this outcome two levels to low quality due to imprecision of results (wide confidence interval) and inconsistency of results.

\section{Recurrence of ARTI}

In the study by Steinsbekk 2005a of individualised homeopathy for preventing URTI, $81 / 97$ (83.5\%) children in the homeopathy group and $81 / 102(79.4 \%)$ children in the placebo group had a URTI during the 12 -week study period (odds ratio (OR) $1.31,95 \% \mathrm{Cl} 0.64$ to $2.70 ; P=0.46$ ). The median number of URTI episodes (lasting three days or more) was one in both groups $(P=0.927$; Analysis 1.1$)$. We downgraded the quality of evidence by one level due to imprecision (wide confidence intervals).

In the Siqueira 2016 trial of non-individualised homeopathy for preventing URTI, 109/294 (37.1\%) children in the pooled homeopathy groups and 49/151 (32.5\%) children in the placebo group had a URTI during the 12-month study period. On an ITT basis, these figures are $215 / 400(53.8 \%)$ children in the pooled homeopathy groups and $98 / 200(49.0 \%)$ children in the placebo group, assuming all children lost to follow-up had a URTI. The mean number of URTI episodes in 12 months (calculated by the review authors) was 0.40 (standard deviation (SD) 0.57 ) in the pooled homeopathy groups and 1.07 (SD 1.60) in the placebo group (MD $-0.47,95 \% \mathrm{Cl}-0.69$ to -0.25$)$. On an ITT basis, these figures are 0.83 (SD 0.86) in the pooled homeopathy groups and 1.3 (SD 1.44) in the placebo group, $\mathrm{P}=0.009$ (assuming two episodes of URTI for all children lost to follow-up, as the study authors propose) (Analysis 1.2). We downgraded the quality of the evidence for the mean number of ARTIs by one level to moderate quality due to large loss to follow-up.

In the Pedrero-Escalas 2016 trial of non-individualised homeopathy for OME, $10 / 45(22.2 \%)$ children in the homeopathy group and $14 / 50(28 \%)$ children in the placebo group developed AOM during the four-month study period $(P=0.52)$. Within the adverse event reporting, there were more episodes of URTI as an "adverse event" in the placebo group during the study period (three episodes in the homeopathy group versus 13 episodes in the placebo group), although the number of affected children was not stated.

We pooled data for the two non-individualised homeopathy studies for the dichotomous outcome of recurrence of ARTI (influenza/URTI in Siqueira 2016 and AOM in Pedrero-Escalas 2016). In the pooled homeopathy group, $225 / 445$ (50.6\%) children had a recurrence of ARTI, compared to $112 / 250$ (44.8\%) children in the pooled placebo group (OR 1.14, $95 \% \mathrm{Cl} 0.83$ to $1.57 ; \mathrm{I}^{2}=0 \%$; fixed-effect model; Analysis 1.3). We downgraded the quality of evidence by two levels to low for this outcome due to large loss to follow-up, in Siqueira 2016, and imprecision of results.

In summary, the study of individualised homeopathy, Steinsbekk 2005a, showed no difference between homeopathy and placebo for prevention of URTI in terms of both the dichotomous outcomes (URTI versus no URTI) and the median number of URTI episodes. The two non-individualised homeopathy studies, Pedrero-Escalas 2016 and Siqueira 2016, had varied results, with no difference in the dichotomous outcome (URTI versus no URTI) for the pooled data, but a significantly lower mean number of URTI episodes in the homeopathy group in Siqueira 2016.

\section{Secondary outcomes}

\section{Duration of illness}

No prevention studies reported on this outcome.

\section{Need for hospitalisation or severe secondary illness}

No prevention studies reported on this outcome.

\section{Days off school and days off work for parents}

Steinsbekk 2005a, a 12-week study of URTI prevention, provided data on days off work for parents. In the homeopathy group 48/97 $(50 \%)$ of parents required a day off work during the study period, compared with $41 / 102(40 \%)$ in the placebo group $(P=0.188)$ (Analysis 1.4). The median number of parental days off work was 0 for both groups.

In summary, no difference was found between groups for days off work for parents. We assessed the quality of the evidence as moderate, downgrading by one level due to imprecision (wide confidence interval).

\section{Any adverse events}

Of the prevention studies, Pedrero-Escalas 2016 and Steinsbekk 2005a formally reported on adverse events. Pedrero-Escalas 2016 provided participant numbers for adverse events leading to withdrawal from the study. In the homeopathy group, 1/45 (2.2\%) children reported an adverse event leading to study withdrawal compared to $4 / 50(8 \%)$ children in the placebo group. The number of major and minor adverse events were reported without numbers of how many children were affected. There was one major adverse event in the homeopathy group (bronchiolitis) and two in the placebo group (bronchiolitis and pneumonia). Eleven minor adverse events were reported in the homeopathy group (5 gastroenteritis, 3 URTI, 2 LRTI, 1 fever without focus) and 22 in the placebo group (3 gastroenteritis, 13 URTI, 3 LRTI, 1 urinary tract infection, 1 agitation, 1 vomiting). The only adverse event of 
statistical significance was URTI: 13 in the placebo group versus 3 in the homeopathy group $(P=0.009)$

In Steinsbekk 2005a, 9/97 (9.3\%) children reported an adverse effect in the homeopathy group compared to $4 / 102$ (3.9\%) in the placebo group $(P=0.126)$. All adverse effects were reportedly mild and transient. No details on the nature of these adverse events were reported. See Analysis 1.5.

Siqueira 2016 stated, "It is important to point out that no discomfort or death induced by the use of test solutions were reported by the children's families during the period of this clinical trial" (p. 75); however, no data on adverse events were presented. See Analysis 1.6.

As there was only one individualised homeopathy study and one non-individualised homeopathy study reporting on adverse events, we did not pool data for this outcome.

In summary, the rates of adverse events were mixed, with an individualised homeopathy study finding higher rates of adverse events in the homeopathy group (Steinsbekk 2005a), and a nonindividualised homeopathy study finding higher rates of adverse events in the placebo group (Pedrero-Escalas 2016). We rated the quality of the evidence for these outcomes (individualised homeopathy adverse events and non-individualised homeopathy adverse events) as moderate and very low, respectively.

\section{Quality of life}

No prevention studies reported on this outcome.

\section{Antibiotic use}

Both individualised homeopathy prevention studies reported on antibiotic use as a "rescue therapy". In Steinsbekk 2005a, 19/97 $(20 \%)$ of homeopathy participants required antibiotics in the 12-week study period compared to $17 / 102(17 \%)$ of placebo participants $(P=0.593)$. In de Lange de Klerk 1994, 30/86 (35\%) of homeopathy participants required antibiotics compared to $42 / 84$ (50\%) of placebo participants. de Lange de Klerk 1994 reported antibiotics required for respiratory problems as well as antibiotics required for other problems; we included only those required for respiratory problems.

In the pooled treatment group, 49/183 (27\%) of children required rescue antibiotics, compared to $59 / 186(32 \%)$ in the pooled placebo group (OR $0.79,95 \% \mathrm{Cl} 0.35$ to $1.76 ; \mathrm{I}^{2}=65 \%$; random-effects model; Analysis 1.7). We did not proceed to sensitivity analysis for this outcome with high statistical heterogeneity because data were from two studies only. In terms of clinical heterogeneity, children in de Lange de Klerk 1994 were followed up for 12 months, whereas in Steinsbekk 2005a the period was 12 weeks. In both studies antibiotic prescription was separate from the study; children could be prescribed non-homeopathic drugs during the study period as required by their usual general practitioner or specialist. There were therefore no specific guidelines or indications for antibiotics dictated by study protocols, likely resulting in clinical heterogeneity in terms of criteria for proceeding to antibiotic rescue therapy. We rated the quality of the evidence as low, downgrading by one level due to unexplained heterogeneity with opposite direction of effect (inconsistency of results) in the two studies (de Lange de Klerk 1994; Steinsbekk 2005a), and a further level due to imprecision of results (wide confidence interval).
Steinsbekk 2005a also reported the median number of days children were taking antibiotics during the study period. The median was 0 days for both groups.

de Lange de Klerk 1994 reported the number of antibiotic courses per child. The mean number of courses among the 86 homeopathy participants was 0.60 (SD 1.05), and the mean number of courses among the 84 placebo participants was 0.80 (SD 1.06); $\mathrm{P}=0.23$; means calculated by review authors based on raw data of number of antibiotic courses per child). See Analysis 1.8. The quality of evidence for this outcome was moderate.

In summary, there was no significant difference in the dichotomous outcome of antibiotic use between the pooled individualised homeopathy group and the pooled placebo group. There was no difference in the median number of antibiotic courses required in Steinsbekk 2005a, and a non-significant difference in the mean number of antibiotic courses in de Lange de Klerk 1994.

\section{Treatment studies}

Results are summarised in Summary of findings 3.

\section{Primary outcomes}

\subsection{Cure (short term, up to 14 days)}

Sinha 2012 published data on short-term cure of children with URTI. Jacobs 2001 published data on treatment failure. We corresponded with the authors of Jacobs 2001, who provided unpublished shortterm cure data. Jacobs 2016 and Malapane 2014 did not assess cure as an outcome.

Sinha 2012 and Jacobs 2001 studied children with AOM and used individualised homeopathy treatments. Sinha 2012 defined cure as an AOM-SOS score of zero and a Tympanic Membrane Examination score of zero (i.e. complete symptomatic and clinical resolution). Jacobs 2001 defined cure as no symptoms or a significant reduction in symptoms.

None of the time points for cure were the same across the two studies (Jacobs 2016; Sinha 2012). Sinha 2012 provided dichotomous data for days 3, 7, and 10. Jacobs 2001 provided dichotomous data for days 5 and 14. We used day 10 data from Sinha 2012 and day 14 data from Jacobs 2001 for pooling, because these were closest to our protocol-defined short-term period of 14 days. These were also considered to be clinically most meaningful due to the natural history of AOM and the likely variability of cure from days 3 to 5 to 7 , regardless of treatment.

In Sinha 2012, at day 3, 4/40 (10\%) of homeopathy participants were cured according to study criteria, compared to $1 / 40(2.5 \%)$ of conventional treatment participants $(P=0.359)$. In Jacobs 2001 , at day $5,29 / 36(72 \%)$ of homeopathy participants were cured based on study criteria, compared to $27 / 39(69 \%)$ of placebo participants $(\mathrm{P}=0.39)$.

Turning to later time points in the short-term period, Sinha 2012 found $23 / 40$ (58\%) of homeopathy participants had achieved cure by day 7 and $37 / 40$ (93\%) by day 10 , compared with $21 / 40(53 \%)$ of conventional treatment participants by day $7(P=0.356)$ and $40 / 40$ $(100 \%)$ by day $10(P=0.137)$. Jacobs 2001 found $25 / 36(69 \%)$ of homeopathy participants were cured on day 14 , compared to $20 / 39$ (51\%) placebo participants $(P=0.17)$. 
For short-term cure (i.e. days 10 to 14), the pooled treatment group achieved cure in $62 / 76(82 \%)$ of children, and the pooled control group achieved cure in $60 / 79(76 \%)$ of children (OR 1.31 favouring placebo, $95 \% \mathrm{Cl} 0.09$ to $19.54 ; \mathrm{I}^{2}=69 \%$; random-effects model; Analysis 2.1). We did not proceed to sensitivity analysis for this outcome with high statistical heterogeneity because data were from two studies only. In terms of clinical heterogeneity, there were differences between the studies regarding time points for assessment (none of the time points for cure were the same across both studies: Sinha 2012 provided dichotomous data for days 3 , 7, and 10, and Jacobs 2001 provided dichotomous data for days 5 and 14) and definition of cure (Sinha 2012 defined cure as an AOMSOS score of zero and a Tympanic Membrane Examination score of zero, and Jacobs 2001 defined cure as no symptoms or a significant reduction in symptoms).

In summary, we found no significant difference in short-term cure of AOM between individualised homeopathy-treated and placebotreated children. We assessed the quality of evidence as very low due to design limitations, inconsistency, and imprecision (wide confidence intervals).

\subsection{Cure (long term, up to 3 months)}

Two studies provided data on long-term cure (Sinha 2012 and Jacobs 2001, by publication and correspondence, respectively). None of the time points provided matched between studies: Sinha 2012 provided long-term cure data for day 21 of illness, and Jacobs 2001 for week 6 of illness.

In Sinha 2012 at day 21, 38/40 (95\%) of homeopathy participants were cured and $40 / 40(100 \%)$ of conventional treatment participants were cured $(P=0.202)$. Jacobs 2001 provided sixweek dichotomous cure data, with $21 / 36(58 \%)$ of homeopathy participants being cured and 15/39 (38\%) of placebo participants being cured $(P=0.13)$. Long-term cure was achieved in 59/76 $(78 \%)$ children in the pooled homeopathy group and 55/79 (70\%) children in the pooled control group (OR $0.99,95 \% \mathrm{Cl} 0.10$ to 9.67; $\mathrm{I}^{2}=57 \%$; random-effects model; Analysis 2.2). We did not conduct sensitivity analysis for this outcome with high statistical heterogeneity because data were from two studies only. Clinical heterogeneity for long-term cure was caused by similar factors as with short-term cure, including differences in time points for assessment and different definition of cure.

In summary, we found no significant difference in AOM long-term cure between individualised homeopathy-treated and placebotreated children. We assessed the quality of evidence as very low due to design limitations, inconsistency, and imprecision (wide confidence intervals).

\section{Disease severity (daily symptom scores)}

Jacobs 2001, Jacobs 2016, Malapane 2014, and Sinha 2012 provided data on symptom scores. Each study used a different symptom scoring scale and different time points for scoring, so we were unable to pool data. In all cases, higher scores represent more severe symptoms.

Sinha 2012 used the validated AOM-SOS scale from 0 to 14 and reported mean daily symptom scores at entry and on days 3,7 , 10 , and 21 . Mean scores in the homeopathy ( 40 children) and conventional treatment ( 40 children) groups respectively were
14.28 and 14.60 on entry $(P=0.553), 8.18$ and 12.55 on day $3(P=$ $0.00), 1.45$ and 1.08 on day $7(P=0.36), 0.72$ and 0.00 on day $10(P=$ $0.14)$, and 0.58 and 0.00 on day $21(P=0.202)$.

Jacobs 2001 used a non-validated scoring system (from 0 to 9) for symptoms of pain, fever, irritability, appetite, energy level, and sleep, and reported mean daily symptom score for three days of follow-up. Mean symptom score at 24 hours in the homeopathy group was 1.6 ( 36 children) compared to 2.3 (33 children) in the placebo group $(P=0.039)$. Additional data provided following correspondence with the study author showed mean symptom scores of 1.826 for the homeopathy group and 2.144 for the placebo group at 48 hours, and 1.108 and 1.719 at 72 hours, respectively. Note: these data did not include ITT analysis for six missing participants.

In summary, the unpooled individualised homeopathy treatment studies did not find a consistent effect: higher symptom scores were observed in the placebo or conventional treatment groups at 24 hours, Jacobs 2001, and two to three days (Jacobs 2001; Sinha 2012), but lower scores at day 7 in Sinha 2012 and a reduction from a significant to a non-significant benefit for the homeopathy group in Jacobs 2001.

Malapane 2014 was a non-individualised homeopathy study of acute viral tonsillitis, focusing primarily on five symptoms: pain associated with tonsillitis, pain on swallowing, erythema, tonsil size, and referred ear pain, with daily measurement over six days for these outcomes. The two instruments used to collect these data were the Wong-Baker FACES pain rating scale and the Symptom Grading Scale (SGS). There were 15 children in each study arm, with the placebo group having slightly more pain and a larger percentage of children with red or very red throat. Intergroup analysis for only three of these five outcomes are provided, all with statistical significance: pain associated with tonsillitis $(P=0.001 ; r=$ $0.8)$; redness of pharynx $(P=0.037 ; r=0.6)$; and tonsil size $(P=0.001$; $r=0.6)$. However, close inspection of the graphs provided for these outcomes suggest that the difference in outcome was not apparent at day 1 to 5 but deviated on day 5 or 6 . In fact, for pain associated with tonsillitis, there was a $30 \%$ increase in pain score in the placebo group from day 5 to day 6 , which is not the normal prognostic pattern for the self resolving condition of viral sore throat that was the inclusion criterion for this study.

Jacobs 2016 was a study of non-individualised homeopathy and was therefore analysed separately from Jacobs 2001 and Sinha 2012. Jacobs 2016 used a non-validated "composite cold" scoring system (from 0 to 12 ) including the four symptoms of runny nose, cough, sneeze, and congestion (a four-point scale for each individual symptom added together to give a cumulative score). Jacobs 2016 assessed mean symptom score for two time points per day for three days of treatment, and a single end-of-study followup at five to 10 days post-index visit. Most published data provided for this outcome were in the format of change from initial baseline symptom score. We also used additional raw data from the trial registry to provide actual mean symptom scores. Note that with the exception of the day 5 to day 10 follow-up, these mean scores were based on only those participants who returned symptom diaries, which was approximately half the study participants. No ITT analysis was performed, and it is difficult to select an appropriate symptom score for those lost to symptom diary follow-up for such an analysis. 
Mean symptom scores in the homeopathy (total 133 children) and placebo (total 130 children) groups were 5.4 and 5.2 respectively at baseline; 4.2 and 5.0 at end of day $1(N=72,76$ respectively; $P=$ $0.01) ; 3.4$ and 4.0 at end of day $2(N=69,69$ respectively; $P=0.15)$; 2.8 and 3.0 at end of day $3(N=60,66$ respectively; $P=0.35)$; and 2.4 and 2.0 on days 5 to $10(\mathrm{~N}=123,117$ respectively; $\mathrm{P}=0.36)$. The change in baseline composite cold score reported in Figure 2 of the paper showed a significantly greater reduction for the homeopathy group compared to placebo group on day 1 only, and not on any of the other days (reduction of 1.25 points in the homeopathy group and 0.13 in the placebo group on the day 1 assessment).

In summary, the non-individualised homeopathy study Jacobs 2016 found a difference in symptom scores in favour of the homeopathy group at day 1 (among participants who returned symptom diaries), but otherwise no significant effect of symptom scores was seen. Malapane 2014 only found a significant difference at day 6 in children with viral sore throat treated with homeopathy. Most viral sore throat spontaneously resolves by day 6 or 7 of the illness, so the pain persisting in the placebo group at day 6 to almost the level experienced at trial entry raises questions regarding a difference in disease aetiology as the more likely cause of this difference rather than the therapeutic intervention. We assessed the quality of the evidence for this outcome as low due to significant attrition bias in Jacobs 2016 and protocol deviation and blinding concerns in Sinha 2012, as well as inconsistency of results.

\section{Recurrence of ARTI}

No treatment studies reported on this outcome.

\section{Secondary outcomes}

\section{Duration of illness}

No treatment studies reported on this outcome.

\section{Need for hospitalisation or severe secondary illness}

No treatment studies reported on this outcome.

\section{Days off school and days off work for parents}

No treatment studies reported on this outcome.

\section{Any adverse events}

Jacobs 2001 and Jacobs 2016 provided data on adverse events reported (Analysis 2.3; Analysis 2.4). We could not combine these two studies because Jacobs 2001 was an individualised homeopathy study and Jacobs 2016 was a non-individualised homeopathy study.

Jacobs 2001 reported no adverse events in either group. We assessed the quality of the evidence for this outcome as low due to imprecision of results and limitations suggesting high likelihood of bias.

Jacobs 2016 reported adverse events in 9/75 (12\%) homeopathy participants and $2 / 79(2.5 \%)$ placebo group participants $(P=0.02$, based on 154 participants who returned diaries). There were 249 participants involved in the 5- to 10-day phone follow-up, however the total number of children affected by the various adverse effects reported at that stage (in Table 6 of the paper) is not clear. Nevertheless, the homeopathy group $(N=128)$ experienced a greater number of adverse effects $(\mathrm{N}=17$; including 3 decreased energy, 2 diarrhoea, 2 gas, 1 hyper behaviour, 4 stomachaches, 4 vomited, 1 aggressive behaviour) compared to placebo $(\mathrm{N}=5$; 1 decreased appetite, 1 diarrhoea, 1 hyper behaviour, 2 urticarial rashes; $N=121$ ). We assessed the quality of the evidence for this outcome as low due to design limitations and imprecision.

Adverse events were not a listed outcome in Malapane 2014; however, the results noted no adverse effects were reported by any of the participants.

\section{Quality of life}

No treatment studies reported on this outcome.

\section{Antibiotic use}

One treatment study reported the need for antibiotics as 'rescue therapy' to treat children with URTI not responding to initial study therapy (either homeopathy or conventional treatment) (Sinha 2012, a study of cure in AOM with commencement of antibiotics from day 3 if not cured prior).

Sinha 2012 reported on the dichotomous outcome of requirement for antibiotics. Sinha 2012 reported 0/40 (0\%) of homeopathy participants required antibiotics and $39 / 40$ (98\%) of conventional treatment participants required antibiotics. The methods described by Sinha 2012 involved antibiotic prescription for both homeopathy and conventional treatment participants after three days if less than $50 \%$ improvement had occurred on AOMSOS and tympanic membrane scales. However, it appears the antibiotic commencement at the three-day mark occurred only for the conventional group, not the homeopathy group. In the homeopathy group, the mean symptom score for homeopathy participants was reduced by less than $50 \%$ by the day 3 assessment (from 14.28 to 8.18), making it impossible that all homeopathy group participants had a $50 \%$ improvement in the first three days of treatment. However, no homeopathy participants were commenced on antibiotics. We contacted the author of Sinha 2012 to clarify these concerns regarding different treatment of study groups and did not receive a response. Given this issue, antibiotic use in Sinha 2012 cannot be interpreted as a valid study outcome and has therefore not been included as a quantitative outcome in the data and analyses. We judged the quality of this evidence to be very low.

Because there were no outcomes with statistically significant results, we did not proceed to calculate absolute risk reduction and numbers needed to treat for an additional beneficial outcome.

\section{DISCUSSION}

\section{Summary of main results}

We included eight RCTs comparing homeopathic remedies with placebo or conventional symptomatic treatment to prevent (4 studies) or treat (4 studies) ARTIs in children. Seven studies referred only to URTIs, and one study did not distinguish between upper and lower respiratory tract infections (influenza), which were grouped together (Siqueira 2016).

\section{Cure}


For the primary outcome of cure, there was both clinical face value and statistical heterogeneity between studies, with important differences in definition of cure and disparate time points for outcome assessment. We pooled data for short-term cure (using time points 10 days and 14 days) and long-term cure (using time points three weeks and six weeks). Short-term cure data showed little difference between homeopathy and control groups for resolution of symptoms of AOM (Jacobs 2001; Sinha 2012). Notably, the cure rates at day 3 were very low in both groups (Sinha 2012); cure rates at days 5 to 7 were approximately $50 \%$ to $70 \%$ in both groups (Jacobs 2001; Sinha 2012); and cure rates at day 10 were approximately $90 \%$ to $100 \%$ in both groups (Sinha 2012). These cure rates are reflective of the natural history of untreated otitis media (Rosenfeld 2003). For pooled short-term cure data, there was an odds ratio of 1.31 (95\% Cl 0.09 to 19.54), favouring the placebo group. The wide confidence interval reflects that two studies found opposite directions of effect at these time points: in Jacobs 2001 the cure rate was higher among children receiving homeopathy, while in Sinha 2012 the cure rate was higher in children receiving conventional treatment.

Long-term cure data also revealed little difference between the homeopathy and control groups, with $95 \%$ to $100 \%$ cure rates at day 21. In Jacobs 2001, six-week cure data showed a non-significant higher cure rate in the homeopathy group $(58 \%)$ compared to the placebo group (38\%). Such a late time point may represent recurrence rather than ongoing symptoms of the initial infection. For pooled long-term cure data, there was an odds ratio of 0.99 (95\% Cl 0.10 to 9.67), favouring the homeopathy group. Again, the wide confidence interval reflects that two studies found opposite directions of effect at these time points: in Jacobs 2001 homeopathy participants had a higher cure rate, while in Sinha 2012 conventional treatment participants had a higher cure rate. In summary, the homeopathy and placebo groups had approximately equivalent cure rates in these studies.

\section{Disease severity (assessed by severity score scales)}

None of the included studies assessed symptoms using the same symptom score scales, therefore it was not possible to pool data for this outcome. It is noteworthy that in many studies, low rates of return of symptom diaries resulted in fewer children being evaluated for symptom score outcomes compared to other outcomes.

Three treatment studies found lower symptom scores in the homeopathy group at the time points reported within the first three days (Jacobs 2001; Jacobs 2016; Sinha 2012). Sinha 2012 and Jacobs 2016 reported later time points, finding lower symptoms scores in the conventional treatment/placebo group on days 7 to 10. Most of the time points reported by individual studies had nonsignificant differences between means.

The prevention studies found either no difference in median daily symptom scores (Steinsbekk 2005a), or non-significantly lower mean scores in the homeopathy group (de Lange de Klerk 1994).

In summary, qualitative analysis of disease severity suggests there is no clear difference between placebo and homeopathy for disease severity.

Recurrence of ARTIs
An individualised homeopathy study showed no difference between homeopathy and placebo for prevention of URTI in terms of both the dichotomous outcome (URTI versus no URTI) and mean number of URTI episodes (Steinsbekk 2005a). Two non-individualised homeopathy studies showed varied results for ARTI recurrence (Pedrero-Escalas 2016; Siqueira 2016), with no difference in the dichotomous outcome (URTI versus no URTI) for the pooled data, but a lower mean number of URTI episodes in the homeopathy group (Siqueira 2016).

\section{Secondary outcomes}

We could not pool data for most secondary outcome measures (days off work for parents, adverse events, and antibiotic use in treatment studies) because there was only one study of each type (preventive or treatment; individualised or non-individualised homeopathy) presenting data for those outcomes.

The only secondary outcome that could be pooled was antibiotic use reported by the prevention studies. There was significant clinical face value heterogeneity between studies for this outcome (de Lange de Klerk 1994; Steinsbekk 2005a). Analysis of pooled dichotomous data for requirement for antibiotic favoured placebo (OR $0.79,95 \% \mathrm{Cl} 0.35$ to 1.76 ). The two studies that reported this outcome found opposite directions of effect: Steinsbekk 2005a found a higher requirement for antibiotics in homeopathy group participants, and de Lange de Klerk 1994 found a higher requirement for antibiotics in placebo group participants.

We assessed most outcomes as providing low-quality evidence, with some outcomes judged as providing very low-quality and a few moderate-quality evidence.

\section{Overall completeness and applicability of evidence}

Limited reporting of adverse events in some studies was a concern (de Lange de Klerk 1994; Sinha 2012), and represents a failure to meet CONSORT requirements for RCTs in terms of reporting harms or unintended effects (Schulz 2010). Studies that reported adverse events found no adverse events in either participant group (Jacobs 2001; Jacobs 2016; Malapane 2014; Siqueira 2016), which is questionable considering the numbers of children involved. We did not identify any studies that specifically investigated the effect of homeopathic remedies on lower respiratory infections.

\section{Quality of the evidence}

There were several key limitations related to the quality of the current evidence, in particular methodological inconsistency among studies, small sample sizes in some studies, high attrition rates in some studies, failure to conduct intention-to-treat analyses, selective reporting, and apparent protocol deviations.

Methodological inconsistency meant robust quantitative metaanalyses could not be conducted. There was significant clinical face value heterogeneity among studies. Data that were amenable to quantitative meta-analysis showed high statistical heterogeneity. Odds ratios were generally small with wide confidence intervals, often in association with contributing studies reporting opposite directions of effect. This meant that little certainty regarding the efficacy of the intervention could be ascertained.

Several included studies were small and inadequately powered to determine statistically significant differences between groups. 
Jacobs 2001 was well conducted with a low risk of bias, however it was a pilot study aimed at determining the appropriate sample size and outcome measures for a future adequately powered study. We could find no such future study after conducting an exhaustive search, and contact with the study author confirmed this lack of a larger follow-on trial. Consequently, as the study authors state, it was "impossible to draw conclusions from this preliminary study" (p. 181), and indeed most outcome measures found a nonsignificant difference between homeopathy and placebo groups (Jacobs 2001). Sinha 2012 was also described as a pilot study.

There was high attrition bias with failure to conduct intentionto-treat analyses in several included studies. In Jacobs 2016 , a generally well-conducted study, only 162 of 261 participants returned symptom diaries. While the baseline demographics between "Did not return symptom diary" and "Returned symptom diary" groups showed no significant differences, there is a reasonable likelihood that failure to return the symptom diary may have been associated with some differences in illness progression or participant or family characteristics. The few participants who returned symptom diaries contributed to inadequate power for analysis of relevant outcomes. Phone follow-up was subject to less risk of attrition bias: 244 of 261 participants completed phone follow-up. Notably, none of the phone-based follow-up outcomes showed any significant results, while some of the symptom diarybased outcomes were reported to favour the homeopathy group.

Selective reporting was a concern in several studies, in particular Siqueira 2016. The results of this study focus on an arbitrary cutoff of three or more flu and ARTI episodes for comparison between groups, a benchmark not set prospectively in the methods and which favoured the homeopathy group. The study did not provide mean numbers for ARTIs for each group and does not acknowledge that the placebo group actually had a greater proportion of children with no ARTI episode during the follow-up period. The primary outcome stated in the methods section was the number and duration in days of ARTIs, the latter not reported anywhere in the paper. Yet other findings not specified in the methods (and favourable to the homeopathy group) were described (without data), such as the number of infections in the first few months following the month of active treatment. Finally, the very low total number of ARTIs during the 12-month follow-up period (compared to the year before and to known incidence data for childhood ARTI) suggests the monthly assessments to check for URTI may not have picked up all true cases.

Apparent protocol deviations were a concern in Sinha 2012. Sinha 2012 was at unclear or high risk of bias across six domains (allocation concealment, blinding of participants and personnel, blinding of outcome assessment - participant-reported outcomes, blinding of outcome assessment - practitioner outcome assessors, selective reporting, other bias). Apparent protocol deviations were the greatest concern in Sinha 2012, with methods and results differing on the matter of antibiotic provision at day 3 for children with less than $50 \%$ improvement. The methods indicated that all children with less than $50 \%$ improvement on day 3 would be commenced on antibiotics. However, in practice only the conventional treatment group participants were commenced on antibiotics, with results stating "In the Conventional treatment group, antibiotics prescribed were azithromycin (17 patients), and amoxicillin (22 patients). Initially all patients were treated with antipyretics, anti-inflammatory for first three days, but only one patient was cured. From the third day, antibiotics were prescribed in 39 patients and they all got cured at end of treatment" (p. 10). Despite a clear difference in how groups were treated (i.e. conventional group commenced on antibiotics on day 3 , homeopathy group not commenced on antibiotics on day 3 despite some children having less than $50 \%$ improvement), requirement for antibiotics was still reported as an outcome measure. The mean symptom scores for the homeopathy group on day 3 were $57 \%$ of the entry symptom scores, making it impossible that the homeopathy participants all had greater than $50 \%$ symptom resolution by day 3 and therefore did not require protocol-driven prescription of antibiotics. This different treatment of groups raises additional concerns for allocation concealment and blinding, as the clinicians prescribing the antibiotic must have been aware of the allocations.

Sinha 2012 was the only study not to disclose funding sources or rule out financial conflicts of interest. Three of the studies were partly funded by manufacturers of the homeopathic products being tested (Jacobs 2001; Jacobs 2016; Pedrero-Escalas 2016).

\section{Potential biases in the review process}

To overcome potential biases in the review process, a minimum of two review authors independently assessed included trials for quality and risk of bias; a third review author independently verified a random selection of extracted data. Sources where homeopathic studies are referenced are not as easily accessible as mainstream therapies, therefore it is possible that we missed assessing some studies that were potentially eligible for inclusion.

\section{Agreements and disagreements with other studies or reviews}

In March 2015, the Australian National Health and Medical Research Council's (NHMRC) Homeopathy Working Committee published an information paper that summarised the evidence on the effectiveness of homeopathy for treating a wide range of health conditions, with the work was overseen by the Homeopathy Working Committee (NHMRC 2015). This assessment was based on:

- overview of published systematic reviews by an independent contractor published in English between 1 January 1997 and 3 January 2013 (Optum 2013);

- independent evaluation of information provided by homeopathy interest groups and the public; and

- consideration of clinical practice guidelines and government reports on homeopathy published in other countries.

The overview considered 57 systematic reviews and 176 individual studies that assessed the effectiveness of homeopathy (individualised homeopathy or clinical homeopathy) compared to placebo or other treatment, for treating 61 health conditions (Optum 2013). The reviewers identified three systematic reviews where the effectiveness of homeopathy was assessed for the treatment of people with an ARTI (Altunc 2007; Bellavite 2011; Linde 1998). Of the three RCTs (unreported or medium to good quality; total of 486 participants, range: 60 to 251) that compared homeopathy with placebo, the one medium-sized, good-quality trial (251 participants) in children with URTI did not detect a difference between homeopathy and placebo (Steinsbekk 2005b). Based on the body of evidence, the reviewers determined that 
homeopathy is not more effective than placebo for the treatment of people with URTI.

When homeopathy was compared with other therapies (including anti-inflammatory drugs and antibiotics) in ARTI, the only systematic review (assessed as of poor quality) identified six studies (Bellavite 2011). Of these, only two studies (level II evidence) were exclusively in children: one medium-sized RCT (quality not reported; 208 children with URTI) (Steinsbekk 2007); and one study (quality not reported; 170 children with pharyngitis or tonsillitis) (de Lange de Klerk 1994). Based on this evidence, the reviewers concluded that there is no reliable evidence that homeopathy is as effective as the other therapies for the treatment of people with ARTI.

One systematic review examined the RCT research literature regarding homeopathy for childhood illnesses (Altunc 2007), with the findings regarding otitis media being similar to those of this review. Another systematic review examined complementary and alternative medicine treatment (including homeopathy) for otitis media (Marom 2016), and found that research into the effects of homeopathic treatment for otitis media is scant and its quality is limited, which is a similar finding to this Cochrane Review.

\section{AUTHORS' CONCLUSIONS}

\section{Implications for practice}

The eight included studies that assessed a spectrum of oral homeopathic medicinal products for preventing and treating acute respiratory tract infections (ARTIs) in children did not find any significant and consistent benefit for cure, disease severity, recurrence of ARTI, or any of the secondary outcomes defined for this review. Severe adverse events related to the homeopathic remedies studied were not reported, but reporting of adverse events was poor and inconsistent. Overall, the findings of this review do not support the use of homeopathic medicinal products for ARTIs in children in clinical practice.

\section{Implications for research}

The results of this review are consistent with all previous systematic reviews on homeopathy. Funders and study investigators contemplating any further research in this area need to consider whether further research will advance our knowledge, given the uncertain mechanism of action and debate about how the lack of a measurable dose can make them effective. The studies we identified did not use a uniform approach to choosing and measuring outcomes or assigning appropriate time points for outcome measurement. The use of validated symptom scales would facilitate future meta-analyses. It is unclear if there is any benefit from individualised (classical) homeopathy over the use of commercially available products.

\section{ACKN O WLEDGEMENTS}

We would like to acknowledge the contributions of Annika Mascarenhas and Jacqueline Seebold, who wrote the protocol under the guidance and supervision of Mieke van Driel and Treasure McGuire. A number of authors contributed to the early development of the review protocol: Carmen Becker, Sven Gottschling, Norbert Graf, Rainer Lüdtke, Maree Kekeff, and Donna Tanchev. We also wish to thank the following medical students who assisted with searches at various stages of this review: William Cundy, Claire Mohr, Maya El Azzi, and Jacqueline Somogyi. 


\section{R E F E R E N C E S}

\section{References to studies included in this review}

de Lange de Klerk 1994 \{published data only\}

de Lange de Klerk ES, Blommers J, Kuik D, Bezemer P, Feenstra L. Effect of homoeopathic medicines on daily burden of symptoms in children with recurrent upper respiratory tract infections. BMJ 1994;309(6965):1329-32.

\section{Jacobs 2001 \{published and unpublished data\}}

Jacobs J, Springer DA, Crothers D. Homeopathic treatment of acute otitis media in children: a preliminary randomized placebo-controlled trial. Pediatric Infectious Disease Journal 2001;20(2):177-83.

\section{Jacobs 2016 \{published data only\}}

Jacobs J, Taylor J. A randomized controlled trial of a homeopathic syrup in the treatment of cold symptoms in young children. Complementary Therapies in Medicine 2016;29:229-34. [DOI: 10.1016/j.ctim.2016.10.013]

\section{Malapane 2014 \{published data only\}}

Malapane E, Solomon E, Pellow J. Efficacy of a homeopathic complex on acute viral tonsillitis. Journal of Alternative and Complementary Medicine 2014;20(11):868-73.

\section{Pedrero-Escalas 2016 \{published data only\}}

Pedrero-Escalas MF, Jimenez-Antolin J, Lassaletta L, DiazSaez G, Gavilán J. Hospital clinical trial: Homeopathy (Agraphis nutans $5 \mathrm{CH}$, Thuyaoccidentalis $5 \mathrm{CH}$, Kalium muriaticum $9 \mathrm{CH}$ and Arsenicum iodatum $9 \mathrm{CH}$ ) as adjuvant, in children with otitis media with effusion. International Journal of Pediatric Otorhinolaryngology 2016;88:217-23. [DOI: 10.1016/ j.ijporl.2016.06.039]

Sinha 2012 \{published data only (unpublished sought but not used)\}

Sinha M, Siddiqui V, Nayak C, Singh V, Dixit R, Dewan D, et al. Randomized controlled pilot study to compare homeopathy and conventional therapy in acute otitis media. Homeopathy 2012;101(1):5-12.

\section{Siqueira 2016 \{published data only\}}

Siqueira C, Homsani F, da Veiga F, Lyrio C, Mattos H, Passos S, et al. Homeopathic medicines for prevention of influenza and acute respiratory tract infections in children: blind, randomized, placebo-controlled clinical trial. Homeopathy 2016;105(1):71-7.

Steinsbekk 2005a \{published data only (unpublished sought but not used)\}

Steinsbekk A, Bentzen N, Fonnebo V, Lewith G. Self treatment with one of three self selected, ultra-molecular homeopathic medicines for the prevention of upper respiratory tract infections in children. A double-blind randomized placebo controlled trial. British Journal of Clinical Pharmacology 2005;59(4):447-55.

\section{References to studies excluded from this review}

Antonello 2012 \{published data only\}

Antonello A. Comparative evaluation of a homeopathic complex medication versus conventional treatment in prevention and treatment of acute respiratory tract infections (ARTIs) in paediatrics. European Journal of Integrative Medicine 2012;4(S1):71-2.

Attena 1995 \{published data only\}

Attena F, Toscano G, Agoxxino E, Del Guidice N. A randomised trial in the prevention of influenza-like syndromes by homeopathic management [La prevention des syndromes grippaux par un medicament homeopathique: etude controlee]. Revue d'Epidemiologie et de Sante Publique 1995;43(4):380-2.

Beghi 2016 \{published data only\}

Beghi GM, Morselli-Labate AM. Does homeopathic medicine have a preventive effect on respiratory tract infections? A real life observational study. Multidisciplinary Respiratory Medicine 2016;11(1):12. [DOI: 10.1186/s40248-016-0049-0]

D'Souza 2012 \{published data only\}

D'Souza R. Efficacy of homeopathy in treatment of acute otitis media with intense otalgia in children. Homeopathic Heritage 2012;37(12):37-42.

\section{Ferley 1987 \{published data only\}}

Ferley JP, Poutignat N, Azzopardi Y, Charrel M, Zmirou D. Evaluation in ambulatory medicine of the activity of a homeopathic complex in the prevention of influenza and influenza syndromes [Évaluation en médicine ambulatoire de l'activiete d'un complexe homéopathique dans la prévention de la grippe et des syndromes grippaux]. Immunologie Medicale 1987;20:22-8

\section{Friese 2001 \{published data only\}}

Friese K, Feuchter U, Lüdtke R, Moeller H. Results of a randomised prospective double-blind clinical trial on the homeopathic treatment of adenoid vegetations. European Journal of General Practice 2001;7(2):48-54. [DOI: 10.3109/13814780109048787]

\section{Harrison 1999 \{published data only\}}

Harrison $\mathrm{H}$, Fixsen A, Vickers A. A randomized comparison of homoeopathic and standard care for the treatment of glue ear in children. Complementary Therapies in Medicine 1999; 7(3):132-5.

\section{Jong 2016 \{published data only\}}

Jong MC, Buskin SL, Ilyenko L, Kholodova I, Burkart J, Weber S, et al. Effectiveness, safety and tolerability of a complex homeopathic medicinal product in the prevention of recurrent acute upper respiratory tract infections in children: a multicenter, open, comparative, randomized, controlled clinical trial. Multidisciplinary Respiratory Medicine 2016;11:9. [DOI: 10.1186/s40248-016-0056-1] 


\section{Lasfargues 1983 \{published data only\}}

Lasfargues G, Cotin G, Boccon-Gibod L. Clinical value of Solacy in childhood rhinopharyngitis. Study using the double-blind method with a placebo and a microscopic examination of the rhinopharyngeal mucosa [Expertis clinique du Solacy dans les rhinopharynites de l'enfant: Etude effectuee en double aveugle contre placebo avec examen microscopique de la muqueuse rhinopharyngee]. Revue de Laryngologie Otologie Rhinologie 1983;104(4):369-72.

\section{NCT00858494 \{unpublished data only\}}

NCT00858494. Homeopathic cold medicine for children. clinicaltrials.gov/ct2/show/study/NCT00858494 (first received 5 March 2009).

\section{Rottey 1995 \{published data only\}}

Rottey E, Verleye G, Liagre R. The effects of a homeopathic remedy made of micro-organisms in the prevention of flu. $A$ randomised double-blind trial in GP practices [Het effect van een homeopathische bereiding van micro-organismen bij de preventie van griepsymptomen. Een gerandomiseerd dubbelblind onderzoek in de huisartspraktijk]. Tijdschrift voor Integrale Geneeskunde 1995;11(1):54-8.

\section{Salami 2008 \{published data only\}}

Salami A, Dellepiane M, Crippa B, Mora F, Guastini L, Jankowska B, et al. Sulphurous water inhalations in the prophylaxis of recurrent upper respiratory tract infections. International Journal of Pediatric Otorhinolaryngology 2008;72(11):1717-22.

\section{Steinsbekk 2005b \{published data only\}}

Steinsbekk A, Fonnebo V, Lewith G, Bentzen N. Homeopathic care for the prevention of upper respiratory tract infections in children: a pragmatic, randomised, controlled trial comparing individualised homeopathic care and waiting-list controls. Complementary Therapies in Medicine 2005;13(4):231-8.

\section{Steinsbekk 2007 \{published data only\}}

Steinsbekk A, Lewith G, Fonnebo V, Bentzen N. An exploratory study of the contextual effect of homeopathic care. A randomised controlled trial of homeopathic care vs. selfprescribed homeopathic medicine in the prevention of upper respiratory tract infections in children. Preventive Medicine 2007;45(4):274-9.

\section{Taylor 2011 \{published data only\}}

Taylor J, Jacobs J. Homeopathic ear drops as an adjunct to standard therapy in children with acute otitis media. Homeopathy 2011;100(3):109-15.

\section{Thinesse-Mallwitz 2015 \{published data only\}}

Thinesse-Mallwitz M, Maydannik V, Kellerc T, Klement P. A homeopathic combination preparation in the treatment of feverish upper respiratory tract infections: an international randomised controlled trial. Forsch Komplementarmedizin 2015;22(3):163-70.

\section{Torbicka 1998 \{published data only\}}

Torbicka E, Brzozowska-Binda A, Wilczynski J, Uzerowicz A. RSV infections in infants: therapy with a homeopathic preparation. Biomedical Therapy 1998;16(4):256-60.

\section{Van Haselen 2016 \{published data only\}}

Van Haselen R, Thinesse-Mallwitz M, Maidannyk V, Buskin S, Weber S, Keller T, et al. The effectiveness and safety of a homeopathic medicinal product in paediatric upper respiratory tract infections with fever: a randomised controlled trial. Global Pediatric Health 2016;3:1-11. [DOI: 10.1177/2333794X16654851]

\section{Zanasi 2014 \{published data only\}}

Zanasi A, Mazzolini M, Tursi F, Morselli-Labate A, Paccapelo A, Lecchi M. Homeopathic medicine for acute cough in upper respiratory tract infections and acute bronchitis: a randomised, double-blind, placebo-controlled trial. Pulmonary Pharmacology \& Therapeutics 2013;27(1):102-8.

\section{References to studies awaiting assessment}

Furuta 2017 \{published data only\}

Furuta SE, Weckx LLM, Fiqueriedo CR. Homeopathic treatment of recurrent tonsillitis in children: a randomized controlled trial. Revista de Homeopatia 2017;80(3/4):136-41.

\section{Niederle 2001 \{published data only\}}

Niederle S. Acute streptococcal-negative tonsillitis in children, a double-blind placebo-controlled study demonstrating the efficacy and tolerability of homeopathic treatment [Akute, streptokokken-negative Tonsillitis bei Kindern Eine doppelblinde Placebokontrollierte Studie belegt die Wirksamkeit und Verträglichkeit der homöopathischen Therapie]. Kassenarzt 2001;21:33-4.

\section{References to ongoing studies}

CTRI/2014/06/004673 \{unpublished data only\}

CTRI/2014/06/004673. Double blind, randomised placebo control study to evaluate efficacy and safety of EMTACT, a homeopathic drug in the management of recurrent upper and lower respiratory tract infections. apps.who.int/trialsearch/ Trial2.aspx?TrialID=CTRI/2014/06/004673 (first received 20 February 2014).

\section{CTRI/2014/12/005294 \{unpublished data only\}}

CTRI/2014/12/005294. A comparative randomised controlled trial of homoeopathy and allopathy in acute otitis media and its recurrence in children. apps.who.int/trialsearch/Trial2.aspx? TrialID=CTRI/2014/12/005294 (first received 29 August 2014).

\section{Additional references \\ Altunc 2007}

Altunc U, Pittler MH, Ernst E. Homeopathy for childhood and adolescence ailments: systematic review of randomised clinical trials. Mayo Clinic Proceedings 2007;82(1):69-75. 


\section{Atkins 2004}

Atkins D, Best D, Briss PA, Eccles M, Falck-Ytter Y, Flottorp S, et al. GRADE Working Group. Grading quality of evidence and strength of recommendations. BMJ 2004;328(7454):1490.

\section{Bellavite 2011}

Bellavite P, Marzotto M, Chirumbolo S, Conforti A. Advances in homeopathy and immunology: a review of clinical research. Frontiers in Bioscience (Schol Ed) 2011;3:1363-89.

\section{Chen 2011}

Chen H, Zhuo Q, Yuan W, Wang J, Wu T. Vitamin A for preventing acute lower respiratory tract infections in children up to seven years of age. Cochrane Database of Systematic Reviews 2011, Issue 1. [DOI: 10.1002/14651858.CD006090.pub2]

\section{Clarke 2015}

Clarke T, Black L, Stussman B, Barnes P, Nahin R. Trends in the use of complementary health approaches among adults: United States, 2002-2012. Hyattsville (MD): National Center for Health Statistics; 2015 Feb. National Health Statistics Report No. 79. [www.cdc.gov/nchs/data/nhsr/nhsr079.pdf]

\section{eTG 2016}

Therapeutic Guidelines. Electronic Therapeutic Guidelines Complete. tgldcdp.tg.org.au/etgcomplete (accessed prior to 5 July 2017).

\section{Fahey 1998}

Fahey T, Sticks N. Antibiotics for children with upper respiratory tract infections. JAMA 1998;280(16):1399-400.

\section{GBD 2015}

GBD 2013 Mortality and Causes of Death Collaborators. Global, regional, and national age-sex specific all-cause and cause-specific mortality for 240 causes of death, 1990-2013: a systematic analysis for the Global Burden of Disease Study 2013. Lancet 2015;9963:117-71. [DOI: 10.1016/ S0140-6736(14)61682-2]

\section{GRADEpro GDT 2014 [Computer program]}

GRADE Working Group, McMaster University. GRADEpro GDT 2014. Hamilton (ON): GRADE Working Group, McMaster University, accessed prior to 17 March 2018.

\section{Grimes 2012}

Grimes D. Proposed mechanisms for homeopathy are physically impossible. Focus on Alternative and Complementary Therapies 2012;17(3):149-55. [DOI: 10.1111/j.2042-7166.2012.01162.x]

\section{Higgins 2011}

Higgins JP, Green S, editor(s). Cochrane Handbook for Systematic Reviews of Interventions Version 5.1.0 (updated March 2011). The Cochrane Collaboration, 2011. Available from handbook.cochrane.org.

\section{Jonas 2003}

Jonas WB, Kaptchuk TJ, Linde K. A critical overview of homeopathy. Annals of Internal Medicine 2003;138(5):393-9.

\section{Karsch-Völk 2014}

Karsch-Völk M, Barrett B, Kiefer D, Bauer R, ArdjomandWoelkart K, Linde K. Echinacea for preventing and treating the common cold. Cochrane Database of Systematic Reviews 2014, Issue 2. [DOI: 10.1002/14651858.CD000530.pub3]

\section{Lee-Treweek 2006}

Lee-Treweek G, Heller T, MacQueen H, Stone J, Spurr S. Complementary and Alternative Medicine: Structures and Safeguards. New York: Routledge, 2006.

\section{Lefebvre 2011}

Lefebvre C, Manheimer E, Glanville J. Chapter 6: Searching for studies. In Higgins JP, Green S, editor(s). Cochrane Handbook for Systematic Reviews of Interventions Version 5.1.0 (updated March 2011). The Cochrane Collaboration, 2011. Available from handbook.cochrane.org.

\section{Linde 1997}

Linde K, Clausius N, Ramirez G, Melchart D, Eitel F, Hedges LV, et al. Are the clinical effects of homeopathy placebo effects? A meta-analysis of placebo-controlled trials. Lancet 1997;350(9081):834-43.

\section{Linde 1998}

Linde K, Melchart D. Randomized controlled trials of individualized homeopathy: a state-of-the-art review. Journal of Alternative and Complementary Medicine 1998;4(4):371-88.

\section{Lüdtke 2008}

Lüdtke R, Rutten AL. The conclusions on the effectiveness of homeopathy highly depend on the set of analysed trials. Journal of Clinical Epidemiology 2008;61(12):119-204.

\section{Marom 2016}

Marom T, Marchisio P, Tamir S, Torretta S, Gavriel, Esposito H. Complementary and alternative medicine treatment options for otitis media: a systematic review. Medicine (Baltimore) 2016;95(6):e2695. [DOI: 10.1097/MD.0000000000002695]

\section{Mathie 2014}

Mathie RT, Lloyd SM, Legg LA, Clausen J, Moss S, Davidson JRT, et al. Randomised placebo-controlled trials of individualised homeopathic treatment: systematic review and meta-analysis. Systematic Reviews 2014;3:142. [DOI: 10.1186/2046-4053-3-142]

\section{Mathie 2017}

Mathie RT, Ramparsad N, Legg LA, Clausen J, Moss S, Davidson JRT, et al. Randomised, double-blind, placebocontrolled trials of non-individualised homeopathic treatment: systematic review and meta-analysis. BioMed Central 2017;6(1):63. [DOI: 10.1186/s13643-017-0445-3]

\section{Nair 2013}

Nair H, Simoes E, Fudan I, Gessner B, Azzizz-Baumgartner E, Zhang J, et al. Global and regional burden of hospital admissions for severe acute lower respiratory infections in young children in 2010: a systematic analysis. Lancet 2013;381(9875):1380-90. [DOI: 10.1016/S0140-6736(12)61901-1] 


\section{NCT01257503}

NCT01257503. Homeopathic cold remedy for children study. clinicaltrials.gov/ct2/show/NCT01257503 (first received 8 December 2010).

\section{NHMRC 2015}

National Health and Medical Resource Council. NHMRC Information Paper: Evidence on the effectiveness of homeopathy for treating health conditions. www.nhmrc.gov.au/ guidelines-publications/cam02 2015 (accessed 4 January 2018). [ISBN Online: 978-1-925129-29-8]

\section{Optum 2013}

Optum. Effectiveness of Homeopathy for Any Clinical Condition: Evaluation of the Evidence. Overview Report. Canberra: NHMRC, 2013.

\section{Rao 2007}

Rao ML, Roy R, Bell IR, Hoover R. The defining role of structure (including epitaxy) in the plausibility of homeopathy. Homeopathy 2007;96(3):175-82.

\section{Review Manager 2014 [Computer program]}

Nordic Cochrane Centre, The Cochrane Collaboration. Review Manager 5 (RevMan 5). Version 5.3. Copenhagen: Nordic Cochrane Centre, The Cochrane Collaboration, 2014.

\section{Rosenfeld 2003}

Rosenfeld RM, Kay D. Natural history of untreated otitis media. In: Rosenfeld RM, Bluestone CD editor(s). Evidence-Based Otitis Media. 2nd Edition. Hamilton, ON: BC Decker Inc, 2003.

\section{Rutten 2008}

Rutten AL, Stolper CF. The 2005 meta-analysis of homeopathy: the importance of post-publication data. Homeopathy 2008;97(4):169-77.

\section{Schulte 1999}

Schulte J. Effects of potentization in aqueous solutions. British Homeopathic Journal 1999;88(4):155-60.

\section{Schulz 2010}

Schulz KF, Altman DG, Moher D, CONSORT Group. CONSORT 2010 statement: updated guidelines for reporting parallel group randomised trials. BMJ 2010;340:c322. [DOI: 10.1136/bmj.c332]

\section{Shang 2005}

Shang A, Huwiler-Müntener K, Nartey L, Jüni P, Dörig S, Sterne JA, et al. Are the clinical effects of homoeopathy placebo effects? Comparative study of placebo-controlled trials of homoeopathy and allopathy. Lancet 2005;366(9487):726-32.

\section{Simoes 2006}

Simoes EAF, Cherian T, Chow J, Shahid-Salles SA, Laxminarayan $\mathrm{R}$, John TJ. Acute respiratory infections in children. In: Jamison DT, Breman JG, Measham AR, Alleyne G, Claeson M, Evans DB, et al. editor(s). Disease Control Priorities in Developing Countries. 2nd Edition. Washington, DC: International Bank for Reconstruction and Development/The World Bank, 2006.

\section{Steinsbekk 2004}

Steinsbekk A, Bentzen N, Fønnebø V, Lewith GT. Randomized controlled trials on treatment by homeopaths and selftreatment with homeopathic medicines: design and protocol. Journal of Alternative and Complementary Medicine 2004;10(6):1027-32.

\section{Ullman 2010}

Ullman D, Frass M. A review of homeopathic research in the treatment of respiratory allergies. Alternative Medicine Review 2010;15(1):48-58.

\section{Walach 2005}

Walach H, Jonas WB, Ives J, Van Wijk R, Weingärter O. Research on homeopathy; state of the art. Journal of Alternative and Complementary Medicine 2005;11(5):813-29.

\section{References to other published versions of this review \\ Becker 2010}

Becker C, Gottschling S, Graf N, Lüdtke R. Homeopathic remedies for acute respiratory tract infections in children. Cochrane Database of Systematic Reviews 2010, Issue 1. [DOI: 10.1002/14651858.CD005974.pub2]

\section{Mascarenhas 2011}

Mascarenhas AR, Seebold JA, Cundy WJ, McGuire T, van Driel ML. Homeopathic remedies for preventing and treating acute respiratory tract infections in children. Cochrane Database of Systematic Reviews 2011, Issue 12. [DOI: 10.1002/14651858.CD005974.pub3]

\section{CHARACTERISTICS OF STUDIES}

Characteristics of included studies [ordered by study ID]

de Lange de Klerk 1994

\begin{tabular}{ll}
\hline Methods & RCT, double-blinded, parallel study, 1-year duration \\
\hline Participants & Setting: paediatric outpatient department of university hospital, Netherlands \\
& Participants: 170 participants were randomised: $86 / 84$ to homeopathy/placebo groups \\
& $\begin{array}{l}\text { Recruitment method: participants were recruited by their general practitioners and by articles in the } \\
\text { popular press. }\end{array}$
\end{tabular}


de Lange de Klerk 1994 (Continued)

Withdrawals and exclusions: 5 children ( 2 in homeopathy group and 3 in placebo) participated for $<26$ weeks and their results were not analysed.

Age range: 18 months to 10 years

Gender: $47 \%$ female

Baseline demographics: the median age was 4.2 years in the homeopathy group and 3.6 years in the placebo group. The lifetime prevalence of otitis media with effusion was $64 \%$ in the homeopathy group and $52 \%$ in the placebo group.

Eligibility criteria:

Inclusion criteria: children who had at least 3 URTIs in the past year or had 2 previous URTIs as well as otitis media with effusion at the time of entry examination

Exclusion criteria: children who had adenoidectomy, tonsillectomy, or a 'constitutional' homoeopathic treatment in the past 6 months; regular medical care for any other chronic condition including chronic non-specific lung disease; untreated dental caries; congenital malformation of the respiratory tract or the heart; mental handicap; neurological disorder; children with height outside the third centile; a history of rheumatic fever, endocarditis, myocarditis, or nephritis; children for whom no suitable homoeopathic constitutional medicine could be chosen at the entry examination because they did not have at least 3 symptoms relevant for the choice of a matching homoeopathic medicine; and children whose parents were not fluent enough in Dutch to answer the questionnaires

Interventions

Homeopathic medicinal products were chosen individually by a homeopathic practitioner for each participating child. Mainly 6th, 30th, and 200th decimal potencies were used. The homeopathic treatment consisted of constitutional medicines for improving general health in the long run and acute medicines for treating URTIs.

Mean daily symptom score, mean percentage of days symptom-free, number of antibiotic courses,
number of adenoidectomies and tonsillectomies over 1-year follow-up

Notes Insufficient reporting of details of the intervention including medication frequency and which homeopathic medicines were used

Funded by a grant from the Dutch Ministry of Welfare, Cultural Affairs and Public Health

\section{Risk of bias}

Bias Authors' judgement Support for judgement

Random sequence genera- Low risk tion (selection bias)

Quote: "We assigned children to the study groups using permuted blocks (size 4) stratified for age in (18-23 months, two to five years, and six to nine years). This achieves balance for age and also for any variables which tend to vary over time or season." (p. 1330)

Comment: well-described methods, low risk of selection bias

\begin{tabular}{|c|c|c|}
\hline $\begin{array}{l}\text { Allocation concealment } \\
\text { (selection bias) }\end{array}$ & Unclear risk & $\begin{array}{l}\text { Quote: "The identity of the treatment groups was concealed until all the data } \\
\text { analysis was complete" (p. 1330) } \\
\text { Comment: specific method of allocation concealment was not reported }\end{array}$ \\
\hline $\begin{array}{l}\text { Blinding of participants } \\
\text { and personnel (perfor- } \\
\text { mance bias) } \\
\text { All outcomes }\end{array}$ & Low risk & $\begin{array}{l}\text { Quote: "The child was given either active medicine or a placebo for the appro- } \\
\text { priate treatment for the whole study period." (p. 1330) } \\
\text { Comment: does not specify whether placebo was indistinguishable from } \\
\text { homeopathy, however as long as participants remained unaware of allocation, } \\
\text { this detail is unlikely to make a difference }\end{array}$ \\
\hline
\end{tabular}


de Lange de Klerk 1994 (Continued)

\begin{tabular}{|c|c|c|}
\hline $\begin{array}{l}\text { Blinding of outcome as- } \\
\text { sessment (detection bias) } \\
\text { Patient reported out- } \\
\text { comes }\end{array}$ & Low risk & $\begin{array}{l}\text { Quote: "The parents kept diaries, and their observations were collected once } \\
\text { every two weeks through structured telephone interviews." (p. 1330) "We cal- } \\
\text { culated each child's daily symptom score for each day of follow up." (p. 1330) } \\
\text { Comment: as parents were blinded, the risk of detection bias for partici- } \\
\text { pant-reported outcomes is likely to be low }\end{array}$ \\
\hline
\end{tabular}

\begin{tabular}{|c|c|c|}
\hline $\begin{array}{l}\text { Blinding of outcome as- } \\
\text { sessment (detection bias) } \\
\text { Practitioner outcome as- } \\
\text { sessors }\end{array}$ & Low risk & $\begin{array}{l}\text { Quote: "The identity of the treatment groups was concealed until all the data } \\
\text { analysis was complete." (p. 1330) "The randomised double blind placebo con- } \\
\text { trolled design was used because we wanted to study the intrinsic effects of the } \\
\text { homeopathic medicines, not the effects of the treatment as a whole, including } \\
\text { counselling and advice." (p. 1331) }\end{array}$ \\
\hline
\end{tabular}

Comment: it is likely that treatment groups were blinded throughout assessment given these statements

Incomplete outcome data Low risk

(attrition bias)

All outcomes
Quote: "A total of 175 children were eligible for study. Data were analysed for all 170 children who participated for more than 26 weeks, including three children (one in the treatment group, two in the placebo group) who stopped taking trial treatment but continued follow up." (p. 1330)

Comment: only 5 of 175 children were excluded from analysis ( 2 from homeopathy, 3 from placebo) due to less than 26 weeks' participation. Exclusions are accounted for.
Selective reporting (re-
Low risk
All primary outcomes stated in methods were reported.

porting bias)

Other bias Low risk No other bias identified.

Jacobs 2001

\begin{tabular}{ll} 
Methods & RCT, double-blinded, controlled pilot study, 6 weeks duration \\
\hline Participants & Setting: private group paediatric practice in seatle, WA, USA
\end{tabular}

Participants
Setting: private group paediatric practice in Seattle, WA, USA
Participants: $75 ; 36$ randomised to homeopathy, 39 to placebo
Recruitment method: clinic patients
Withdrawals and exclusions: 3 children (2 from homeopathy, 1 from placebo) lost to follow-up

Age range: 18 months to 6 years

Gender: $40 \%$ female

Eligibility criteria:

Inclusion criteria: diagnosis of otitis media (when there was middle ear effusion, along with 1 or both of: ear pain characterised as moderate or severe, fever of greater than $38^{\circ} \mathrm{C}$ orally). Middle ear effusion determined by pneumatic otoscopy.

Exclusion criteria: children with a history of ear pain for greater than 36 hours or those who had received antibiotics within the past week or homeopathic medications within the previous 72 hours; children who had previous tonsillectomy, adenoidectomy, or tympanostomy tubes as well as those with a perforated tympanic membrane and/or a discharge from the ear; children on concurrent medication for another acute or chronic illness; children with a cleft palate or Down syndrome

\section{Interventions \\ Homeopathic medicinal product versus placebo}


Jacobs 2001 (Continued)

Homeopathic product: children were given individualised homeopathic medicine. 8 different medications were prescribed in the study, but the 4 most common were prescribed in $88 \%$ of cases:

- Pulsatilla nigricans (62.7\%)

- Chamomilla (10.7\%)

- Sulphur (9.3\%)

- Calcarea carbonica (5.3\%)

Medications were prepared on No. 38 lactose pellets impregnated and tumbled dry with an identical amount of either a homeopathic medication in the $30 \mathrm{C}$ potency, prepared in accordance with Homeopathic Pharmacopoeia of the USA, or placebo (water/alcohol solution lacking active substance).

Outcomes Number of treatment failures at 5 days, 2 weeks, and 6 weeks; diary symptom score during first 3 days; middle ear effusion at 2 and 6 weeks' post-treatment

Outcomes provided by correspondence with author: cure rate (no symptoms or significant reduction in symptoms), mean daily symptom scores

Adverse events

Notes Funded by a grant from the Standard Homeopathic Company

\section{Risk of bias}

Bias Authors' judgement Support for judgement

Random sequence genera- Low risk tion (selection bias)

Quote: "For each of the 16 individual homeopathic medicines... coded bottles that had been randomised to contain either active medication or placebo using a random number generator and pattern blocks of 4 and 6." (p. 179)

Comment: use of random number generator suggests robust random sequence generation.

Allocation concealment Low risk
(selection bias)

Quote: "Study medications were randomised into code bottles by a pharmacist at the Standard Homeopathic Company in Los Angeles, who held the code until the study was completed." (p. 180)

Comment: robust allocation concealment

\begin{tabular}{|c|c|c|}
\hline $\begin{array}{l}\text { Blinding of participants } \\
\text { and personnel (perfor- } \\
\text { mance bias) } \\
\text { All outcomes }\end{array}$ & Low risk & $\begin{array}{l}\text { Quote: "One half of the children were given active homeopathic medicine, and } \\
\text { the other half received placebo." (p. 179); "There were no detectable differ- } \\
\text { ences in taste, odour or colour between the treatment medication and place- } \\
\text { bo" (p. 180) }\end{array}$ \\
\hline & & $\begin{array}{l}\text { Comment: adequate blinding of children and parents. Homeopathic practi- } \\
\text { tioners blinded. Low risk of broken blinding, as homeopathy and placebo were } \\
\text { identical. }\end{array}$ \\
\hline
\end{tabular}

Blinding of outcome as- Low risk

Parents assessed children's symptoms and were adequately blinded.

sessment (detection bias)

Patient reported out-

comes

\begin{tabular}{|c|c|c|}
\hline $\begin{array}{l}\text { Blinding of outcome as- } \\
\text { sessment (detection bias) }\end{array}$ & Low risk & $\begin{array}{l}\text { Quote: "Follow-up visits were made by an otolaryngology resident (LD), who } \\
\text { was blinded as to treatment allocation" (p. 179) }\end{array}$ \\
\hline $\begin{array}{l}\text { Practitioner outcome as- } \\
\text { sessors }\end{array}$ & & Comments: outcome assessors of follow-up visits were also blinded. \\
\hline
\end{tabular}


Jacobs 2001 (Continued)

Incomplete outcome data Low risk (attrition bias)

All outcomes
Participant-reported outcomes:all participants in homeopathy group returned symptom diaries. 6/39 participants in placebo group did not return symptoms diary. No data exclusions made from returned forms.

Practitioner-assessed outcomes: 3 children (2 from homeopathy, 1 from placebo group) lost to follow-up. No data exclusions made from returned participants.

Selective reporting (re- Low risk All primary outcomes mentioned in methods reported.
porting bias)

Methods A parallel assignment RCT of homeopathy treatment for URTI

Participants

263 children diagnosed with URTI

Setting: University of Washington Medical Center, Roosevelt Pediatric Care Center, Seattle, WA, USA

Participants: $263 ; 128$ randomised to homeopathy, 133 to placebo

Recruitment method: parents approached in primary care practice, but method of recruitment not stated.

Withdrawals and exclusions: of 263 randomised participants, 1 was excluded before commencing treatment due to a positive strep culture at enrolment, and 1 was excluded due to age over 5 years at enrolment. Symptom diaries were returned by 163 participants, and 155 returned dosage logbooks; 244 completed phone follow-up at 7 to 10 days post-index visit (i.e. 17 were lost to phone follow-up).

Age range: 2 to 5 years

Gender: $48 \%$ female

Eligibility criteria:

Inclusion criteria: clinical diagnosis of URTI, duration of symptoms less than 7 days, parent who spoke English

Exclusion criteria: history of asthma, on any prescribed medication, prescribed any medication other than acetaminophen or ibuprofen at index visit, use of homeopathic remedy within 48 hours of index visit

Interventions

Homeopathy ( $5 \mathrm{~mL}$ up to 6 times daily as needed for cold symptoms of commercial liquid formulation Hyland's Cold 'n Cough 4 Kids, which contains: Allium Cepa 6X Hepar Sulph Calc 12X Natrum Muriaticum 6 X Phosphorous $12 \mathrm{X}$ Pulsatilla $6 \mathrm{X}$ Sulphur $12 \mathrm{X}$ Hydrastis $6 \mathrm{X}$ ( $6 \mathrm{X}$ potency means a 1:10 dilution 6 successive times, $12 X$ is the same dilution 12 times)). Ingredients were added to a liquid preparation that included Glycyrrhiza extract as sweetener.

Placebo ( $5 \mathrm{~mL}$ placebo liquid up to 6 times daily as needed). Placebo was similar in appearance, with some similarity of taste (liquid preparation included Glycyrrhiza extract as sweetener).

Outcomes The parent-scored outcomes were as follows.

- Overall symptom severity at 7- to 10-day follow-up. (Change in cold symptoms of child during the 7 to 10 days after the index visit for a URTI. Parents assessed severity of 4 symptoms (runny nose, cough, sneeze, and congestion) in their child using a 4-point scale for each symptom, $0=$ none to $3=$ severe. Cold score is the sum of scores for each symptom (0 to 12). Parents assessed cold score at baseline, twice daily on study days 1 to 3 , and at the 7- to 10-day follow-up.) 
- Adverse events. (Parents were asked to record any side effects after each dose of study medications. Parents were also asked about side effects during follow-up phone call.)

- Change in severity of cold symptoms 1 hour after a dose. (Parents measured change in runny nose, cough, nasal congestion, and sneezing severity 1 hour after administering a dose of study medication up to the first 10 doses of study medication. Change in symptom was rated on a 7-point scale (from 0 to 6), with 0 indicative of the symptom being much worse and 6 indicative of the symptom being much improved. The unit of analysis for each outcome was doses of medication. Each participant could contribute data on 0 to 10 doses.)

- Change in non-specific symptoms 1 hour after a dose. (Parents measured change in severity of irritability, lethargy, fussiness, and appetite 1 hour after administering a dose of study medication up to the first 10 doses of study medication. Change in symptom was rated on a 7-point scale (0 to 6), with 0 indicative of the symptom being much worse and 6 indicative of the symptom being much improved. The unit of analysis for each outcome was doses of medication. Each participant could contribute data on 0 to 10 doses.)

- Change in functional status of child at 5- to 10-day follow-up. (Change in functional status of child at the 5- to 10-day phone follow-up after the index visit for a URTI. Parents rated 5 activities (vigorous activity, activities that require concentration, activities with family or friends, appetite, and sleep) once daily on study days 1 to 5 in their child and again at the 5- to 10-day follow-up.)

- Change in health status at 5- to 10-day follow-up. (Change in health status of child during the 5 to 10 days after the index visit for a URTI. Parents rated health status on 1-to-10 scale, with 1 indicating perfect health and 10 indicating very sick. Health status was rated once daily on study days 1 to 3 and again at the 5- to 10-day follow-up.)

\section{Risk of bias}

\begin{tabular}{lll}
\hline Bias & Authors' judgement & Support for judgement \\
\hline $\begin{array}{l}\text { Random sequence genera- } \\
\text { tion (selection bias) }\end{array}$ & Low risk & $\begin{array}{l}\text { Quote: "Each participant was consecutively assigned a unique study identi- } \\
\text { fication number and the parent was provided a bottle of study medication } \\
\text { with the corresponding identification number. The contents, either the home- } \\
\text { opathic syrup or a placebo, were assigned using a computerized randomisa- } \\
\text { tion sequence in blocks of four by the University of Washington Investigational } \\
\text { Drug Service, which labelled all of the medication bottles." (p. 230) }\end{array}$ \\
& Comment: robust random sequence generation method used.
\end{tabular}

Allocation concealment Low risk

(selection bias)

Quote: "The parent was provided a bottle of study medication with the corresponding identification number... the University of Washington Investigational Drug Service... labelled all of the medication bottles." (p. 230) "The homeopathic syrup and placebo were identical in appearance, smell and taste." ( $p$. 230)

Comment: robust allocation concealment method used.

\begin{tabular}{|c|c|c|}
\hline $\begin{array}{l}\text { Blinding of participants } \\
\text { and personnel (perfor- }\end{array}$ & Low risk & $\begin{array}{l}\text { Given robust allocation concealment and all reporting of outcomes done by } \\
\text { parents, risk of performance bias is likely to be low. }\end{array}$ \\
\hline
\end{tabular}

\begin{tabular}{|c|c|c|}
\hline $\begin{array}{l}\text { Blinding of outcome as- } \\
\text { sessment (detection bias) }\end{array}$ & Low risk & $\begin{array}{l}\text { Given robust allocation concealment and all reporting of outcomes done by } \\
\text { parents, risk of performance bias is likely to be low. }\end{array}$ \\
\hline
\end{tabular}
Patient reported outcomes

\begin{tabular}{ll}
\hline Blinding of outcome as- & Low risk
\end{tabular} Not applicable - no practitioner outcome assessments


Jacobs 2016 (Continued)

Practitioner outcome as-

sessors

\section{Incomplete outcome data High risk} (attrition bias)

All outcomes
Symptom diary-based outcomes subject to high risk of attrition bias, as only 162 of 261 participants returned symptom diaries. While the baseline demographics between "Didn't return symptom diary" and "Returned symptom diary" groups showed no significant differences, there is a reasonable likelihood that failure to return symptom diary may have been associated with some differences in illness progression or participant/family characteristics. The small number of participants who returned symptom diaries also results in inadequate power for the relevant outcomes.

Phone follow-up outcomes subject to less risk of attrition bias: 244 of 261 participants completed phone follow-up. Note that none of the phone follow-upbased outcomes showed any significant results.

Selective reporting (re- Unclear risk
porting bias)
There were several planned outcomes for which no results were reported; time off school for children and days off work for parents are not mentioned in results.

Results with positive outcomes (e.g. diary symptom scores at assessment points 1 and 2) are described in detail, while for some results with negative outcomes (e.g. composite cold scores at 5- to 10-day follow-up, functional outcomes at 5- to 10-day follow-up) no actual data are provided in the results.

Other bias Low risk

\begin{abstract}
Sponsor: Standard Homeopathic Company
Quote: "The only disclosure restriction on the Principal investigators is that the sponsor can review results communications prior to public release and can embargo communications regarding trial results for a period that is more than 60 days but less than or equal to 180 days. The sponsor cannot require changes to the communication and cannot extend the embargo."

Conflict of interest statement: "Dr Jacobs served in the past as a consultant for Standard Homeopathic Company." (p. 234)
\end{abstract}

\title{
Malapane 2014
}

Methods RCT, double-blinded, placebo-controlled pilot study, 6 days' duration

Participants

\author{
Setting: a primary school in Gauteng, South Africa \\ Participants: $30 ; 15$ randomised to homeopathy, 15 to placebo
}

Recruitment method: parents or guardians and teachers were requested to refer children reporting a sore throat or tonsillitis to the researcher.

Withdrawals and exclusions: none

Age range: 6 to 12 years

Gender: $73.3 \%$ female in placebo group and $53.3 \%$ female in treatment group

Eligibility criteria:

Inclusion criteria: children had to have symptoms of viral tonsillitis (sore throat, pain on swallowing, erythema and/or oedema of the tonsils, and enlarged or tender tonsillar and cervical lymph nodes), recent onset tonsillitis (i.e. $\leq 2$ days), and possible presence of exudates on the pharynx and tonsils. 
Exclusion criteria: positive rapid streptococcal antigen test result; diphtheria; otitis media; lymphadenopathy, except for the tonsillar and cervical lymph nodes; tonsillectomy; a medical history of rheumatic fever or glomerular nephritis; malabsorption syndrome; diseases that compromise breathing stridor (e.g. bronchitis, bronchopneumonia, or very enlarged tonsils); temperature $>39^{\circ} \mathrm{C}$; HIV/ AIDS; symptoms of Group AStreptococcus and confirmed diagnosis; using long-term medication, immune stimulants (including homeopathic or herbal remedies), and/or antibiotic treatment during the previous 14 days; or analgesic, antipyretic, or cold medications (e.g. decongestant, antihistamine, antitussive or throat lozenges) within the previous 8 hours

Interventions Homeopathic medicinal product versus placebo

Each participant was given instructions to dissolve 2 tablets 4 times a day under their tongue (after breakfast, lunch, and supper and before bedtime), with the first dose administered by the researcher. Each child received an information leaflet detailing the dosage and storage instructions.

Homeopathic product: the homeopathic complex used in this study was commercially available in the South African market under the trade name Tonzolyt and was marketed for the treatment of acute or chronic tonsillitis and pharyngitis. It includes the following remedies: Atropa belladonna D4, Calcarea phosphoricum D4, Hepar sulphuris D4, Kalium bichromate (potassium dichromate) D4, Kalium muriaticum D4, Mercurius protiodide D10, and Mercurius biniodid D10. The D (or Decimal) potency is created by diluting the crude substance in a 1:10 ratio (i.e. 1 part solute in 10 parts solvent, usually ethanolwater solution); each dilution is followed by succussions (vigorous shaking against a hard surface).

Placebo: the placebo was similar in appearance and taste and was labelled in the same manner as the treatment medication.

Pain score (daily for 6 days)
Pain on swallowing
Referred ear pain
Tonsil size
Erythema/inflammation of pharynx
Vital signs
At each consultation, participants completed the Wong-Baker FACES Pain Rating Scale and a Symptom
Grading Scale (SGS) under the supervision of the researcher, and a relevant physical examination was
performed.
The SGS was used to grade tonsillar hypertrophy and erythema/inflammation of the pharynx. The re-
searcher also determined the presence of associated ear pain and pain on swallowing using the SGS.

Notes Author disclosure statement states that no competing financial interests exist. No other mention of funding support

\section{Risk of bias}

Bias Authors' judgement Support for judgement

\begin{tabular}{lll}
\hline $\begin{array}{l}\text { Random sequence genera- } \\
\text { tion (selection bias) }\end{array}$ & Low risk & $\begin{array}{l}\text { Quote: "Assignment to medication or placebo was randomised by an outside } \\
\text { party using the simple random sampling method." (p. 869) }\end{array}$ \\
& \begin{tabular}{l} 
Comment: robust method of random sequence generation used. \\
\hline $\begin{array}{l}\text { Allocation concealment } \\
\text { (selection bias) }\end{array}$ \\
Low risk
\end{tabular} & $\begin{array}{l}\text { Quote: "the participants received one bottle containing } 48 \text { tablets of the } \\
\text { homeopathic complex medicated onto lactose tablets or un-medicated lac- } \\
\text { tose tablets. The placebo was similar in appearance and taste and was labelled } \\
\text { in the same manner as the treatment medication." (p. 869) }\end{array}$
\end{tabular}




\begin{tabular}{|c|c|c|}
\hline $\begin{array}{l}\text { Blinding of participants } \\
\text { and personnel (perfor- }\end{array}$ & Unclear risk & $\begin{array}{l}\text { Quote: "This was a 6-day, double-blind, placebo-controlled pilot study with } \\
\text { daily follow-up assessments" (p. 869) }\end{array}$ \\
\hline All outcomes & & $\begin{array}{l}\text { Comment: although study was stated to be double-blind, there was no de- } \\
\text { scription of how blinding of personnel or participants took place. }\end{array}$ \\
\hline
\end{tabular}

\begin{tabular}{|c|c|c|}
\hline $\begin{array}{l}\text { Blinding of outcome as- } \\
\text { sessment (detection bias) }\end{array}$ & Unclear risk & $\begin{array}{l}\text { Comment: although study was stated to be double-blind, there was no de- } \\
\text { scription of how blinding of participants took place. }\end{array}$ \\
\hline
\end{tabular}
comes

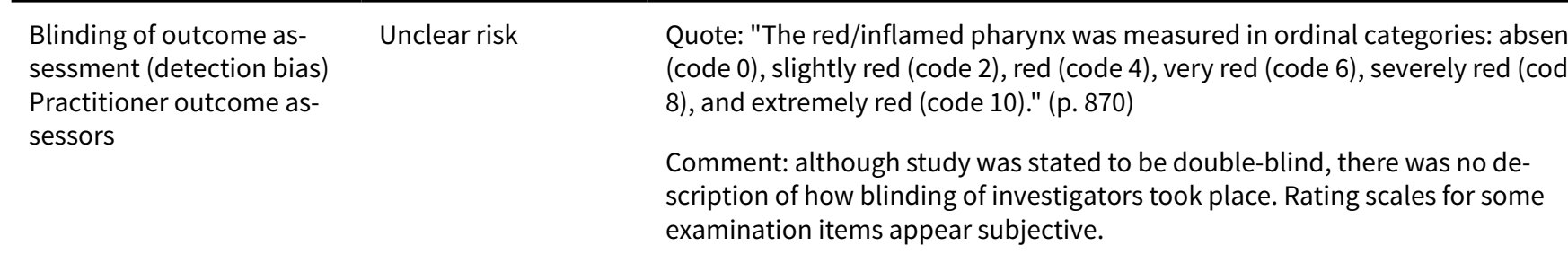

Incomplete outcome data Low risk No loss to follow-up, data provided for all 30 enrolled participants
(attrition bias)

All outcomes

\begin{tabular}{|c|c|c|}
\hline $\begin{array}{l}\text { Selective reporting (re- } \\
\text { porting bias) }\end{array}$ & Unclear risk & $\begin{array}{l}\text { All outcomes described in methods are reported in results, however inade- } \\
\text { quate raw data provided. Only means of rating scales reported in text, not pre- } \\
\text { sented in a table with components of severity that contributed to the final } \\
\text { mean score. }\end{array}$ \\
\hline
\end{tabular}

Other bias Unclear risk Positive outcomes emphasised in the discussion, but lack of clinically significant findings despite statistical significance were played down because of the use of reporting means of rating scales rather than any dichotomous outcomes.
Study is of small sample size, allocation concealment poorly described; un- equal groups at beginning regarding severity of disease. The duration of pain/ symptoms at baseline is not reported, which is vital information when study- ing a self limiting condition.

Despite these issues, the discussion claims "Analysis between groups showed that the homeopathic complex outperformed placebo, with a large effect size. The associated symptom of pain on swallowing also significantly improved over time, while the placebo group did not". (p. 872)

Intervention stated to be well tolerated with no adverse events, however very small sample size with population from a single source and demographic group.

Children were self administering medication sublingually with aid of a leaflet no mechanism described to ensure correct administration technique or adherence.

Methods RCT, double-blinded, controlled study, 3 months treatment


Recruitment method: participants were referred to tertiary healthcare hospital by primary care paediatricians who had diagnosed otitis media with effusion, using simple otoscopy.

Withdrawals and exclusions:

- 2 participants failed/abandoned prior to commencement;

- 3/45 homeopathy participants withdrew (1 voluntary withdrawal, 1 due to adverse effects, 1 due to surgical procedure); and

- 6/50 placebo participants withdrew (1 voluntary withdrawal, 4 due to adverse effects, 1 due to surgical procedure).

Age range: 2 months to 12 years

Gender: $63 \%$ male in experimental; $64 \%$ male in placebo

Eligibility criteria:

Inclusion criteria: otitis media with effusion diagnosed by pneumatic otoscopy examination

Exclusion criteria: neonatal screening fail, receptive language disorder, neuro-sensorial hearing loss, autism, craniofacial abnormalities, Down syndrome; middle or internal ear malformation, ciliary motility disorders, cholesteatoma, acute mastoiditis, acute otitis media; recent vaccination (<30 days); obstructive sleep apnoea; tympanic perforation; tympanostomy tubes or adenoidectomy; lactose or glucose intolerance; treating asthma; corticosteroid, antihistamine, or mucolytic therapy

Homeopathic product: for 3 months children received 2 homeopathic treatments: homeopathic treatment A (Agraphis nutans $5 \mathrm{CH}$ and Thuya occidentalis $5 \mathrm{CH}$ ) at a dosage of 5 granules of each, once a day, preferably in the evening, and homeopathic treatment $\mathrm{B}$ (Kalium muriaticum $9 \mathrm{CH}$ and Arsenicum iodatum $9 \mathrm{CH}$ ) at a dosage of 5 granules, twice a day.

Placebo: the placebo group received placebo treatment instead of the homeopathy treatment. Boiron Laboratories prepared the homeopathy and placebo treatments, following European Good Manufacturing Practice (EGMP) requirements.

Both groups received aerosol therapy (model Apex Mini-Nebe $230 \mathrm{~V}-50 \mathrm{Hrz} 0.6 \mathrm{~A}$ ) consisting of 1 session every 24 hours for 20 days of 1 vial ambroxol hydrochloride $(7.5 \mathrm{mg} / \mathrm{mL}), 1$ vial budesonide $(0.25 \mathrm{mg} /$ $\mathrm{mL}$ suspension), and $2 \mathrm{~mL}$ physiological saline for 45 days.

Outcomes Outcomes:

Presence of OME versus absence of OME (assessed via PNO)

- Recovery (PNO changed from negative in first visit to positive in third visit)

- Recurrence (after positive PNO in second visit, changed to negative PNO in third visit)

Acute otitis media

Eardrum perforation

Mastoiditis

Adverse events

Note that occurrence of AOM is the only outcome relevant to this review of ARTI.

\section{Risk of bias}


Pedrero-Escalas 2016 (Continued)

\section{Bias Authors' judgement Support for judgement}

Random sequence genera- Low risk tion (selection bias)
Quote: "A double blind, placebo-controlled, and randomised parallel group study" (p. 218); "Treatment assignment was set up with a permuted-block randomisation algorithm and a masking plan was followed to guarantee the double-blindness." (p. 218)

Comment: robust method of random sequence generation used.

Note differences in baseline demographics. "The groups were homogeneous at baseline except for the variable 'school absenteeism for otological causes' and 'the number of Acute otitis media in the previous year.'" (p. 219)

"Therefore a univariate and multivariate regression analysis was performed for baseline adjustment and to ascertain whether this disparity affected the results of the study. The odds ratio (OR) and the adjusted OR were obtained for each of these 2 variables, and it was found that both OR were of the same magnitude and were not confounding factors." Note: no data provided for the above statement.

\begin{tabular}{ll}
\hline $\begin{array}{l}\text { Allocation concealment } \\
\text { (selection bias) }\end{array}$ & Low risk \\
& $\begin{array}{l}\text { Comment: no statement assuring similarity in appearance/taste/smell of } \\
\text { homeopathic treatment and placebo treatment. However, methods state } \\
\text { there was a masking plan. }\end{array}$
\end{tabular}

Blinding of participants Low risk Likely to be adequately double-blinded given reference to a masking plan
and personnel (performance bias)

All outcomes

\begin{tabular}{|c|c|c|}
\hline $\begin{array}{l}\text { Blinding of outcome as- } \\
\text { sessment (detection bias) } \\
\text { Patient reported out- } \\
\text { comes }\end{array}$ & Low risk & Likely to be adequately double-blinded given reference to a masking plan \\
\hline $\begin{array}{l}\text { Blinding of outcome as- } \\
\text { sessment (detection bias) } \\
\text { Practitioner outcome as- } \\
\text { sessors }\end{array}$ & Low risk & $\begin{array}{l}\text { Quote: "Tympanometry examination was performed in the three visits to sup- } \\
\text { port the diagnosis of PNO." "The patient's follow-up was always performed by } \\
\text { the same clinician who had included the patient in the study." "A masking plan } \\
\text { was followed to guarantee the double-blindness." (p. 219) }\end{array}$ \\
\hline & & Comment: likely to be adequately double-blinded \\
\hline
\end{tabular}

Incomplete outcome data Low risk

Withdrawal numbers were low, and all were explained.

(attrition bias)

All outcomes

Selective reporting (re- Low risk porting bias)

Quote: "There were no changes to the trial design before starting recruitment that could have affected the trial quality."(p. 218)

Comment: low risk of reporting bias, all outcomes described in methods are reported in results.

Other bias Low risk


Sinha 2012

\begin{tabular}{ll}
\hline Methods & Randomised, placebo-controlled, parallel-group pilot study, 11 months' duration \\
\hline Participants & Setting: the General Paediatric Clinic of the Regional Research Institute of Homeopathy in Jaipur, India \\
Participants: $80 ; 40$ randomised to homeopathy, 40 to conventional treatment \\
Recruitment method: clinic patients \\
Withdrawals and exclusions: 2 in homeopathy group due to lack of follow-up. 1 excluded from conven- \\
tional treatment group due to convulsions. \\
Age range: 2 to 6 years \\
Gender: $50 \%$ female \\
Eligibility criteria: \\
Inclusion criteria: earache of no more than 36 hours' duration; tympanic membrane bulging with loss \\
of landmarks \\
$\begin{array}{l}\text { Exclusion criteria: children having any discharge or history of discharge from ear; history of convul- } \\
\text { sions; subperiosteal abscess of mastoid; grossly deviated nasal septum; suspected enlarged adenoids } \\
\text { (persistent nasal discharge, snoring, history of tonsillar hypertrophy); OME; on antibiotics in the past } 7 \\
\text { days or on corticosteroid therapy; suffering from any systemic disease }\end{array}$ \\
\hline
\end{tabular}

Interventions Homeopathy group: children in homeopathy group were prescribed appropriate homeopathic medicinal products in 50 millesimal (LM) potencies. Medicine was repeated 2 to 6 hourly depending upon the severity of child's signs/symptoms.

"Repertorisation was done on the basis of totality of symptoms by using CARA software. After repertorisation, medicine was selected on the basis of Homeopathic Materia Medica."

The potency and the identity of the medicine was changed according to the outcome of the first prescription. A maximum of 2 changes in prescription were permitted.

Medicines prescribed were: Arsenicum album (1), Calcarea carbonica (1), Chamomilla (4), Cina (1) Hepar sulphuratum (1) Lycophodium clavatum (3) Mercurius solubilis (7) Pulsatilla nigricans (14) Silicea (6) sulphur (2).

Conventional treatment group: observation for 3 days (and treatment with antipyretics, anti-inflammatories). Then prescription of antibiotics if less than 50\% improvement on AOM-SOS and tympanic membrane scales. Antibiotics prescribed were azithromycin (17 children) and amoxicillin (22 children).

Outcomes Change of symptoms (0 to 21 days)

Time to cure using AOM-SOS scale plus tympanic membrane scale

Signs on tympanic membrane exam

Notes No mention of any funding sources, no conflict of interest statement available

\section{Risk of bias}

\begin{tabular}{lll}
\hline Bias & Authors' judgement & Support for judgement \\
\hline $\begin{array}{ll}\text { Random sequence genera- } \\
\text { tion (selection bias) }\end{array}$ & Low risk & $\begin{array}{l}\text { Quote: “Randomization was done by a computer generated random number } \\
\text { list to receive either of the interventions" (p.7). "The participant's enrolment } \\
\text { numbers were used for the purpose of randomisation." (p. 7) }\end{array}$ \\
& $\begin{array}{l}\text { Comment: use of random number generator suggests robust random se- } \\
\text { quence generation. }\end{array}$
\end{tabular}


Sinha 2012 (Continued)

Allocation concealment (selection bias)
Unclear risk

Quote: "The parents/guardian and the research personnel remained unaware of the participant's group assigned throughout the study."

Comment: specific allocation concealment such as coded bottles not described.

\begin{tabular}{|c|c|c|}
\hline $\begin{array}{l}\text { Blinding of participants } \\
\text { and personnel (perfor- }\end{array}$ & High risk & $\begin{array}{l}\text { Quote: "The parents/guardian and the research personnel remained unaware } \\
\text { of the participant's group assigned throughout the study." (p. 7) }\end{array}$ \\
\hline All outcomes & & $\begin{array}{l}\text { Comment: does not give details of blinding, e.g. double-dummy technique or } \\
\text { method of making treatments indistinguishable to participants. In conven- } \\
\text { tional treatment group, children were given symptomatic treatment with anal- } \\
\text { gesic, anti-inflammatory, and antipyretics, which are likely to be identifiable } \\
\text { as separate from homeopathy (there would need to be a separate protocol for } \\
\text { giving these medications as they are not safe to repeat } 2 \text { to } 6 \text { hourly depending } \\
\text { upon the severity of child's signs/symptoms). Therefore high risk of homeopa- } \\
\text { thy and conventional treatment groups being identifiable to participants. }\end{array}$ \\
\hline
\end{tabular}

Blinding of outcome as- High risk sessment (detection bias) Patient reported outcomes
Quote: "To assess the severity of disease, response of each patient was noted by the investigator and ENT Specialist as per the information gathered from parents/guardians on AOM-SOS scale and with the help of Tympanic Membrane Examination scale on third, seventh, tenth and 21st day respectively." (p. 8)

Comment: the 2 treatment groups' interventions were quite different, e.g. conventional analgesics and antipyretics versus homeopathy regimen. In the absence of clear documentation as to how these regimens were made indistinguishable, blinding of outcome assessment for parent-reported outcomes cannot be relied upon.
Blinding of outcome as- Unclear risk sessment (detection bias) Practitioner outcome assessors
Quote: "In both the groups, patients were followed up in person on third, seventh, tenth and 21st day assessed with the AOM-SOS scale and Tympanic Membrane Examination scale." "In homeopathy group, all follow-ups were done as per the guidelines laid down for the second prescription in the protocol, i.e. increasing the potency and change of medicine depending on the outcome of the first prescription." (p. 8)

Comment: does not give any detail of blinding or if ear, nose, and throat specialists performing tympanic membrane exams were blinded. The above quote suggests that practitioner may be aware of group, as for homeopathy participants they were adjusting the prescription.

\section{Incomplete outcome data Low risk} (attrition bias)

All outcomes
2 children in homeopathy group did not attend last 2 follow-ups, but were still included in analysis (last observation carried forward).

One child in conventional treatment group was excluded from study due to hospitalisation with convulsions.

Comment: minimal dropouts, which are accounted for 
Sinha 2012 (Continued)

appears that antibiotic commencement at the 3-day mark occurred only for the conventional group, not the homeopathy group.

In the homeopathy group, only 4 children were cured at day 3 , and the mean symptom score for homeopathy participants was reduced by less than $50 \%$ (from 14.28 to 8.18 ), making it impossible that all homeopathy group participants had a $50 \%$ improvement in the first 3 days of treatment. However, no homeopathy participants were commenced on antibiotics. The study makes much of the fact that "In Homeopathy group antibiotics were not required for any case." (p. 11).

It seems that the total symptom score was a sum of the AOM-SOS scale and the Tympanic Membrane Examination scale, with a maximum score of 22 . We suspect that the criteria for commencing antibiotics was a score above 11 , which is not actually the same as less than $50 \%$ reduction in symptoms score for each child. The placebo group had a higher mean symptom score at the commencement of the study, so a larger percentage would be above a fixed numerical score, even with an identical amount of symptomatic improvement. This is a major bias within the study design.

Siqueira 2016

Methods Double-blinded RCT, 30 days' treatment with 1-year duration of follow-up

Participants

Setting: children belonging to families from low economic and social classes who do not have access to the private health system or additional health care, or both, at Petropolis, Rio de Janeiro, Brazil

Participants: 600; 200 randomised to InfluBio, 200 to homeopathic complex, and 200 to placebo

Recruitment method: Brazilian Public Health System in Petropolis (BPHSP), Rio de Janeiro

Withdrawals and exclusions:

- InfluBio: 55 lost to follow-up, 145 analysed

- Homeopathic complex: 51 lost to follow-up, 149 analysed

- Placebo: 49 lost to follow-up, 151 analysed

Age range: 1 to 5 years

Gender: $42.3 \%$ female for homeopathic complex, $48.3 \%$ female for placebo, and $42.8 \%$ female for InfluBio for those who completed the study

Eligibility criteria:

Inclusion criteria: no apparent disease

Exclusion criteria: history of wheezing and asthma, HIV infection, immunodeficiency; type I diabetes, malignancies, corticosteroid treatment; congenital anomalies, liver disease, history of at least 1 episode of respiratory infection in the 30 days prior to the beginning of the study

Each test solution was administered by the child's tutor twice a day, for 30 days, in April. The dosage applied was 1 drop/year of age; the sample had been previously diluted in a tablespoon of filtered water.

Homeopathic product 1: InfluBio was prepared from purified influenza virus sample A/Victoria/3/75 (H3N2), provided by the Virus Surface Structure Laboratory at the Federal University of Rio de Janeiro, Brazil. 
Siqueira 2016 (Continued)

Briefly, $1 \mathrm{~mL}$ of this infectious virus suspension at $0.240 \mathrm{HAU} / 25 \mathrm{~mL}$ was diluted in $9 \mathrm{~mL}$ of sterile distilled water in order to make the first dilution (1:10 dilution) following Brazilian Homeopathic Pharmacopea.

This 1:10 sample was submitted to 100 mechanical succussions for $33 \mathrm{~s}$ (approximately $3 \mathrm{~Hz}$ ), originating the first potency, which was named decimal $\left(1 \mathrm{dH}, 10 \_1\right)$. This procedure was successively repeated to obtain biotherapy $30 \mathrm{dH}$ (10_30), which was denominated InfluBio.

Homeopathic product 2: a homeopathic complex composed of bacterial strains (Streptococcus and Staphylococcus) and inactivated influenza virus, prepared following the same homeopathic procedures as above until the $30 \mathrm{dH}$ potency, which corresponds to a dilution of 10_30. This medicine is used routinely in patients in the BPHSP for the prophylaxis and treatment of diseases of the upper respiratory tract.

Placebo: the placebo was the biotherapy vehicle, i.e. ethanol $30 \%$ (volume per volume), which is commonly employed as a vehicle for homeopathic medicines.

Outcomes Number of episodes of influenza and ARTI in 1 year (2009 to 2010)

To characterise the number of influenza and ARTI episodes, at least 2 of the following symptoms had to be present: fever (temperature $>37.8^{\circ} \mathrm{C}$ ), runny nose, prostration, myalgia, headache, and cough.

Duration, in days, of influenza and ARTI symptoms (not reported in results)

Adverse events (not reported in results)

Notes

Partly sponsored by FAPERJ and Instituto Roberto Costa, and Coorenacao de Aperfeicoamento de Pessoal de Nival Superior granted the author a PhD scholarship.

\section{Risk of bias}

Bias Authors' judgement Support for judgement

Random sequence genera- Low risk tion (selection bias)

Quote: "The children were randomised followed a numbered list to three intervention groups (Homeopathic Complex, Placebo, and InfluBio), with 200 patients each (1:1:1), block sizes of 6, using Epi Info software" (p. 73)

Comment: robust method of allocation concealment was likely used, however meaning of "randomised following a numbered list" is unclear.

Allocation concealment Low risk
(selection bias)

Quote: "Following this list, and also to guarantee concealment, independent pharmacists dispensed the test solutions to the health agents who gave the solutions to child's parent or guardian. During the study, neither the families nor the health agents and doctors knew which solution was being given to each child. To this effect, we created a random code of letters (A, B, C) to identify the solutions, which was kept under the custody of the general coordinator of the research." (p. 73)

"All solutions were identical in appearance and taste." (p. 74)

Comment: robust method of allocation concealment used.

Blinding of participants Low risk and personnel (perfor-

mance bias)

All outcomes
Quote: "The following groups were blinded: the patients and their guardians; physicians; health agents; and the researchers who performed the data analysis. The physicians $(n=300)$ and health agents $(n=400)$ were trained according to an established protocol, which was identical to each child." (p. 73)

Comment: robust method of blinding used.

\begin{tabular}{|c|c|c|}
\hline $\begin{array}{l}\text { Blinding of outcome as- } \\
\text { sessment (detection bias) } \\
\text { Patient reported out- } \\
\text { comes }\end{array}$ & Low risk & $\begin{array}{l}\text { Quote: "The following groups were blinded: the patients and their guardians; } \\
\text { physicians; health agents; and the researchers who performed the data analy- } \\
\text { sis. The physicians }(n=300) \text { and health agents }(n=400) \text { were trained according } \\
\text { to an established protocol, which was identical to each child." (p. } 73 \text { ) }\end{array}$ \\
\hline
\end{tabular}


Comment: robust method of blinding used.

Blinding of outcome as- Low risk sessment (detection bias) Practitioner outcome assessors
Quote: "The following groups were blinded: the patients and their guardians; physicians; health agents; and the researchers who performed the data analysis. The physicians $(n=300)$ and health agents $(n=400)$ were trained according to an established protocol, which was identical to each child." (p. 73)

Comment: robust method of blinding used.
Incomplete outcome data Unclear risk (attrition bias)

All outcomes
Quote: "Of the 600 children selected for the study, 445 (74.17\%) children finished it and 155 (25.83\%) children were classified as dropouts, since they quit during the research period. The main reasons for this loss were change of residence or adhesion to private health insurance plans." (p. 74)

Comment: Reasons for loss to follow-up mentioned in a general sense, but no specific numbers for each group. Note that baseline demographic data are only provided for the 445 children who completed the study, not the 145 dropouts.

Intention-to-treat analysis planned for in methods, but those lost to follow-up were not part of the study flowchart (Figure 1); were not included in the baseline characteristics (Table 1); were not included in Table 2 analysis of number of flu and ARTIs symptomatic episodes in the first year postintervention; and the key outcome data in Figure 2 are presented in such a way that it is unclear if ITT analysis was actually used.

Selective reporting (re- High risk
porting bias)
Results focus on arbitrary cut-off of 3 or more flu and ARTI episodes for comparison between groups, a benchmark that was not set prospectively in the methods. Results do not provide mean numbers of ARTIs, however these can be approximately calculated from the data in Table 2 .

Outcomes listed in methods but not reported in results:

- Duration, in days, of flu and ARTI symptoms

- Adverse events

Regarding adverse events, the results state "It is important to point out that no discomfort or death induced by the use of test solutions were reported by the children's families during the period of this clinical trial." (p. 75), however no data on adverse events are provided.

Results include mention of increase in ARTI episodes in first 2 months in the placebo group, but no data presented, and this was not mentioned in the methods.

Analysis more difficult given combination of influenza and URTIs into 1 study. Use of diagnostic criteria (at least 2 of the following symptoms had to be present: fever (temperature $>37.8^{\circ} \mathrm{C}$ ), runny nose, prostration, myalgia, headache, and cough) does not specifically select for episodes of influenza or URTI.

Very low total number of ARTIs during the 12-month follow-up period (compared to the year before and to known incidence data for childhood ARTI). This suggests the monthly assessments to check for URTI may not have picked up all cases.

Declaration: none of the authors have a conflict of interest. 
Steinsbekk 2005a

\begin{tabular}{|c|c|}
\hline Methods & Double-blind, randomised, parallel-group, placebo-controlled design, for prevention of URTIs \\
\hline \multirow[t]{9}{*}{ Participants } & $\begin{array}{l}\text { Setting: Trondheim, Norway. Participants were recruited via a database search of presentations to ca- } \\
\text { sualty department at a university hospital. }\end{array}$ \\
\hline & $\begin{array}{l}\text { Participants: } 251 \text { randomised, } 199 \text { started the trial; } 97 \text { randomised to the homeopathy group and } 102 \\
\text { to the placebo group }\end{array}$ \\
\hline & $\begin{array}{l}\text { Recruitment method: patients were sent a letter with the informed consent form included for the par- } \\
\text { ents to sign and return if they agreed to participate. }\end{array}$ \\
\hline & $\begin{array}{l}\text { Withdrawals and exclusions: all children who started treatment were included in analysis. Those who } \\
\text { did not begin treatment were accounted for. }\end{array}$ \\
\hline & Age range: 0 to 10 years \\
\hline & Gender: $45 \%$ female \\
\hline & Eligibility criteria: \\
\hline & $\begin{array}{l}\text { Inclusion criteria: children < } 10 \text { years with a previous diagnosis of URTI by a medical doctor (ear pain, } \\
\text { acute or chronic otitis media, streptococcal infection, sinusitis, tonsillitis) }\end{array}$ \\
\hline & $\begin{array}{l}\text { Exclusion criteria: concomitant serious disease or daily use of medicines such as antibiotics, corticos- } \\
\text { teroids (except in inhalers), and cytotoxic agents, and use of homeopathic medicines in the } 3 \text { months } \\
\text { prior to inclusion }\end{array}$ \\
\hline \multirow[t]{4}{*}{ Interventions } & C30 potency of either Calcarea carbonica, Pulsatilla, or sulphur \\
\hline & $\begin{array}{l}\text { Children were assigned } 1 \text { of these medicines based on the parent reading an information sheet and an- } \\
\text { swering } 2 \text { questions related to their child's symptoms. }\end{array}$ \\
\hline & $\begin{array}{l}\text { Instructions: } 2 \text { pills } 2 \text { days per week for } 12 \text { weeks, with } 1 \text { pill up to once every hour if child had an acute } \\
\text { episode of URTI }\end{array}$ \\
\hline & $\begin{array}{l}\text { "The placebos were lactose pills and indistinguishable from the homeopathic medicines in package, } \\
\text { look, taste and smell." }\end{array}$ \\
\hline
\end{tabular}

Outcomes $\quad$ Median daily symptom score, days with URTI, antibiotic use, analgesic use, days off work for parents,
adverse events

Notes Sources of support: Norwegian Research Council

\section{Risk of bias}

\begin{tabular}{lll}
\hline Bias & Authors' judgement & Support for judgement \\
\hline $\begin{array}{l}\text { Random sequence genera- } \\
\text { tion (selection bias) }\end{array}$ & Low risk & $\begin{array}{l}\text { Quote: "Randomization was done by an independent trial service office that } \\
\text { provided a randomisation list." (p. 449) } \\
\text { Comment: robust method of random sequence generation }\end{array}$ \\
\hline $\begin{array}{l}\text { Allocation concealment } \\
\text { (selection bias) }\end{array}$ & Low risk & $\begin{array}{l}\text { Quote: "Each box consisted of bottles numbered consecutively, with placebo } \\
\text { and homeopathic medicines allocated according to the randomisation list." (p. } \\
450)\end{array}$ \\
\hline $\begin{array}{l}\text { Blinding of participants } \\
\text { and personnel (perfor- } \\
\text { mance bias) }\end{array}$ & Low risk & $\begin{array}{l}\text { Comment: robust method of allocation concealment } \\
\text { opathic medicines in package, look, taste and smell." (p. 450) Comment: ade- } \\
\text { quate blinding of participants }\end{array}$ \\
\hline
\end{tabular}


Steinsbekk 2005a (Continued)

All outcomes

\begin{tabular}{|c|c|c|}
\hline $\begin{array}{l}\text { Blinding of outcome as- } \\
\text { sessment (detection bias) }\end{array}$ & Low risk & $\begin{array}{l}\text { Quote: "Daily patient diaries were used as the main outcome measure and } \\
\text { were completed by the child's parents." (p. 450) }\end{array}$ \\
\hline $\begin{array}{l}\text { Patient reported out- } \\
\text { comes }\end{array}$ & & $\begin{array}{l}\text { Comment: parents completed the daily symptom diary for their children and } \\
\text { appear to be adequately blinded. }\end{array}$ \\
\hline
\end{tabular}

\begin{tabular}{|c|c|c|}
\hline $\begin{array}{l}\text { Blinding of outcome as- } \\
\text { sessment (detection bias) }\end{array}$ & Low risk & $\begin{array}{l}\text { Quote: "A double-blind randomised parallel group placebo controlled trial" ( } \mathrm{p} \text {. } \\
\text { 448) }\end{array}$ \\
\hline $\begin{array}{l}\text { Practitioner outcome as- } \\
\text { sessors }\end{array}$ & & $\begin{array}{l}\text { Comment: practitioner blinding less important as outcomes were assessed by } \\
\text { parents. Robust methods above suggest detection bias unlikely. }\end{array}$ \\
\hline
\end{tabular}

Incomplete outcome data Low risk (attrition bias)

All outcomes
Quote: "Analysis Confirmatory testing of the main outcome measure is based on intention to treat, with all patients who started the study included in the analysis." (p. 451)

29/126 randomised children in homeopathy group and 23/125 in placebo group did not start the study. Reasons for not starting: too busy, other treatment, chance of placebo, been healthy, no reason.

16/97 in homeopathy group and 18/102 in placebo group had missing data for part of study. Reasons given: moved, on holiday, on other treatment, too busy, no reason.

Comment: similar numbers and reasons for participants not starting and for incomplete data. All participants who started the study were included in data analysis.

Selective reporting (re- Low risk All outcome measures listed in methods reported in results.
porting bias)

Other bias Low risk Well-designed, well-reported study

ARTI: acute respiratory infection

AOM: acute otitis media

AOM-SOS: Acute Otitis Media Severity of Symptoms

HAU: haemagglutinating unit

ITT: intention-to-treat

OME: otitis media with effusion

OR: odds ratio

PNO: pneumatic otoscopy

RCT: randomised controlled trial

URTI: upper respiratory infection

Characteristics of excluded studies [ordered by study ID]

\begin{tabular}{ll}
\hline Study & Reason for exclusion \\
\hline Antonello 2012 & $\begin{array}{l}\text { Not randomised: "Two therapeutic choices have been proposed to the family. On the basis of per- } \\
\text { sonal beliefs, the PRM treatment or the conventional one has been chosen." }\end{array}$ \\
\hline Attena 1995 & Study on adults \\
\hline Beghi 2016 & Retrospective study, not a trial \\
\hline D'Souza 2012 & Single-blind study
\end{tabular}




\begin{tabular}{|c|c|}
\hline Study & Reason for exclusion \\
\hline Ferley 1987 & Study on all age groups range 5 to 95 years, mean age 36.5 years \\
\hline Friese 2001 & $\begin{array}{l}\text { Study assessed efficacy of homeopathic treatment on adenoid vegetations, which is not an acute } \\
\text { respiratory tract infection. }\end{array}$ \\
\hline Harrison 1999 & Study was non-blinded. \\
\hline Jong 2016 & $\begin{array}{l}\text { Study was non-blinded. Compared homeopathy versus homeopathy with no placebo or conven- } \\
\text { tional treatment group. }\end{array}$ \\
\hline Lasfargues 1983 & $\begin{array}{l}\text { Intervention was vitamin A plus, L-cystine, saccharomyces and sulphur (commercial product 'Sola- } \\
\text { cy'); this is not a homeopathic remedy. }\end{array}$ \\
\hline NCT00858494 & Open-label study (trial registry only) \\
\hline Rottey 1995 & Study on adults, not children \\
\hline Salami 2008 & Intervention was sulphurous water inhalation, this is not a homeopathic remedy. \\
\hline Steinsbekk 2005b & The waiting-list control group was not considered blinded. \\
\hline Steinsbekk 2007 & Study not double-blinded. \\
\hline Taylor 2011 & Homeopathic intervention was administered via ear drops, not orally. \\
\hline Thinesse-Mallwitz 2015 & Study not double-blinded \\
\hline Torbicka 1998 & Intervention was delivered intramuscularly. Not blinded \\
\hline Van Haselen 2016 & Study not double-blinded. \\
\hline Zanasi 2014 & Study on adults \\
\hline
\end{tabular}

Characteristics of studies awaiting assessment [ordered by study ID]

\section{Furuta 2017}

\begin{tabular}{ll}
\hline Methods & Homeopathic medicinal preparation individualised to child's symptoms \\
\hline Participants & $\begin{array}{l}40 \text { children in outpatient hospital setting in Sao Paulo, Brazil, who were awaiting surgery for recur- } \\
\text { rent tonsillitis }\end{array}$ \\
\hline Interventions & $\begin{array}{l}20 \text { children administered individualised 30C homeopathic preparations based on symptoms and } \\
\text { signs, as a single dose: daily } 6 \mathrm{cH} \text { dose of Baryta carbonica and daily } 12 \mathrm{cH} \text { preparation based on } \\
\text { Streptococcus, Staphylococcus, Haemophilus influenzae and tonsil for } 4 \text { months. } 20 \text { children admin- } \\
\text { istered identical placebo. }\end{array}$ \\
\hline Outcomes & Episode of acute tonsillitis \\
\hline Notes & $25 \%$ loss to follow-up in the placebo group \\
\hline
\end{tabular}


Niederle 2001

Methods

Participants

Interventions

\section{Outcomes}

Notes

Study published in German.

Characteristics of ongoing studies [ordered by study ID]

\section{CTRI/2014/06/004673}

Trial name or title
Double blind, randomised placebo control study to evaluate efficacy and safety of EMTACT, a homeopathic drug in the management of recurrent upper and lower respiratory tract infections

Methods

NB: unpublished trial - all information from clinical trial registry record

Randomised, parallel-group, placebo-controlled trial of homeopathy for recurrent upper and lower respiratory tract infections

Computer-generated randomisation

Method of allocation concealment: central

Participant, investigator, and outcome assessor blinded.

\section{Participants}

Setting: India. 2 sites of study listed: Bhiwandi Homeopathic Integrated Medical Practitioners (BHIMPA) and Life Force research projects

No. of participants: target sample size 150 , unclear if this number achieved

Recruitment method: not stated

Withdrawals and exclusions: not stated

Age range: 3 to 70 years

Gender: both male and female

Eligibility criteria:

Inclusion criteria

- Having episodes of recurrent URTI or LRTI or both, at least 4 times in previous 6 months, for at least 1 day at a time

- At least 1 symptom from at least 2 of the location group symptoms, such as nasal symptoms (sneezing, running nose, nose block), throat symptoms (sore throat), bronchial symptoms (cough, wheezing), head and sinus symptoms (headache, face-ache), general symptoms (fever, fatigue, low appetite)

- Willing to refrain from taking nasal decongestants, antihistamines, or cough/cold preparations, antibiotics, and homeopathic medicines during the trial period, unless symptoms are severe

Exclusion criteria

- Ongoing treatment for tuberculosis or untreated tuberculosis (to rule out by full blood count, ESR, chest X-ray)

- Any clinically significant medical condition or abnormality 
- Homeopathic treatment for any chronic disease within 1 month

- Immunocompromised patient

- Children who are scheduled to receive any other investigational drug during the course of the study

Interventions

Intervention: homeopathic drug EMTACT, 30c potency, orally 6 pills 3 times a day for 6 months

Comparator agent: placebo, size 30 pills, orally 6 pills 3 times a day for 6 months

Outcomes All evaluated at 6-month time point.

Frequency of attacks: to evaluate the efficacy of potentised preparation EMTACT 30c potency by measuring the reduction in frequency of attacks of recurrent upper and lower respiratory tract infections

Improvement in appetite

Increase in weight

Efficacy in terms of symptoms severity, including nasal symptoms (sneezing, running nose, nose block), throat symptoms (sore throat), bronchial symptoms (cough, wheezing), head and sinus symptoms (headache, face-ache), general symptoms (fever, fatigue, low appetite), using questionnaire/clinical symptomatic relief from baseline

Efficacy in terms of duration of symptoms

Evaluation of health economics parameters such as children missing school and adults missing office work due to recurrent upper and lower respiratory tract infections

Safety measures (lab parameters complete blood count, ESR, chest X-ray, urine, renal function, liver function)

\begin{tabular}{ll}
\hline Starting date & 20 February 2014 \\
\hline Contact information & Dr Rajesh Shah \\
& rajesh@askdrshah.com \\
\hline Notes & $\begin{array}{l}\text { Source of monetary or material support: Homeopathy India Private Limited for Life Force research } \\
\text { projects }\end{array}$
\end{tabular}

\section{CTRI/2014/12/005294}

\section{Trial name or title}

A comparative randomised controlled trial of homoeopathy and allopathy in acute otitis media and its recurrence in children

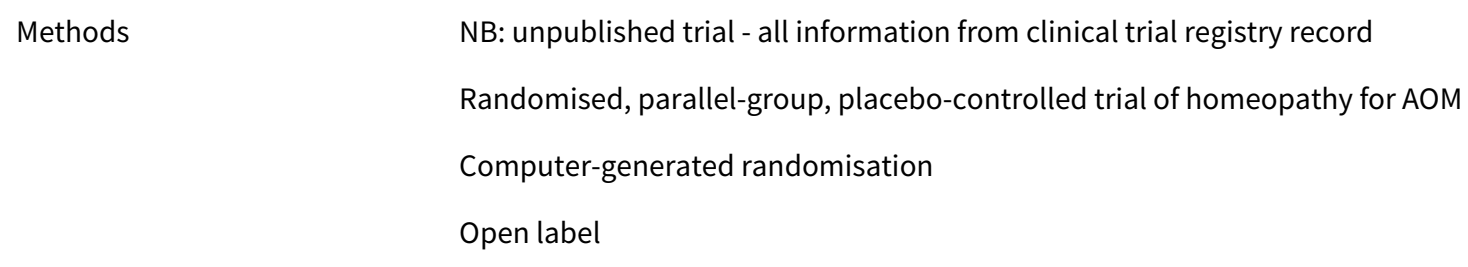

Participants
- Children of both sexes, aged 2 to 12 years
- Earache of no more than 36 hours
- Pain in ear with or without fever


- Fullness/heaviness in ear with or without signs of URTI

- History of episode of AOM with proper record of diagnosis in last 1 year

- Tympanic membrane bulging with loss of landmarks

Exclusion criteria:

- History of convulsions

- Subperiosteal abscess of mastoid

- Gross deviated nasal septum

- Any discharge or history of discharge from ear

- Suspected cases of adenoids (presenting with persistent nasal discharge, snoring, and chronic history of tonsillar hypertrophy)

- Otitis media with effusion

- Child on antibiotics in the past 7 days

- Child on steroid treatment

- Child suffering from any systemic disease

Interventions

Homeopathy: individualised homeopathic medicine shall be given in centesimal potency $(6 \mathrm{c}, 30 \mathrm{c}$, $200 \mathrm{c}$, or $1 \mathrm{M}$ potency) to be taken orally as per the prescribing totality of the case for a period 3 days. If the child does not improve by more than $50 \%$, antibiotics shall be prescribed as per the discretion of the ENT consultant, after which individualised homeopathic medicine shall be given for a period of 1 year for assessing the recurrence.

Allopathy: allopathic medicine such as antipyretics for fever analgesics, anti-allergic will be given symptomatically for 3 days as per the prescription of the ENT consultant. If the child does not improve within 3 days, antibiotics shall be administered for period of 5 days as per the discretion of the ENT consultant.

1. Changes in Tympanic Membrane Examination scale and AOM-SOS scale
2. Time to improvement in pain through FACES Pain Scale-Revised between the groups
3. Recurrence (number of episodes, intensity, duration) of AOM between the groups
4. Usage of antibiotics in both groups
5. Improvement in quality of life of children as evident from the OM- 6 Health Related Quality of Life
scale at baseline, 6 months, and 12 months

Starting date 29 August 2014

\begin{tabular}{ll}
\hline Contact information & Dr Praveen Oberai oberai.praveen@gmail.com \\
& Dr RK Manchanda dgccrh@gmail.com
\end{tabular}

\section{Notes}

AOM: acute otitis media

AOM-SOS: Acute Otitis Media Severity of Symptoms

ENT: ear, nose, and throat

ESR: erythrocyte sedimentation rate

LRTI: lower respiratory tract infection

URTI: upper respiratory tract infection

\section{DATA AND ANALYSES}


Comparison 1. Prevention studies

\begin{tabular}{|c|c|c|c|c|}
\hline Outcome or subgroup title & No. of studies & $\begin{array}{l}\text { No. of partici- } \\
\text { pants }\end{array}$ & Statistical method & Effect size \\
\hline $\begin{array}{l}1 \text { Recurrence of ARTI - individualised } \\
\text { homeopathy }\end{array}$ & 1 & & $\begin{array}{l}\text { Odds Ratio (M-H, Fixed, } \\
95 \% \mathrm{Cl})\end{array}$ & $\begin{array}{l}\text { Totals not select- } \\
\text { ed }\end{array}$ \\
\hline $\begin{array}{l}2 \text { Mean number of ARTI episodes - non- } \\
\text { individualised homeopathy }\end{array}$ & 1 & & $\begin{array}{l}\text { Mean Difference (IV, Fixed, } \\
95 \% \mathrm{CI})\end{array}$ & $\begin{array}{l}\text { Totals not select- } \\
\text { ed }\end{array}$ \\
\hline $\begin{array}{l}3 \text { Recurrence of ARTI - non-individu- } \\
\text { alised homeopathy }\end{array}$ & 2 & 695 & $\begin{array}{l}\text { Odds Ratio (M-H, Fixed, } \\
95 \% \mathrm{Cl})\end{array}$ & $1.14[0.83,1.57]$ \\
\hline $\begin{array}{l}4 \text { Days off work for parents - individu- } \\
\text { alised homeopathy }\end{array}$ & 1 & & $\begin{array}{l}\text { Odds Ratio (M-H, Random, } \\
95 \% \mathrm{Cl})\end{array}$ & $\begin{array}{l}\text { Totals not select- } \\
\text { ed }\end{array}$ \\
\hline $\begin{array}{l}5 \text { Adverse events - individualised home- } \\
\text { opathy }\end{array}$ & 1 & 199 & $\begin{array}{l}\text { Odds Ratio (M-H, Random, } \\
95 \% \mathrm{Cl})\end{array}$ & $2.51[0.75,8.42]$ \\
\hline $\begin{array}{l}6 \text { Adverse events - non-individualised } \\
\text { homeopathy }\end{array}$ & 1 & & $\begin{array}{l}\text { Odds Ratio (M-H, Fixed, } \\
95 \% \mathrm{Cl})\end{array}$ & $\begin{array}{l}\text { Totals not select- } \\
\text { ed }\end{array}$ \\
\hline $\begin{array}{l}7 \text { Need for antibiotics - individualised } \\
\text { homeopathy }\end{array}$ & 2 & 369 & $\begin{array}{l}\text { Odds Ratio (M-H, Random, } \\
95 \% \mathrm{Cl})\end{array}$ & $0.79[0.35,1.76]$ \\
\hline $\begin{array}{l}8 \text { Number of courses of antibiotics - indi- } \\
\text { vidualised homeopathy }\end{array}$ & 1 & & $\begin{array}{l}\text { Mean Difference (IV, Ran- } \\
\text { dom, } 95 \% \mathrm{CI} \text { ) }\end{array}$ & $\begin{array}{l}\text { Totals not select- } \\
\text { ed }\end{array}$ \\
\hline
\end{tabular}

Analysis 1.1. Comparison 1 Prevention studies, Outcome 1 Recurrence of ARTI - individualised homeopathy.

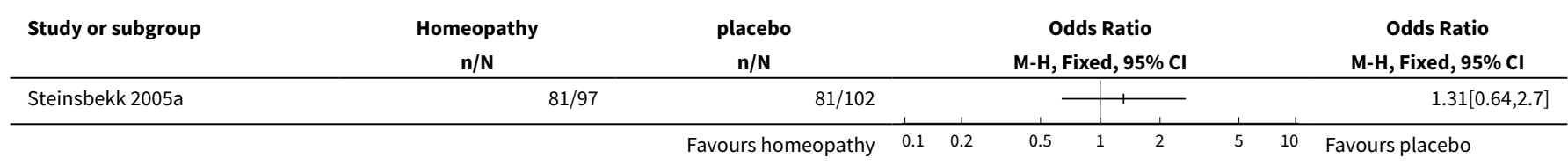

\section{Analysis 1.2. Comparison 1 Prevention studies, Outcome 2 Mean} number of ARTI episodes - non-individualised homeopathy.

\begin{tabular}{|c|c|c|c|c|c|c|c|}
\hline \multirow[t]{2}{*}{ Study or subgroup } & \multicolumn{2}{|c|}{ Homeopathy } & \multicolumn{2}{|c|}{ placebo } & \multirow{2}{*}{\multicolumn{2}{|c|}{$\begin{array}{c}\text { Mean Difference } \\
\text { Fixed, } 95 \% \mathrm{Cl}\end{array}$}} & \multirow{3}{*}{$\begin{array}{c}\begin{array}{c}\text { Mean Difference } \\
\text { Fixed, } \mathbf{9 5} \% \mathbf{~ C l}\end{array} \\
-0.47[-0.69,-0.25]\end{array}$} \\
\hline & $\mathbf{N}$ & $\operatorname{Mean}(S D)$ & $\mathbf{N}$ & $\operatorname{Mean}(S D)$ & & & \\
\hline Siqueira 2016 & 400 & $0.8(0.9)$ & 200 & $1.3(1.4)$ & + & & \\
\hline
\end{tabular}


Analysis 1.3. Comparison 1 Prevention studies, Outcome 3 Recurrence of ARTI - non-individualised homeopathy.

\begin{tabular}{|c|c|c|c|c|c|}
\hline Study or subgroup & $\begin{array}{c}\text { Homeopathy } \\
\mathrm{n} / \mathrm{N}\end{array}$ & $\begin{array}{c}\text { placebo } \\
\mathbf{n} / \mathbf{N}\end{array}$ & $\begin{array}{c}\text { Odds Ratio } \\
\text { M-H, Fixed, 95\% Cl }\end{array}$ & Weight & $\begin{array}{c}\text { Odds Ratio } \\
\text { M-H, Fixed, } 95 \% \text { CI }\end{array}$ \\
\hline Pedrero-Escalas 2016 & $10 / 45$ & $14 / 50$ & $\longrightarrow+$ & $14.58 \%$ & $0.73[0.29,1.87]$ \\
\hline Siqueira 2016 & $215 / 400$ & $98 / 200$ & & $85.42 \%$ & $1.21[0.86,1.7]$ \\
\hline Total $(95 \% \mathrm{Cl})$ & 445 & 250 & & $100 \%$ & $1.14[0.83,1.57]$ \\
\hline \multicolumn{6}{|c|}{ Total events: 225 (Homeopathy), 112 (placebo) } \\
\hline Test for overall effect: & & & & & \\
\hline
\end{tabular}

Analysis 1.4. Comparison 1 Prevention studies, Outcome 4 Days off work for parents - individualised homeopathy.

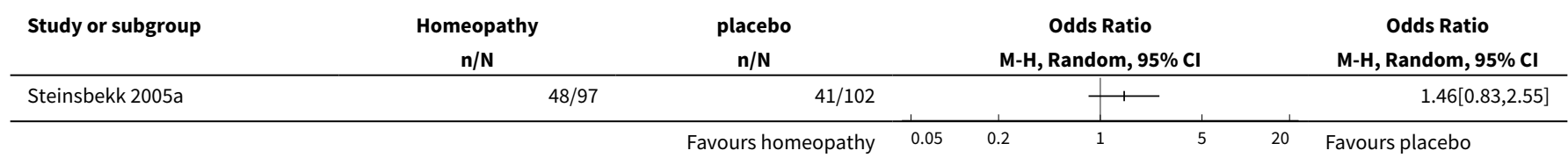

Analysis 1.5. Comparison 1 Prevention studies, Outcome 5 Adverse events - individualised homeopathy.

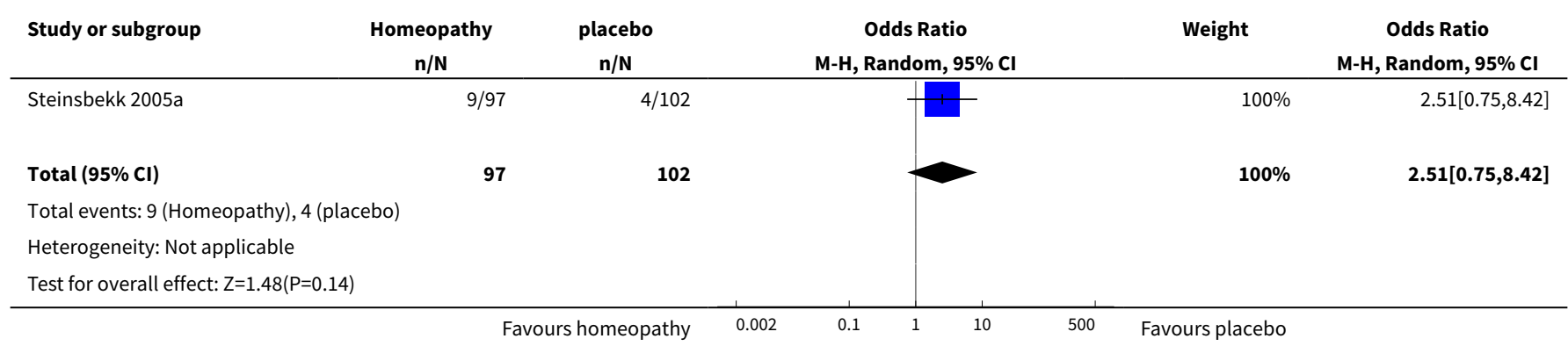

Analysis 1.6. Comparison 1 Prevention studies, Outcome 6 Adverse events - non-individualised homeopathy.

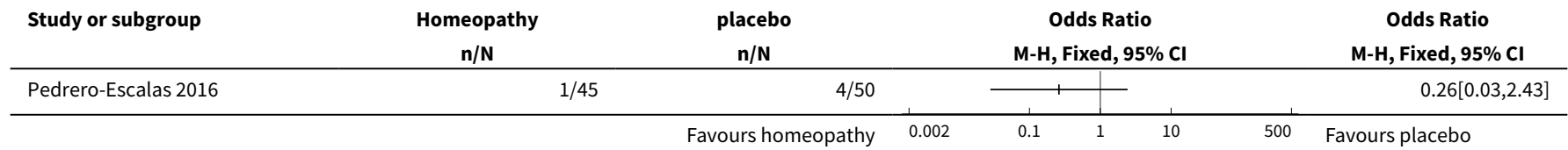

Analysis 1.7. Comparison 1 Prevention studies, Outcome 7 Need for antibiotics - individualised homeopathy.

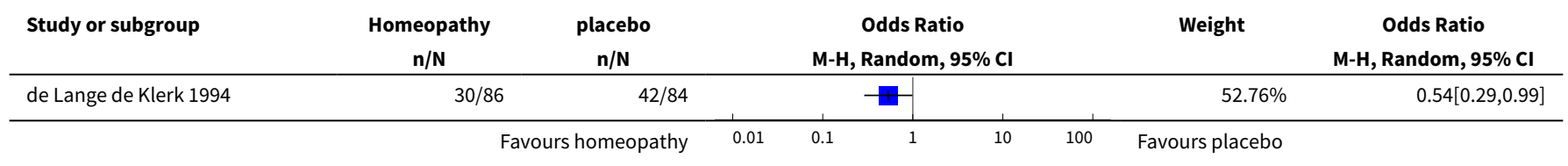




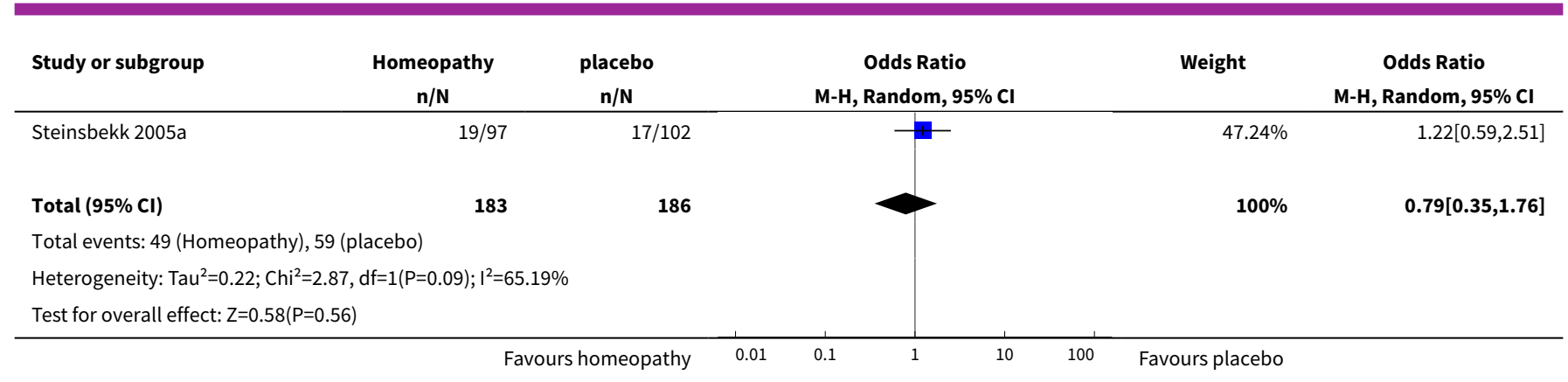

Analysis 1.8. Comparison 1 Prevention studies, Outcome 8 Number of courses of antibiotics - individualised homeopathy.

\begin{tabular}{|c|c|c|c|c|c|c|}
\hline \multirow[t]{2}{*}{ Study or subgroup } & \multicolumn{2}{|c|}{ Homeopathy } & \multicolumn{2}{|c|}{ placebo } & \multirow{2}{*}{$\begin{array}{l}\text { Mean Difference } \\
\text { Random, } 95 \% \mathrm{Cl}\end{array}$} & \multirow{2}{*}{$\begin{array}{l}\text { Mean Difference } \\
\text { Random, } 95 \% \mathrm{CI}\end{array}$} \\
\hline & $\mathbf{N}$ & Mean(SD) & $\mathbf{N}$ & $\operatorname{Mean}(S D)$ & & \\
\hline de Lange de Klerk 1994 & 86 & $0.6(1.1)$ & 84 & $0.8(1.1)$ & + & $-0.19[-0.51,0.13]$ \\
\hline
\end{tabular}

\section{Comparison 2. Treatment studies}

\begin{tabular}{lllll}
\hline Outcome or subgroup title & No. of studies & $\begin{array}{l}\text { No. of partici- } \\
\text { pants }\end{array}$ & Statistical method & Effect size \\
\hline $\begin{array}{l}1 \text { Short-term cure - individualised } \\
\text { homeopathy }\end{array}$ & 2 & 155 & $\begin{array}{l}\text { Odds Ratio (M-H, Random, } \\
95 \% \mathrm{Cl})\end{array}$ & $1.31[0.09,19.54]$ \\
\hline $\begin{array}{l}2 \text { Long-term cure - individualised } \\
\text { homeopathy }\end{array}$ & 2 & 155 & $\begin{array}{l}\text { Odds Ratio (M-H, Random, } \\
95 \% \mathrm{Cl})\end{array}$ & $0.99[0.10,9.67]$ \\
\hline $\begin{array}{l}3 \text { Adverse events - individualised } \\
\text { homeopathy }\end{array}$ & 1 & 75 & $\begin{array}{l}\text { Odds Ratio (M-H, Random, } \\
95 \% \mathrm{Cl})\end{array}$ & $0.0[0.0,0.0]$ \\
\hline $\begin{array}{l}4 \text { Adverse events - non-individualised } \\
\text { homeopathy }\end{array}$ & 1 & & $\begin{array}{l}\text { Odds Ratio (M-H, Fixed, 95\% } \\
\text { Cl) }\end{array}$ & $\begin{array}{l}\text { Totals not select- } \\
\text { ed }\end{array}$ \\
\hline
\end{tabular}

Analysis 2.1. Comparison 2 Treatment studies, Outcome 1 Short-term cure - individualised homeopathy.

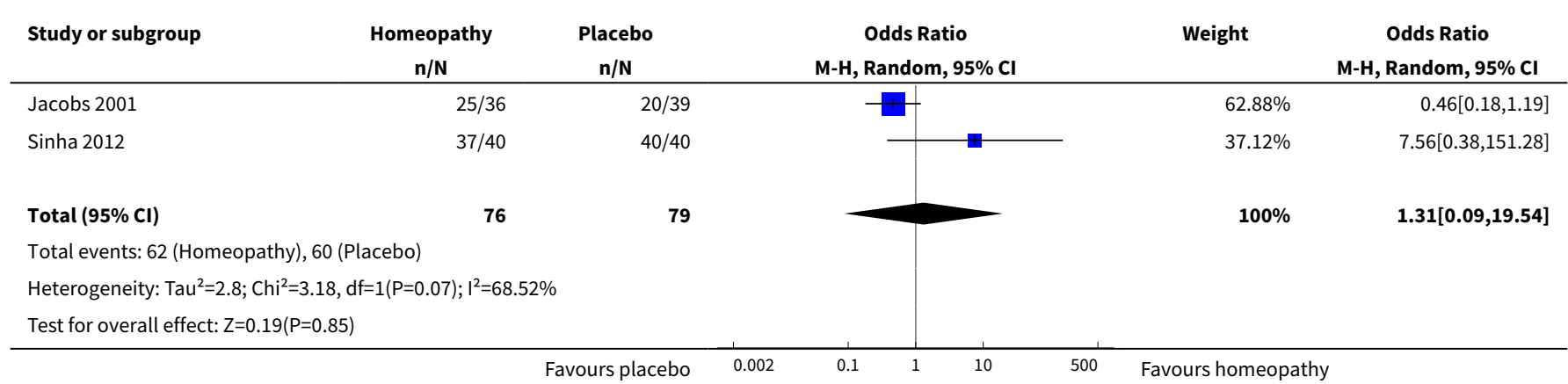


Analysis 2.2. Comparison 2 Treatment studies, Outcome 2 Long-term cure - individualised homeopathy.

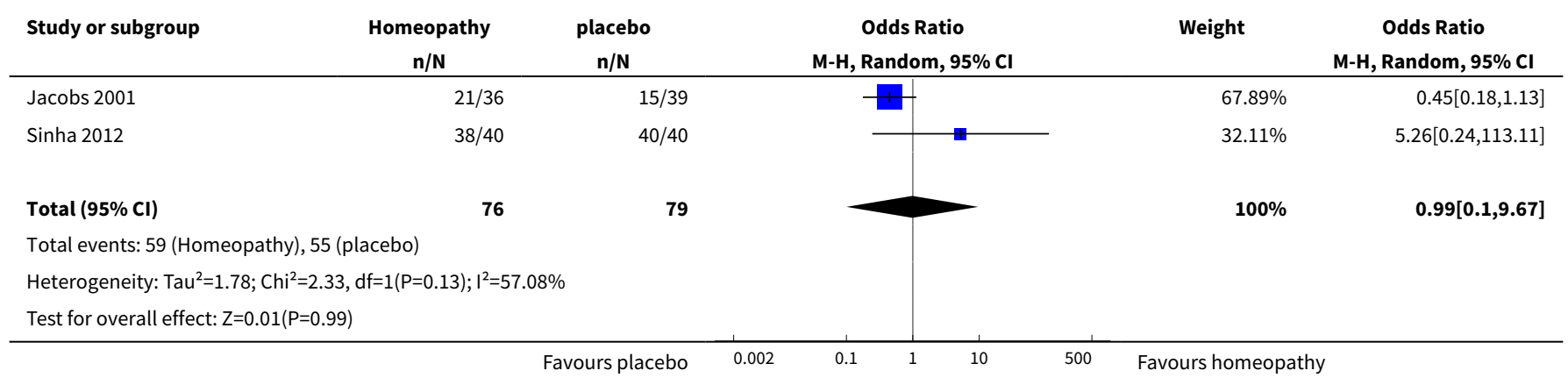

Analysis 2.3. Comparison 2 Treatment studies, Outcome 3 Adverse events - individualised homeopathy.

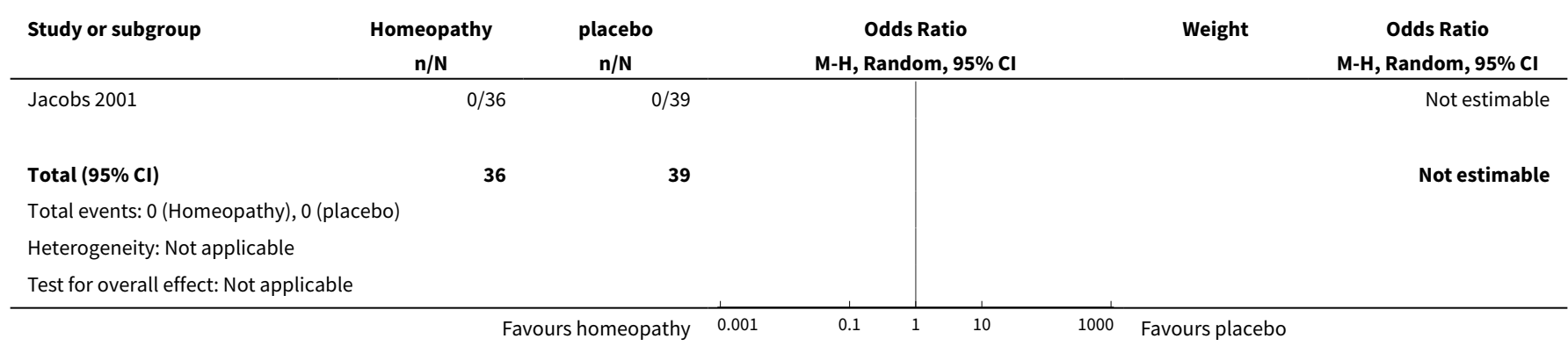

Analysis 2.4. Comparison 2 Treatment studies, Outcome 4 Adverse events - non-individualised homeopathy.

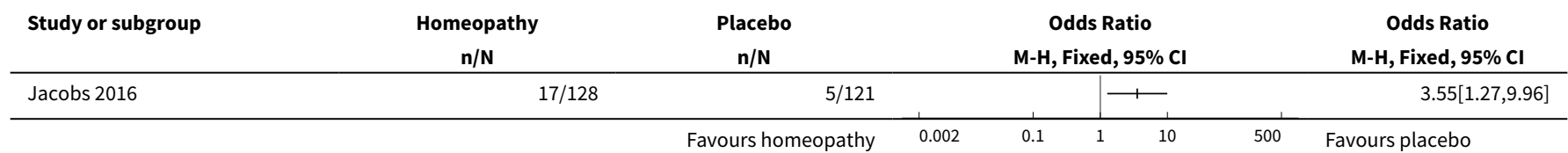

\section{APPENDICES}

\section{Appendix 1. MEDLINE (Ovid) search strategy}

1 exp Respiratory Tract Infections/

2 respiratory tract infection ${ }^{\star}$.tw.

3 (respiratory adj3 infection*).tw.

4 (urti or uri or Irti or lri or ari).tw.

5 Nasopharyngitis/

6 (nasopharyngit ${ }^{\star}$ or rhinopharyngit $\left.{ }^{\star}\right)$. tw.

7 exp Sinusitis/

8 sinusit*.tw.

9 rhinitis/

10 rhinit $^{\star}$.tw.

11 (rhinosinusit ${ }^{\star}$ or nasosinusit $\left.{ }^{\star}\right)$.tw.

12 ((runny or running or blocked or congest ${ }^{\star}$ or discharg* ${ }^{\star}$ or stuffed or stuffy) adj2 (nose* or nasal)).tw.

Homeopathic medicinal products for preventing and treating acute respiratory tract infections in children (Review) 
13 (rhinorrhea or rhinorrhoea).tw.

14 Sneezing/

15 sneez ${ }^{\star}$.tw.

16 Pharyngitis/

17 pharyngit*.tw.

18 pharyngotonsillit*.tw.

19 sore throat ${ }^{\star}$.tw.

20 (throat $^{\star}$ adj2 (infect ${ }^{\star}$ or inflam $\left.{ }^{\star}\right)$ ).tw.

21 Tonsillitis/

22 tonsillit*.tw.

23 exp Laryngitis/

24 laryngit*.tw.

25 (croup $^{\star}$ or laryngotracheobronchit* ${ }^{\star}$ or pseudocroup ${ }^{\star}$ ).tw.

26 tracheitis/

27 (tracheit $^{\star}$ or rhinotracheit ${ }^{\star}$ ).tw.

28 Epiglottitis/

29 epiglottit ${ }^{\star}$.tw.

30 Common Cold/

31 common cold*.tw.

32 coryza.tw.

33 exp Otitis Media/

34 otitis media.tw.

35 (AOM or OME).tw.

36 Cough/

37 cough*.tw.

38 Influenza, Human/

39 (influenza* or flu).tw.

40 exp Bronchitis/

41 (bronchit $^{\star}$ or bronchiolit* or tracheobronchit*).tw.

42 exp Pneumonia/

43 (pneumon* $^{\star}$ or bronchopneumon* or pleuropneumon $\left.{ }^{\star}\right)$.tw.

44 or/1-43

45 Homeopathy/

46 formularies, homeopathic/ or pharmacopoeias, homeopathic/

47 (homeopath* or homoeopath* or homoop* or omeop* or homopath*).tw.

48 Complementary Therapies/

49 Holistic Health/

50 Materia medica/

51 (materia medica or nosode $^{\star}$ ).tw.

52 (pulsatilla or chamom* or sulphur or sulfur or calcarea or drosera or tonsiotren or lomabronchin).tw,nm.

53 (dilut* adj2 (very or ultra* or high or serial ${ }^{\star}$ or substance* or agent $\left.^{\star}\right)$ ).tw.

54 (potentis ${ }^{\star}$ or potentiz $\left.{ }^{\star}\right)$. tw.

55 or $/ 45-54$

5644 and 55

\section{Appendix 2. Embase (Elsevier) search strategy}

\#53 \#49 AND \#52 267

\#52 \#50 OR \#51 910664

\#51 random*:ab,ti OR placebo*:ab,ti OR factorial*:ab,ti OR crossover*:ab,ti OR 'cross over':ab,ti OR 'cross-over':ab,ti OR volunteer*:ab,ti OR assign*:ab,ti OR allocat*:ab,ti OR ((singl* OR doubl*) NEAR/1 blind*):ab,ti AND [embase]/lim 869899

\#50 'randomized controlled trial'/exp OR 'single blind procedure'/exp OR 'double blind procedure'/exp OR 'crossover procedure'/exp AND [embase]/lim252067

\#49 \#39 AND \#48 2128

\#48 \#40 OR \#41 OR \#42 OR \#43 OR \#44 OR \#45 OR \#46 OR \#47 49140

\#47 'alternative medicine'/de AND [embase]/lim16394

\#46 potentis*:ab,ti OR potentiz*ab,ti AND [embase]/lim108

\#45 (dilut* NEAR/2 (ultra* OR very OR high OR serial* OR substance* OR agent*)):ab,ti AND [embase]/lim 5847

\#44 pulsatilla:ab,ti OR chamom*:ab,ti OR sulphur:ab,ti OR calcarea:ab,ti OR drosera:ab,ti OR tonsiotren:ab,ti OR lomabronchin:ab,ti AND [embase]/lim 8413

\#43 'dilution'/de AND [embase]/lim16121

\#42 'homeopathic agent'/de AND [embase]/lim1238 
\#41 homeopath*:ab,ti OR homoeopath*:ab,ti OR homoop*:ab,ti OR omeop*:ab,ti OR homopath*:ab,ti AND [embase]/lim 3423 \#40 'homeopathy'/de AND [embase]/lim 5221

\#39 \#1 OR \#2 OR \#3 OR \#4 OR \#5 OR \#6 OR \#7 OR \#8 OR \#9 OR \#10 OR \#11 OR \#12 OR \#13 OR \#14 OR \#15 OR \#16 OR \#17 OR \#18 OR \#19 OR \#20 OR \#21 OR \#22 OR \#23 OR \#24 OR \#25 OR \#26 OR \#27 OR \#28 OR \#29 OR \#30 OR \#31 OR \#32 OR \#33 OR \#34 OR \#35 OR \#36 OR \#37 OR \#38 394354

\#38 pneumon*:ab,ti OR bronchopneumon*:ab,ti OR pleuropneumon*:ab,ti AND [embase]/lim 110201

\#37 'pneumonia'/exp AND [embase]/lim123999

\#36 bronchit* $^{\star}$ :ab,ti OR bronchiolit*:ab,ti OR tracheobronchit*:ab,ti AND [embase]/lim 21505

\#35 'bronchitis'/de OR 'bronchiolitis'/exp OR 'tracheobronchitis'/de AND [embase]/lim 22361

\#34 influenza*:ab,ti OR flu:ab,ti AND [embase]/lim 62485

\#33 'influenza'/de AND [embase]/lim 24710

\#32 cough*:ab,ti AND [embase]/lim 29603

\#31 'coughing'/de AND [embase]/lim 39171

\#30 'otitis media':ab,ti OR aom:ab,ti OR ome:ab,ti AND [embase]/lim 17479

\#29 'otitis media'/exp AND [embase]/lim18904

\#28 coryza:ab,ti OR ((common OR head) NEXT/1 cold*):ab,ti AND [embase]/lim 2409

\#27 'common cold'/de OR 'common cold symptom'/de AND [embase]/lim 4150

\#26 epiglottit*:ab,ti AND [embase]/lim 967

\#25 'epiglottitis'/exp AND [embase]/lim1385

\#24 tracheitis:ab,ti AND [embase]/lim 363

\#23 'tracheitis'/de OR 'rhinotracheitis'/de AND [embase]/lim 859

\#22 laryngit*:ab,ti OR laryngotracheobronchit*:ab,ti OR croup:ab,ti AND [embase]/lim 2087

\#21 'laryngitis'/de OR 'croup'/de OR 'laryngotracheobronchitis'/de OR 'pseudocroup'/de AND [embase]/lim 3326

\#20 tonsillit*:ab,ti AND [embase]/lim 3096

\#19 'tonsillitis'/de AND [embase]/lim 3739

\#18 (sore NEAR/2 throat*):ab,ti AND [embase]/lim 3146

\#17 'sore throat'/de AND [embase]/lim 6717

\#16 pharyngit*:ab,ti OR pharyngotonsillit*ab,ti AND [embase]/lim 3965

\#15 'pharyngitis'/de AND [embase]/lim 8981

\#14 sneez*:ab,ti AND [embase]/lim 2547

\#13 'sneezing'/de AND [embase]/lim 2920

\#12 rhinorrhea*:ab,ti OR rhinorrhoea*:ab,ti AND [embase]/lim 3153

\#11 'rhinorrhea'/de AND [embase]/lim 4538

\#10 ((nose* OR nasal) NEAR/2 (runny OR running OR discharg* OR congest* OR blocked OR stuff*)):ab,ti AND [embase]/lim 3318

\#9 'nose infection'/de AND [embase]/lim655

\#8 rhinit $^{\star}:$ ab,ti OR rhinosinusit*:ab,ti OR nasosinusit*:ab,ti AND [embase]/lim 20732

\#7 'rhinitis'/de OR 'rhinosinusitis'/de AND [embase]/lim 13413

\#6 sinusit*:ab,ti AND [embase]/lim 9870

\#5 'sinusitis'/exp AND [embase]/lim19491

\#4 rhinopharyngit*:ab,ti OR nasopharyngit*:ab,ti AND [embase]/lim 577

\#3 'rhinopharyngitis'/de AND [embase]/lim 3994

\#2 'respiratory tract infection':ab,ti OR 'respiratory tract infections':ab,ti OR 'respiratory infection':ab,ti OR 'respiratory infections':ab,ti OR ari:ab,ti OR urti:ab,ti OR Irti:ab,ti AND [embase]/lim 25828

\#1 'respiratory tract infection'/de OR 'lower respiratory tract infection'/de OR 'upper respiratory tract infection'/de AND [embase]/lim 43841

\section{Appendix 3. CINAHL (EBSCO) search strategy}

S57 S47 and S56 104

S56 S48 or S49 or S50 or S51 or S52 or S53 or S54 or S55 163363

S55 (MH "Quantitative Studies") 7122

S54 TI placebo* OR AB placebo* 18174

S53 (MH "Placebos") S6102

S52 TI random* OR AB random* 88920

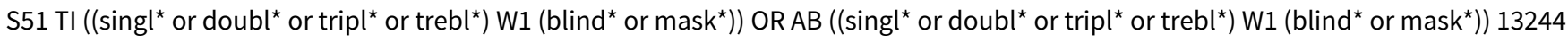

S50 TI clinic $^{\star}$ trial $^{\star}$ OR AB clinic $^{\star}$ trial $^{*} 26495$

S49 PT clinical trial 49449

S48 (MH "Clinical Trials+") 100290

S47 S34 and S46 S 650

S46 S35 or S36 or S37 or S38 or S39 or S40 or S41 or S42 or S43 or S44 or S45 23798

S45 TI (potentis* or potentiz*) OR AB (potentis* or potentiz ${ }^{\star}$ ) 55 
S44 TI (dilut* N2 (ultra* or high or very or serial* or substance* or agent ${ }^{\star}$ )) OR AB (dilut* N2 (ultra* or high or very or serial ${ }^{\star}$ or substance* or agent $\left.\left.{ }^{\star}\right)\right) 174$

S43 TI (pulsatilla or chamom* or sulphur or sulfur or calcarea or drosera or tonsiotren* or lomabronchin^) OR AB (pulsatilla or chamom* or sulphur or sulfur or calcarea or drosera or tonsiotren* or lomabronchin $\left.{ }^{\star}\right) 566$

S42 TI (materia medica or nosode ${ }^{\star}$ ) OR AB (materia medica or nosode*) 141

S41 (MH "Holistic Health") 1456

S40 (MH "Alternative Therapies") 17086

S39 TI ( homeopath* or homoeopath* or homoop* or omeop* or homopath*) OR AB (homeopath* or homoeopath* or homoop ${ }^{\star}$ or omeop $^{\star}$ or homopath*) 2807

S38 (MH "Homeopaths") 230

S37 (MH "Homeopathic Provings") 66

S36 (MH "Homeopathic Agents+") 2366

S35 (MH "Homeopathy") 3426

$\mathrm{S} 34 \mathrm{~S} 1$ or $\mathrm{S} 2$ or $\mathrm{S} 3$ or $\mathrm{S} 4$ or $\mathrm{S} 5$ or $\mathrm{S} 6$ or $\mathrm{S} 7$ or $\mathrm{S} 8$ or $\mathrm{S} 9$ or $\mathrm{S} 10$ or $\mathrm{S} 11$ or $\mathrm{S} 12$ or $\mathrm{S} 13$ or $\mathrm{S} 14$ or $\mathrm{S} 15$ or $\mathrm{S} 16$ or $\mathrm{S} 17$ or $\mathrm{S} 18$ or $\mathrm{S} 19$ or $\mathrm{S} 20$ or $\mathrm{S} 21$ or $\mathrm{S} 22$ or S23 or S24 or S25 or S26 or S27 or S28 or S29 or S30 or S31 or S32 or S33 46074

S33 TI (pneumon* or bronchopneumon* or pleuropneumon*) OR AB (pneumon* or bronchopneumon* or pleuropneumon*) 9138

S32 (MH "Pneumonia+") 7610

S31 TI (bronchit* or bronchiolit* or tracheobronchit*) OR AB (bronchit* ${ }^{\star}$ or bronchiolit* or tracheobronchit $\left.{ }^{\star}\right) 1622$

S30 (MH "Bronchitis+") 1381

S29 TI ( influenza* or flu ) OR AB ( influenza* or flu ) 9614

S28 (MH "Influenza, Human+") 2329

S27 TI cough* OR AB cough* 3693

S26 (MH "Cough") 1981

S25 TI (aom or ome) OR AB (aom or ome) 389

S24 TI otitis media OR AB otitis media 1725

S23 (MH "Otitis Media+") 2528

S22 TI (common cold* or coryza) OR AB (common cold* or coryza) 513

S21 (MH "Common Cold") 1362

S20 TI tracheit* OR AB tracheit* 29

S19 TI (laryngit* or epiglottit* or croup or pseudocroup or laryngotracheobronchit*) OR AB (laryngit* or epiglottit* or croup or pseudocroup or laryngotracheobronchit*) 474

S18 (MH "Laryngitis+") 575

S17 TI tonsillit* OR AB tonsillit* 183

S16 (MH "Tonsillitis") 317

S15 $\mathrm{TI}$ sore throat* OR AB sore throat* 511

S14 TI pharyngotonsillit* OR AB pharyngotonsillit* 21

S13 TI pharyngit* OR AB pharyngit* 439

S12 (MH "Pharyngitis") 924

S11 TI sneez* OR AB sneez* 362

S10 (MH "Sneezing") 54

S9 TI (rhinorrhea* or rhinorrhoea*) OR AB (rhinorrhea* or rhinorrhoea*) 245

S8 TI ((nose ${ }^{\star}$ or nasal) N2 (runny or running or discharg ${ }^{\star}$ or congest ${ }^{\star}$ or blocked or stuff $\left.{ }^{\star}\right)$ ) OR AB ((nose* or nasal) N2 (runny or running or discharg* or congest* or blocked or stuff*)) 402

S7 TI (sinusit* or rhinit* or rhinosinusit* or nasosinusit*) OR AB (sinusit* or rhinit* or rhinosinusit* or nasosinusit ${ }^{\star}$ ) 3335

S6 (MH "Rhinitis") 1662 Edit S6

S5 (MH "Sinusitis+") 2249 Edit S5

S4 TI (nasopharyngit* or rhinopharyngit*) OR AB (nasopharyngit* or rhinopharyngit*) 49

S3 TI (urti or Irti or ari) OR AB (urti or lrti or ari) 305

S2 TI (respiratory tract infection* or respiratory infection*) OR AB (respiratory tract infection* or respiratory infection*) 3257

S1 (MH "Respiratory Tract Infections+") 30852

\section{Appendix 4. AMED (Ovid) search strategy}

1 exp respiratory tract infections/

2 (respiratory adj3 infect $\left.{ }^{\star}\right)$.tw.

3 (urti or uri or Irti or lri or ari).tw.

4 (nasopharyngit* or rhinopharyngit*).tw.

5 sinusitis/

6 sinusit*.tw.

7 rhinitis/

8 rhinit*.tw.

9 (rhinosinusit* $^{\star}$ or nasosinusit $\left.{ }^{\star}\right)$.tw. 
10 ((runny or running or blocked or congest* or discharg* or stuffed or stuffy) adj2 (nose* or nasal)).tw.

11 (rhinorrhea or rhinorrhoea).tw.

12 sneez ${ }^{*}$. tw.

13 pharyngitis/

14 pharyngit*.tw.

15 pharyngotonsillit*.tw.

16 (throat* adj2 (sore or inflam* ${ }^{\star}$ or infect $\left.^{\star}\right)$ ).tw.

17 tonsillitis/

18 tonsillit*.tw.

19 laryngit*.tw.

20 (croup $^{\star}$ or laryngotracheobronchit* ${ }^{\star}$ or pseudocroup $\left.{ }^{\star}\right)$.tw.

21 (tracheit $^{\star}$ or rhinotracheit $\left.{ }^{\star}\right)$.tw.

22 epiglottit ${ }^{\star}$.tw.

23 common cold/

24 common cold $^{\star}$.tw.

25 coryza.tw.

26 otitis media/

27 otitis media.tw.

28 (AOM or OME).tw.

29 cough/

30 cough*.tw.

31 influenza/

32 (influenza* or flu).tw.

33 bronchitis/

34 (bronchit $^{\star}$ or bronchiolit ${ }^{\star}$ or tracheobronchit ${ }^{\star}$ ).tw.

35 pneumonia/

36 (pneumon $^{\star}$ or bronchopneumon ${ }^{\star}$ or pleuropneumon ${ }^{\star}$ ).tw.

37 or/1-36

38 exp homeopathy/

39 exp homeopathic drugs/

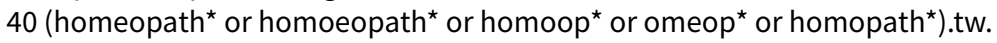

41 materia medica/

42 (materia medica or nosode ${ }^{\star}$ ).tw.

43 (pulsatilla or chamom* or sulphur or sulfur or calcarea or drosera or tonsiotren or lomabronchin).tw.

44 (dilut* $^{\star}$ adj2 (very or ultra* or high or serial ${ }^{*}$ or substance* or agent $^{\star}$ )).tw.

45 (potentis $^{\star}$ or potentiz $\left.{ }^{\star}\right)$.tw.

46 or/38-45

4737 and 46

48 exp clinical trials/

49 random ${ }^{\star} . t w$.

50 placebo*.tw.

51 allocat*.tw.

52 (crossover* or cross over $\left.{ }^{\star}\right)$. tw.

$53\left(\left(\right.\right.$ doubl $^{\star}$ or singl $\left.l^{\star}\right) \operatorname{adj1}$ blind $\left.^{\star}\right)$. tw.

54 trial.ti.

55 or/48-54

5647 and 55

\section{Appendix 5. British Homeopathic Library (Soutron) search strategy}

respiratory or nasopharyngitis or rhinopharyngitis or sinus! or rhinitis or rhinosinusitis or nasosinusitis or rhinorrhea or rhinorrhoea or sneeze or pharyngitis or pharyngotonsillitis or tonsillitis or laryngitis or croup or pseudo-croup or laryngotracheobronchitis or tracheitis or epiglottitis or "common cold" or "common colds" or coryza or "otitis media" or cough! or influenza or flu or bronchitis or bronchiolitis or pneumonia or bronchopneumonia or pleuropneumonia or "nasal congestion" or "runny nose" or "nasal discharge" or "blocked nose"

Search within results: random! or placebo! or trial! or "single blind" or "double blind" or "single blinded" or "double blinded"

\section{Appendix 6. CAMbase search strategy}

Individual searches combining homeopathy with each of the terms for common cold. i.e homeopathy and respiratory, homeopathy and sinusitis, homeopathy and rhinitis etc. 
WHAT'S NEW

\begin{tabular}{lll}
\hline Date & Event & Description \\
\hline 3 September 2018 & Amended & $\begin{array}{l}\text { The Abstract was shortened to fit within the recommended word } \\
\text { count. }\end{array}$ \\
\hline
\end{tabular}

3 September $2018 \quad$ New citation required but conclusions

We corrected outcome 2.1 (short-term cure - individualised have not changed homeopathy) and outcome 2.2 data (long-term cure - individualised homeopathy) \& corresponding analyses, with no change to the conclusions as the pooled data were non-significant. The outcome 2.1 data table initially had placebo and homeopathy groups reversed during data entry; correction of this led to the change of the non-significant odds ratio from in favour of homeopathy before the correction, to in favour of placebo after correction. For the outcome 2.2 data table the correction resulted in a change in the odds ratio from 1.01 to 0.99 .

\section{HISTOR Y}

Protocol first published: Issue 2, 2006

Review first published: Issue 4, 2018

\begin{tabular}{lll}
\hline Date & Event & Description \\
\hline 4 January 2010 & $\begin{array}{l}\text { New citation required and major } \\
\text { changes }\end{array}$ & $\begin{array}{l}\text { A new team of review authors have taken over this previously } \\
\text { withdrawn protocol. }\end{array}$ \\
\hline 1 September 2009 & Amended & $\begin{array}{l}\text { Protocol was withdrawn from Issue 1, 2010 of the Cochrane Li- } \\
\text { brary. }\end{array}$ \\
\hline 6 February 2008 & Amended & Converted to new review format \\
\hline
\end{tabular}

\section{CONTRIBUTIONS OF AUTHORS}

DK was the contact person with the editorial base.

$\mathrm{KH}$ co-ordinated contributions from the coauthors and wrote the final draft of the review.

MVD and TM supervised the writing of the protocol.

$\mathrm{BB}, \mathrm{DK}$, and $\mathrm{KH}$ screened papers against eligibility criteria and reviewed the titles and abstracts to identify potentially eligible studies, and searched clinical trial registries.

DK independently reviewed studies where disagreements about inclusion occurred.

$\mathrm{BB}, \mathrm{DK}, \mathrm{KH}$, and TM independently assessed trial quality with the Cochrane 'Risk of bias' tool and extracted data from every included study using the standardised data collection forms to minimise errors and reduce potential bias. KH completed this process for studies identified in later electronic search updates.

DK independently verified a random selection of data extraction.

$\mathrm{BB}$ and $\mathrm{KH}$ contacted study authors to seek unpublished data, address concerns regarding risk of bias, and for information regarding ongoing trials.

$\mathrm{BB}, \mathrm{KH}, \mathrm{DK}$, and TM entered data into Review Manager 5.

$\mathrm{KH}, \mathrm{DK}, \mathrm{TM}$, and MVD analysed and interpreted data.

MVD commented on all drafts and advised on methods and interpretation.

MVD and TM drafted the clinical sections of the Background, which was updated by BB.

$\mathrm{DK}, \mathrm{TM}, \mathrm{KH}$, and MVD responded to the comments from the referees.

DK is the guarantor of the update. 


\section{DECLARATIONS OF INTEREST}

Kate Hawke: none known.

Mieke L van Driel: none known.

Benjamin J Buffington: none known.

Treasure M McGuire: none known.

David King: none known.

\section{SOURCES OF SUPPORT}

\section{Internal sources}

- No financial support received, Other.

\section{External sources}

- No financial support received, Other.

\section{DIFFERENCES BETWEEN PROTOCOL AND REVIEW}

We changed the Types of interventions from "oral individualised homeopathic preparations (both simple preparations, involving single substances or complex preparations involving more than one substance)" targeting acute respiratory tract infections to "any type of oral homeopathic medicinal product involving the delivery of a homeopathic product, either by a homeopath following a consultation, or studies where a homeopathic remedy was delivered without a consultation". We made this change to enable the inclusion of studies that used a non-individualised (i.e. preformulated or over-the-counter) homeopathic remedy. This is becoming an increasingly common method of accessing homeopathic remedies by healthcare consumers, which also warrants assessment of the available evidence. We separated studies of individualised and non-individualised treatments for the review because individualised homeopathy involves an assessment by a practitioner and selection of treatment based on the patient/symptoms/personality, etc., while conversely, nonindividualised (one-size-fits-all) homeopathic remedies are becoming popular but are only chosen based on the indication (e.g. 'cold and flu') and could be considered a different type of intervention.

We added disease severity as indicated by mean symptom score to the Primary outcomes. Given the self limiting nature of most respiratory tract infections, a difference in disease severity is clinically significant. Many currently available respiratory tract infection remedies are aimed at reduction in symptoms rather than cure, so it was warranted to also evaluate the homeopathic treatments for this outcome.

We added antibiotic use as a 'rescue therapy' or surrogate for treatment failure to the Secondary outcomes. Both additional outcomes were informed by outcome measures used in other systematic reviews of acute respiratory tract infections. We removed two other secondary outcomes from the protocol, length of stay in hospital and incidence of severe complications, and collapsed them into the existing outcome 'need for hospitalisation'. The new combined secondary outcome now reads as 'need for hospitalisation or secondary illness'.

Regarding measures of treatment effect, as there were no outcomes with statistically significant results, we did not proceed to calculate absolute risk reduction and numbers needed to treat for an additional beneficial outcome as planned in the protocol.

Regarding assessment of heterogeneity, as there were at most two studies with data on any given outcome, we did not perform sensitivity analysis.

Regarding assessment of reporting biases, fewer than 25 trials were available, so we did not construct funnel plots to test for funnel plot asymmetry.

\section{NOTES}

The original protocol was withdrawn from Issue 1, 2010 of the Cochrane Library, as the review authors (Becker C, Gottschling S, Graf N, Ludtke R) were unable to write the review. The protocol for this review was rewritten and adapted to the new Cochrane format by Annika R Mascarenhas, Jacqueline A Seebold, William J Cundy, Treasure McGuire, and Mieke L van Driel. Online publication date: December 2011. $\mathrm{TM}$ and MVD enrolled BB, DK, and $\mathrm{KH}$ to assist in completing the review.

\section{NDEX TERMS}

\section{Medical Subject Headings (MeSH)}

Acute Disease; Administration, Oral; Anti-Bacterial Agents [therapeutic use]; Homeopathy [adverse effects] [*methods]; Intention to Treat Analysis; Placebos [therapeutic use]; Randomized Controlled Trials as Topic; Recurrence; Research Support as Topic; Respiratory Tract Infections [prevention \& control] [ ${ }^{\star}$ therapy] 


\section{MeSH check words}

Child; Child, Preschool; Humans; Infant 